\title{
OBERSTE BEHÖRDEN DES REICHS, DER LÄNDER UND PROVINZEN UND FÜR AUS- WÄRTIGE ANGELEGENHEITEN
}

\subsection{Oberste Reichsbehörden}

Zur Ausübung seiner persönlichen Herrschaft bediente Hitler sich einer Vielzahl traditioneller wie neu geschaffener Behörden und Institutionen, die ihm teils unmittelbar und allein unterstanden, teils in andere Organisationen eingebunden waren. Soweit sie seiner Funktion als Parteiführer und als Oberbefehlshaber der Wehrmacht zugeordnet waren, sind sie in den Abschnitten 9 und 8 behandelt, auBerhalb der Ministerialverwaltung stehende Reichskommissare und Reichsbevollmächtigte in den ihrer fachlichen Kompetenz entsprechenden Kapiteln und, falls sie sich einer vorhandenen Behörde bedienten - z. B. der Generalbevollmächtigte für die Reichsverwaltung des Reichsinnenministeriums und der Reichsbevollmächtigte für den totalen Kriegseinsatz des Reichspropagandaministeriums - bei deren Überlieferung.

\subsubsection{Präsidialkanzlei des Führers und Reichskanzlers}

\author{
BA, Best. R 53 \\ ZStA, Best. 06.01
}

In Koblenz sind aus den letzten beiden Amtsjahren Hindenburgs einzelne, vielfach vor 1933 einsetzende Akten (36 Bde) vor allem über Ehrungen durch Gemeinden (Ehrenbürgerschaften, Straßenbenennungen, 9 Bde) und Repräsentationspflichten (7 Bde), ferner über Audienzen (5 Bde) und Interviews (4 Bde) vorhanden. Hitlers Funktion als Staatsoberhaupt ist dort hauptsächlich durch GruBbotschaften, Treuegelöbnisse und Zustimmungserklärungen zu seiner Politik (23 Bde, 1935-1939), Glückwünsche zum Jahreswechsel, seinen Geburtstagen und anderen Jubiläen (49 Bde, 1935-1939), ferner durch einzelne Gnadengesuche (2 Bde, 1933-1940, darunter für Pfarrer Niemöller) und Akten über Ordensverleihungen (5 Bde, insbes. Genehmigung der Annahme italienischer und spanischer Orden, 1935-1944) dokumentiert. Eine umfangreiche Sammlung von Eingaben und Zuschriften aus der Bevölkenung wurde dem Hauptarchiv der NSDAP überlassen (Best. NS 26).

Im Potsdamer Bestand stammen aus den Amtsjahren Hindenburgs zum einen ganze Bandreihen zum Dispositionsfonds (Stiftung von Ehrenpreisen, Ehrengaben (11 Bde), Ehrenpatenschaften (42 Bde), Hindenburgspende und -kuren (4 bzw. 2 Bde)), die z.T. bereits vor 1933 beginnen. Die Amtszeit Hitlers wird belegt durch Geburtstagsglückwünsche (4 Bde, 1944), Unterlagen über Audienzen (1934-1935), Sympathieund Protestkundgebungen (1938), Einladungen (1934-1935) sowie durch umfangreiche Serien zu Orden und Ehrenzeichen (165 Bde, 1933-1944), dabei Treudienstehrenzeichen (75 Bde), Kriegsauszeichnungen (22 Bde), Ehrenkreuz Deutsche Mutter (6 Bde).

Überwiegend vor 1933 angelegte und über die Amtszeit Hindenburgs hinaus weitergeführte Sachakten betreffen neben innerdienstlichen Fragen (8 Bde), Geschäftsverteilungsplänen von Reichsministerien (6 Bde) folgende Sachgebiete: 
- Innenpolitik (99 Bde), u. a. Reichspräsident/Reichsregierung (5 Bde), Ernennung, Entlassung und Verabschiedung von Beamten (34 Bde), Lage des Arbeitsmarktes (5 Bde), Religions- und Kirchenangelegenheiten (5 Bde), Wirtschafts- und Finanzpolitik (7 Bde), Land- und Forstwirtschaft (9 Bde), Post- und Verkehrswesen (8 Bde).

- AuBenpolitik (4I Bde), u. a. Intemationale Organisationen und Verträge (15 Bde), zwischenstaatliche Abkommen (23 Bde).

- Militärpolitik (13 Bde), u. a. Reichswehr (6 Bde), Reichsmarine (4 Bde), Adjutant der Wehrmacht beim Führer (4 Bde).

Außerdem ist ein Rest von persönlichem Schriftwechsel des Leiters der Präsidialkanzlei, Staatssekretär bzw. -minister Otto Meißner, der im „Wilhelmstraßen“-ProzeB vom amerikanischen Militärgerichtshof in Nürnberg freigesprochen wurde, und des $\mathrm{Mi}$ nisterialrats bzw. Gesandten Kiewitz (je 4 Bde) vorhanden.

Lit: TRIALS of WAR CRIMINALS. vol. 12-14. - O. MEISSNER: Staatssekretär unter Ebert - Hindenburg - Hitler. 1950. - H. O. MEISSNER: Junge Jahre im Reichspräsidentenpalais. 1986.

\subsubsection{Reichskanzlei BA, Best. R 43}

Der Bestand enthält vor allem fast vollständig die bis Kriegsende angelegten Sachakten (Teilbestand R 43 II, einzelne Nachakten zu älteren Serien auch im Teilbestand R 43 I), während die separat geführten Geheimakten - auch des Ministerrats für die Reichsverteidigung (Protokolle von 6 Sitzungen 1939 IMT Bd 31, Dokument 2852 PS) - offenbar vernichtet wurden. Damit vereinigt wurden Handakten von Beamten sowie Mikrofilme von ca. 800 Einzelvorgängen (Teilbestand R 43 F) im ZStA, Best. 07.01 (196 Bde), die noch nicht in die Registratur gelangt waren. Er hat folgende Gliederung: - Arbeit (52 Bde): u. a. Deutsche Arbeitsfront und „Kraft durch Freude“ (5 Bde), Reichstreuhänder der Arbeit (2 Bde), Reichskommissar für Arbeitsbeschaffung.

- Auswärtige Angelegenheiten: Allgemeines (85 Bde), u. a. Besuche ausländischer Politiker, Saargebiet (12 Bde, 1933-1938), Abtretungsgebiete (Oberschlesien, Danzig, Memel, Eupen-Malmedy, insges. 14 Bde, 1933-1940), Pazifismusbewegung (2 Bde, 1933-1939), Auslandsdeutschtum (13 Bde). - Beziehungen zu einzelnen Staaten (178 Bde, auch betr. im Krieg besetzte Gebiete).

- Bankwesen (32 Bde, vor allem betr. Reichsbank und andere Banken).

- Bau- und Bodenwirtschaft (139 Bde): u. a. Sozialer Wohnungsbau (11 Bde, 1940-1945), Neugestaltung deutscher Städte (90 Bde, davon 29 Bde betr. Berlin, auch Bayreuth, Braunau, Hermann-Göring-Stadt Salzgitter, Linz/Donau, Litzmannstadt, Straßburg, Stadt des KdF-Wagens Wolfsburg, Waldbröl, Wewelsburg), Gauwohnungskommissare (2 Bde, 1940-1944).

- Beamtenwesen (100 Bde): u. a. Besoldung, Zugehörigkeit zur NSDAP, Uniformen und Amtsbezeichnungen, Berufsbeamtengesetz, Befördenungen in Einzelfällen.

- Berg- und Hüttenwesen (14 Bde): u. a. Mineralölwirtschaft.

- Besprechungen (Terminabsprachen und Aufzeichnungen, 3 Bde).

- Börsenwesen (1 Bd, 1933-1941).

- Eisenbahnen (21 Bde, auch betr. Güterkraftverkehr).

- Ernährungswesen (3 Bde).

- Film- und Lichtspielwesen (4 Bde).

- Finanzwesen (61 Bde): u. a. betr. Finanzausgleich, Steuern, Zölle, Devisenbewirtschaftung, Währungsfragen.

- Funkwesen (4 Bde). 
- Gemeindeverwaltung (21 Bde).

- Geschäftsgang (38 Bde): u. a. Eingaben, Anschriftenlisten, Sprachregelungen.

- Gewerbewesen (23 Bde): Handwerk und Pflege des Mittelstandes, u. a durch Reichskommissar für den gewerblichen Mittelstand (1933), Einzelfälle zweckentfremdeter Beherbergungsbetriebe (1941-1945), Gewerbeordnung.

- Handel und Wirtschaft: Allgemeines, Handelsrecht (6 Bde); Handelsverträge mit einzelnen Staaten (25 Bde); Wirtschaftspolitik (170 Bde), u. a. Preisfestsetzungen (Reichskommissar für Preisüberwachung, 1933-1937, und für die Preisbildung, 19371944), Generalrat der Wirtschafi (1933-1934), Organisation der gewerblichen Wirtschaft, Außenhandel, Vierjahresplan, Energiewirschaft, Bekämpfung des Schwarzhandels.

- Haushaltswesen (12 Bde).

- Innere Politik: Allgemeines (2 Bde); Schutz von Volk und Staat (15 Bde, hauptsächlich Vermögenseinziehung in Einzelfällen); Feier- und Gedenktage, Kundgebungen (6 Bde).

- Judentum (13 Bde).

- Jugend (23 Bde, insbes. Hitlerjugend und Arbeitsdienst).

- Justiz (96 Bde), u. a. Strafrecht und andere Rechtsgebiete (mit 9 Bden betr. einzelne Strafverfahren, 8 Bden betr. Gnadenrecht im allgemeinen und in Einzelfällen), Erteilung von Aussagegenehmigungen.

- Kaiserliches Haus und sonstige Fürstenhäuser (5 Bde bis 1943).

- Kirche (51 Bde, dabei auch Deutsche Glaubensbewegung 1934-1937).

- Kolonien (2 Bde, 1932-1935).

- Kraftfahrwesen (9 Bde).

- Krieg (1939-1945): Allgemeines (6 Bde); Kriegs- und Kriegsernährungswirtschaft (13 Bde); Kriegsfinanzierung (4 Bde); Abfindungen für Wehrmachtangehörige auBerhalb der Reichsgrenzen (65 Bde); Verkehrswesen (6 Bde); Nachrichtenverkehr, Presse und Propaganda (4 Bde); Kriegsschäden (4 Bde); Rechtspflege, Feindvermögen (4 Bde); Verwaltung besetzter Gebiete vor allem in der Sowjetunion (36 Bde); Sozialpolitik (2 Bde); Kriegsauszeichnungen (2 Bde); Krieg gegen einzelne Staaten (17 Bde); Arbeitseinsatz, Vereinfachungs- und Einsparungsmaßnahmen, totaler Krieg (48 Bde); Luftkrieg (12 Bde); Kriegsgefangenenfragen (2 Bde); Deutscher Volkssturm (2 Bde).

- Kunst und Wissenschaft (91 Bde): Forschungen und Anstalten; Museen und Kunstsammlungen; Urheberrecht; Künstler, Komponisten und Schriftsteller; Theater, Zeitrechnung; Denkmalschutz, Denkmäler, Reichswetterdienst.

- Länder (204 Bde): u. a. Allgemeines; Reichsstatthalter (38 Bde); Baden (2 Bde); Bayern (8 Bde); Braunschweig (3 Bde); Bremen (4 Bde); Hamburg (3 Bde); Hessen (2 Bde); Lippe, Lübeck (je 1 Bd); Oldenburg (2 Bde); Preußen (12 Bde); Württemberg (2 Bde); Saarpfalz (2 Bde); Österreich, österreichische Länder (28 Bde); Sudetenland (11 Bde); eingegliederte Ostgebiete (3 Bde); Protektorat Böhmen und Mähren (29 Bde); Generalgouvernement (14 Bde); ElsaB und Lothringen (12 Bde); Luxemburg (2 Bde).

- Land- und Forstwirtschaft (50 Bde).

- Luftfahrt und Flugwesen (9 Bde).

- Marine (3 Bde).

- Medizinalwesen (48 Bde): u. a. Bevölkerungs- und Rassenpolitik (6 Bde); Sport, Olympische Spiele (7 Bde).

- Militär (74 Bde, dabei auch 2 Bde betr. Technische Nothilfe, 13 Bde betr. Luftschutz,

2 Bde betr. Reichsverteidigungskommissare). 
- Münzwesen (1 Bd).

- Orden und Ehrenzeichen (6 Bde).

- Parteien: DNVP (2 Bde, 1931-1938); DVP (1 Bd, 1919-1933); Zentrum (2 Bde, 1931-1937); SPD (2 Bde, 1931-1937); KPD (3 Bde, 1931-1940); NSDAP und Gliederungen (40 Bde).

- PaB- und Fremdenwesen (10 Bde).

- Personalwesen (3 Bde betr. führende Persönlichkeiten im allgemeinen, 1942-1944).

- Polizei (17 Bde, dabei Schutzhaft-Einzelfälle, 1933-1942).

- Post und Telegraphie (11 Bde).

- Presse (24 Bde): u. a. Interviews Hitlers mit der Auslandspresse (1933-1938); Verbot von Zeitungen und Zeitschriften (1933-1935).

- Reichs- und Staatsangehörigkeit (9 Bde).

- Reichsarchiv (8 Bde, auch betr. Reichsinstitut für Gescnichte des neuen Deutschland).

- Reichsbehörden (103 Bde): Errichtung, Organisation und Personalangelegenheiten der Ministerien und einzelner oberster Reichsbehörden (darunter Reichsdruckerei, Reichsfinanzhof, Rechnungshof des Deutschen Reiches, Reichsbank. Reichsamt für Landesaufnahme, Reichswohnungskommissar, Bundesamt für Heimatwesen).

- Reichsbesitz (6 Bde, vor allem betr. öffentliche Aufträge).

- Reichsgebiet (28 Bde): u. a. Unterstützung für Grenzgebiete im Osten und Westen (Ost- und Westhilfe); Flaggen und Hoheitszeichen; Bestellung von Reichskommissaren. - Reichsgesetzgebung (5 Bde betr. Verfahrensfragen).

- Reichskanzlei (200 Bde): Organisation, Dienststellenverwaltung (Personalangelegenheiten, Haushalts- und Kassensachen), dabei Neu- und Erweiterungsbauten (18 Bde), Dienstgebäude Berchtesgaden (5 Bde ab 1936), Beschaffung von Kunstgegenständen (9 Bde), SicherheitsmaBnahmen (11 Bde), Kulturfonds (10 Bde ab 1937).

- Reichskanzler (persönliche Angelegenheiten Hitlers, 90 Bde): Ahnenforschung, Vermächtnisse, Beleidigungen, Übersetzungen von „Mein Kampf“ (17 Bde); Repräsentationsfonds (9 Bde); Adjutanturen (3 Bde, ab 1935); Reisen (3 Bde, bis 1939); Verwertung des Namens, insbesondere Benennung von Straßen (11 Bde); Glückwünsche und Beileidsbekundungen (3 Bde); Amt des Vizekanzlers (2 Bde); Gewährung von Dotationen und Sonderzahlungen vor allem an Minister und Generale, auch Künstler (11 Bde, ab 1937); Ehrenmitglied- und -bürgerschaften (4 Bde, bis 1939); Patenschaften (14 Bde, bis 1938); Drohungen und Attentate (2 Bde); Material für Reden (4 Bde); Stiftung von Ehrenpreisen (4 Bde).

- Reichsministerium (60 Bde): Geschäftsordnung der Reichsregierung, Kabinettsitzungen (mit 19 Bden Protokollen, 1933-1938, 8 Bden Beschlüssen, auch im Umlaufverfahren, 1933-1944); Reichsministergesetz (1929-1935); Angelegenheiten von Ministern ohne Geschäftsbereich (Frank, HeB, Schacht, SeyB-Inquart).

- Reichspräsident (8 Bde, 1933-1943): u. a. Präsidialkanzlei und Wehrmachtadjutantur, Neujahrsempfänge.

- Reichsrat (5 Bde, 1919-1934).

- Reichstag (17 Bde): Angelegenheiten der Wahlen, Mitglieder, Beamten, Sitzungen und Gebäude (dabei Reichstagsbrand).

- Schäden (Reichshaftpflicht, Personen-, Kriegs- und Katastrophenschäden, 10 Bde).

- Schiffahrt (30 Bde, auch Reichswasserstraßen und Kanalbauten). 
- Schulwesen: Universitäten und Fachhochschulen, Studenten (17 Bde); Reichsschulgesetz, höhere, Volks- und Mittelschulen (18 Bde, dabei Adolf-Hitler-Schulen, Religionsunterricht); Fortbildungseinrichtungen, Fach- und Berufsschulen ( $8 \mathrm{Bde}$, dabei Deutsche Hochschule für Politik); Deutsche Sprache und Schrift (6 Bde).

- Statistik (5 Bde).

- Stiftungèn (13 Bde, dabei Hindenburg-Spende, Nobelpreis-Stiftung, Stiftung für Opfer der Arbeit).

- Vereinswesen (17 Bde, vor allem betr. Kyffhäuserbund, Stahlhelm - Bund der Frontsoldaten, auch Freimaurer, Auflösung von republikanischen und vaterländischen Vereinen).

- Verfassung (11 Bde, vor allem betr. Reichsreform, Ermächtigungsgesetz, Volksabstimmungen, Verhältnis von Partei und Staat).

- Verkehrswesen, Fremdenverkehr (5 Bde).

- Versicherungswesen (Sozial- und Privatversicherung, 16 Bde).

- Verwaltung(sreform und -vereinfachung, 16 Bde).

- Wegesachen, Reichsautobahnen (15 Bde).

- Wohlfahrtswesen (18 Bde): u. a. Winterhilfswerk, Sammlungsverbote, Unterstützungsgesuche.

- Personalakten: Einige der über Reichskanzler und Staatssekretäre vor 1933 angelegte Personalakten (so über Luther und Wirth) wurden in der NS-Zeit fortgefuhrt, die übrigen betreffen Papen, Lammers, seinen Staatssekretär Wilhelm Kritzinger, die Reichskabinetts- und Ministerialräte und sämtliche Mitarbeiter der Behörde mit EinschluB von Hausarbeitern und Kraftfahrern und enthalten auch Vorgänge über Göring, die Minister Kerrl und Popitz, Reichsleiter Bouhler und einzelne andere Angehörige oberster Reichsbehörden.

Büro des Reichsministers und Chefs der Reichskanzlei Hans-Heinrich Lammers Die Akten dieses Teilbestandes (151 Bde sowie Mikrofilme von weiteren 378 Bden im ZStA) betreffen persönliche Angelegenheiten (20 Bde), Mitgliedschaft in politischen Organisationen (7 Bde), Staats- und Parteiangelegenheiten (3 Bde, 1933-1939), Verwaltung der Reichskanzlei (150 Bde, hauptsächlich über Gebäude und deren Ausstattung, auch in Berchtesgaden, außerdem einzelne Glückwunschschreiben an Hitler, Registraturhilfsmittel), wissenschaftlich-publizistische Tätigkeit ( $3 \mathrm{Bde}$ ), die Funktionen als Vorsitzender des Reichsverbandes Deutscher Verwaltungs-Akademien (47 Bde), der Gemeinschaft studentischer Verbände (6 Bde) und Vorstand der Dankspendenstiftung des deutschen Volkes (45 Bde) und enthalten privaten und privatdienstlichen Schriftwechsel (253 Bde), darunter Eingaben und Glückwünsche.

Ergänzungsüberlieferung liegt in den Akten des Nürnberger IMT-Verfahrens gegen die Reichsregierung als verbrecherische Organisation und des Verfahrens gegen Lammers im „Wilhelmstraßen“-ProzeB vor dem amerikanischen Militärgerichtshof vor, ferner in Nachkriegsaufzeichnungen des Unterstaatssekretärs Kritzinger und des Reichskabinettsrats Leo Killy (BA, Kl. Erw. 343 bzw. 234).

LiL: FINDBÜCHER zu Beständen des Bundesarchivs. Bd. 13. - A CATALOG of Files and Microfilms. vol. Il, S. 999- 1142, III, S. 459-480. - TRIALS of WAR CRIMINALS. vol. 12-14. - R. M. W. KEMPNER: Das Dritte Reich im Kreuzverhör. 1962. - AKTEN der Reichskanzlei. Teil I: 1933/34. 1983. - K-P. LIERE: Aus den Akten der Reichskanzlei. Med. Diss. 1980. - SCHRIFTEN ZUM STAATSAUFBAU 45. 1940. - S. SCHÖNE: Von der Reichskanzlei zum Bundeskanzleramt. 1968. - G. FRANZ-WILLING: Die Reichskanzlei 1933-1945. 1984. - H.MOMMSEN: Aufgabenkreis und Verantwortlichkeit des Staatssekretärs . . Kritzinger. 1966. - 
L. GRUCHMANN: Die „Reichsregierung“ im Führerstaat. 1975.- D. REBENTISCH: Hitlers Reichskanzlei zwischen Politik und Verwaltung. 1986.

\subsubsection{Geschäftsführende Reichsregierung Dönitz BA, Best. R 62}

Aus der Tätigkeit der von Großadmiral Dönitz am 2. Mai 1945 unter Graf Schwerin von Krosigk als Leitendem Minister ernannten Reichsregierung, die sich bis zu ihrer Verhaftung durch englische Truppen am 23. Mai in Flensburg bemühte, Deutschland aus dem Chaos der Niederlage herauszuführen, sind nur rund 100 Vorgänge (15 Bde. z. T. ab April) überliefert. Sie betreffen die Organisation (36 Vorgänge, mit Reden von Dönitz und Speer), die Durchführung der Kapitulation (25 Vorgänge mit Kopien der Kapitulationsurkunden, Originale BA-MA, Best. RW 4, weiteres im Best. RW 44, OKWFührungsstab Nord, und Denkschriften an die Alliierten), militärische Maßnahmen (5 Vorgänge), Möglichkeiten der Außenpolitik (12 Vorgänge), die Neuordnung von innerer Verwaltung und Justiz ( 9 Vorgänge, dabei Plan zur Abureilung von NS-Verbrechen) und wirtschaftliche Angelegenheiten, vor allem Sicherung der Lebensmittelversorgung (16 Vorgänge).

Lit: FINDBÜCHER zu Beständen des Bundesarchivs. Bd. 13. 1.Auflage 1975. S. 875-887. - GULES to German Records. vol 18. - W. LÜDDE-NEURATH: Regierung Dönitz. 1980.

\subsubsection{Vizekanzlei von Papen BA, Best. R 53}

Die Registratur der von Papen zur Führung seiner Geschäfte als Stellvertreter des Reichskanzlers vom 30. Januar 1933 bis zu seinem Rücktritt am 18. Juni 1934 dienenden Kanzlei ist nur zum Teil erhalten geblieben $(216 \mathrm{Bde})$; wesentliche Unterlagen wurden am 30. Juni 1934 im Zusammenhang mit der vorübergehenden Festnahme des Vizekanzlers und seiner wichtigsten Mitarbeiter durch die Gestapo beschlagnahmt und sind verschollen. Der Bestand umfaßt noch sog. Geheimakten mit Gesetzentwürfen und Rundschreiben der Reichsministerien und anderer oberster Behörden (38 Bde), Akten über die Dienststellenverwaltung (34 Bde bis 1935), Eingaben und Zuschriften in allgemeinen politischen (30 Bde) und privaten Angelegenheiten (15 Bde, auch Gnadengesuche), einzelne Sachakten (40 Bde) u. a. über Saargebiet, nationale Verbände, Justiz, Reichs- und Verwaltungsreform, Beamten-, Rassen- und Kulturpolitik, insbes. über das Verhältnis zu den Kirchen (7 Bde), Finanz- und Wirtschaftsfragen, Berichte über ausländische Reaktionen auf die Lage in Deutschiand (7 Bde) und Korrespondenz Papens (5 Bde) und seines persönlichen Referenten F. C. v. Savigny ( 3 Bde), ferner Material zu Reden und Veröffentlichungen Papens, seiner Teilnahme an Kundgebungen und Veranstaltungen, Audienzen und Ehrungen. Ergänzungsüberlieferung liegt in den Akten des Verfahrens gegen Papen vor dem IMT in Nürnberg und in Aufzeichnungen und Aussagen seines Mitarbeiters Fritz Günther v. Tschirschky (IfZ, Best. ZS 568) vor.

Lit.: FINDBÜCHER zu Beständen des Bundesarchivs. Bd. 2. - F. v. PAPEN: Der Wahrheit eine Gasse. 1952. -F. G. v. TSCHIRSCHKY: Erinnerungen eines Hochverräters. 1972.

\subsubsection{Reichskommissar für die Rückgliederung des Saargebietes} ZStA, Best. 09.05

Der größte Teil des Bestandes enthält die ab Januar 1920 vom Oberpräsidenten der Rheinprovinz als Reichskommissar für die Übergabe des Saargebiets angelegten Ak- 
ten. Sie wurden von Vizekanzler von Papen als Saarbevollmächtigter der Reichsregierung ab November 1933 und nach der Volksabstimmung 1935 von Gauleiter Bürckel als Reichskommissar (vgl. unten 1.1.6.3) fortgeführt. Sie sind folgendermaBen geglieder:

- Übergabe des Saargebietes (2 Bde, 1922-1935).

- Finanzwesen (4 Bde, 1925-1934), u. a. Ruhegehälter und Pensionen, Anleihen, Aufwertung.

- Verwaltung des Saargebietes, Regierungskommission (4 Bde, 1921-1935).

- Beamtenfragen (14 Bde, 1926-1935).

- Steuer-, Kassen- und Fürsorgewesen (16 Bde, 1924-1935).

- Post-, Eisenbahn- und Verkehrswesen, Zollangelegenheiten (6 Bde, 1927-1935).

- Bergwesen, Handel und Gewerbe (3 Bde, 1922-1935).

- Kirchen- und Schulangelegenheiten (3 Bde, 1921-1935).

- Arbeiterverhältnisse, u. a. Arbeitsdienst (6 Bde, 1926-1935).

- Landwirtschaft, Forst-, Fischerei- und Jagdwesen (1 Bd, 1932-1935).

- Justiz (15 Bde, 1931-1935, vor allem Rechts- und Verwaltungshilfe (10 Bde).

- Agenten, Fremdenlegion (6 Bde,1932-1935).

- Politische Verhältnisse (26 Bde), dabei Abstimmung und Wahlen (5 Bde), politische Flüchtlinge (16 Bde).

- Presse- und Vereinswesen (3 Bde, 1923-1934).

- Personenstandsangelegenheiten, Schadenersatzansprüche (10 Bde, 1920-1935, auch Nachweis arischer Abstammung).

- Statistik (2 Bde, 1930-1935).

- Kriegsgräberfürsorge, Kriegsschäden (3 Bde, 1925-1934).

- Militärwesen (42 Bde, 1932-1935).

- Polizeiwesen (4 Bde, 1933-1935).

- Büroangelegenheiten, Geschäftsordnung, Geschäftsberichte (8 Bde).

\subsubsection{Reichsstatthalter}

So unterschiedlich wie Stellung und Behördenorganisation der im späteren Gebiet der Bundesrepublik Deutschland als Aufsichtsinstanz für die Landesregierungen ab 1933 eingesetzten elf Reichsstatthalter ist auch deren Überlieferung. Sie fehlt völlig von den Reichsstatthaltern in Baden, Gauleiter Robert Wagner, in Oldenburg und Bremen, Gauleiter Röver und nach dessen Tod Gauleiter Wegener, und in Hamburg, Gauleiter Kaufmann, desgleichen vom Reichsstatthalter für Braunschweig und Anhalt, den Gauleitern von Magdeburg-Anhalt Loeper und ab 1936 Jordan, in der Außenstelle Oranienbaum des Staatsarchivs Magdeburg und vom Reichsstatthalter (bis 1937) für Lübeck, des mecklenburgischen Gauleiters Hildebrandt, im Staatsarchiv Schwerin; für Braunschweig liegt eine Ersatzüberlieferung in einem umfangreichen Manuskript Jordans vor (Memoiren eines Hitler-Statthalters 1933-1945, BA, Best. NS 20/128). Reichsstatthalter in PreuBen war Hitler selbst, hatte jedoch Göring als Ministerpräsidenten mit der ständigen Vertretung beauftragt, so daß sich die entsprechende Überlieferung - abgesehen von einigen Spuren in Akten der Reichskanzlei - im PreuBischen Staatsministerium befindet, und ebenso war in Hessen das Amt des Reichsstatthalters mit der Führung der Landesregierung vereinigt (vgl. unten Abschnitte 1.2.1 und 1.2.5). Damit verbleiben noch folgende Bestände: 


\subsubsection{Reichsstatthalter in Bayern}

M, Best. RSth

Der Bestand (825 Bde) enthält Akten aus der Amtszeit des Reichsstatthalters und NSDAP-Reichsleiters General Franz Ritter von Epp (1933-1945) in folgender Gliederung:

- Auswärige Angelegenheiten (32 Bde): Beziehungen zu einzelnen - überwiegend europäischen - Staaten (dabei Nationalsozialismus in Österreich); Volksabstimmung im Saargebiet, AnschluB Österreichs und des Sudetenlandes, Angelegenheiten eingegliederter und besetzter Gebiete; Auslandsdeutschtum.

- Aufbau des Reiches: Verfassung; MaBnahmen aus AnlaB der nationalsozialistischen Machtergreifung; Flaggen, Staatsfeiertage (insges. 14 Bde); Organe und Behörden des Reiches (14 Bde); Organisation, Aufgaben und Dienststellenverwaltung der Behörde des Reichsstatthalters (98 Bde); Staatsregierung und Landesbehörden (21 Bde); Beamtenrecht (96 Bde, mit Listen und Beurteilungen, Berufsbeamtengesetz).

- Innere Verwaltung: Berichte (9 Bde) der Regierungs- und Polizeipräsidenten (19341939) und der Bayerischen Politischen Polizei (1933-1936); Grenzangelegenheiten (5 Bde, bis 1941); Verfassung und Verwaltung der Gemeinden (54 Bde, bis 1943); Reichsund Staatsangehörigkeit (2 Bde, Allgemeines und Einzelfälle, auch Anwendung des Nürnberger Reichsbürgergesetzes); Organisation der Polizei (20 Bde); öffentliche Sicherheit (10 Bde mit Ereignismeldungen, dabei auch Verhängung von Schutzhaft, Maßnahmen gegen Asoziale und zur Bekämpfung der Unsittlichkeit); Gesundheitswesen und Jugendfürsorge (17 Bde, u. a. Erbgesundheitsgesetz, Verhütung von Krankheiten, Berufsangelegenheiten); Sammlungen (12 Bde, u. a. Winterhilfswerk, Adolf-HitlerSpende); Parteien und Verbände (18 Bde, vor allem Kriegervereine, Freikorps, jüdische Vereine); NSDAP und Gliederungen (25 Bde, dabei Reichsparteitage, Feiern am 9. November. Ausschreitungen, auch gegen Juden, Ordensburgen, Wehrpolitisches Amt); Presse (20 Bde, Aufsicht, Berichte der Auslandspresse) und amtliche Veröffentlichungen (3 Bde).

- Wirtschaft und Verkehr (112 Bde): Berichte über Lage der Wirtschaft; Arbeitsbeschaffungsmaßnahmen; Vergabe öffentlicher Aufträge; Vierjahresplan; Preisbildung und -überwachung; Freiwilliger und Reichsarbeitsdienst; Bewirtschaftungsmaßnahmen (1939-1945); Ernährung, Landwirtschaft, Forst-, Jagd- und Fischereisachen; Statistik; Vermessungswesen; Landesplanung.

- Reichs- und Staatsfinanzen, Finanzausgleich, Staatshaushalt (10 Bde).

- Justiz (25 Bde): Zivil- und Strafrechtspflege (dabei Verfahren wegen Beleidigung von Reichs- und Staatsministern, Anwendung des Gnadenrechts, Strafvollstreckung, Schriftwechsel des Staatssekretärs Hans Georg Hofmann als Mitglied des Volksgerichtshofes 1935-1941); Gerichtsorganisation; Akademie für Deutsches Recht.

- Kultus: Angelegenheiten der katholischen und der evangelischen Kirche, der Sekten und der Deutschen Glaubensbewegung (21 Bde); Wissenschaft (Universitäten, Professoren, Studenten), Unterrichtswesen und Kunst (30 Bde); Sport (4 Bde, dabei Olympische Spiele, 1933-1939).

- Militärische Angelegenheiten: Wehrmacht und Wehrmachtbauten, zivile Reichsverteidigung (16 Bde, dabei Reichsverteidigungskommissare, Volkssturm); Luftschutz und Luftangriffe, vor allem auf München (21 Bde); Angelegenheiten ausländischer Kriegsgefangener (2 Bde, 1943).

- Orden, Ehrenzeichen, Titel (64 Bde): Allgemeines und Verleihung einzelner Auszeichnungen (u. a. Olympia-Ehrenzeichen, Sudetenland-Medaille, Kriegsverdienstkreuz) 
und Titel, Annahme ausländischer Orden (1937-1944).

- Angelegenheiten einzelner Personen (45 Bde): Besetzung von Ämtern (Vorgänge über einzelne Beamte auch im BDC); Maßnahmen gegen einzelne Gegner des Nationalsozialismus; Denkschriften; Korruptionsfälle (1924-1945).

Den Bestand ergänzen Unterlagen über persönliche Angelegenheiten Epps in dessen NachlaB, darunter ein Tagebuch (16 Bde, mit Anlagen, 1933-1943, Eingaben an ihn (1937-1944), Vorgänge über Ehrungen, Glückwünsche, Einladungen, Besuche bei ihm, auch Manuskript von Lebenserinnerungen 1933-1945)); ein anderer NachlaBteil (BA, Best. NL 101) enthält vorwiegend Schriftgut aus der Zeit vor 1933 und aus NSDAPFunktionen, jedoch auch Epps Korrespondenz mit Hitler und Göring (1933, 1940-1944).

Lit: WIDERSTAND und Verfolgung in Bayern. Bd. V. 1976. S. 127-216. - J. KLENNER: Vertältnis von Partei und Staat 1933- 1945. 1974. - P. E. HÜBINGER: Thomas Mann und Reinhard Heydrich in den Akten des Reichsstatthalters v. Epp. 1980

\subsubsection{Reichsstatthalter in Württemberg S, Best. E 140}

Im Bestand sind lediglich Handakten des vom Reichsstatthalter und Gauleiter Wilhelm Murr berufenen Staatssekretärs Karl Waldmann überliefert (168 Bde). Sie betreffen die Organisation (1936-1937) und Personalangelegenheiten (1933-1936) der Staatsverwaltung, Preisbildung bei Lebensmitteln, ländliches Siedlungswesen, Kommunalverwaltung (dabei Besetzung von Bürgermeisterstellen, 1933-1936, Bauten der Stadt Stuttgart), Angelegenheiten der Wirtschaft (u. a. Arbeitsbeschaffungsmaßnahmen 1933-1935, Württembergische Bank 1933-1942, Handelskammer 1934-1935) und Kultur (Verhältnis der NSDAP zur evangelischen Kirche, Deutsche Christen 1935-1936, Landesbühne 1934), Neuordnung des Gesundheitswesens (1934-1936), Anwendung des Reichsbürgergesetzes (1936) und einzelne Personalangelegenheiten (ca. 100 Fälle, dabei Beschwerden gegen Entlassungen nach dem Berufsbeamtengesetz 1936-1940, Ausschlüsse aus der NSDAP).

Lit:: REPERTORIEN des Hauptstaatsarchivs Stuttgart. Bestand E 140. 1973.

\subsubsection{Reichsstatthalter in der Westmark, Saarbrücken}

Nach der Volksabstimmung von 1935 wurde das Saarland dem Reichskommissar für die Rückgliederung des Saarlandes (ab 1936 für das Saarland, oben 1.1.5) und Gauleiter der Saarpfalz Josef Bürckel unterstellt; seine Behörde übernahm die Funktionen der Internationalen Regierungskommission für das Saargebiet, soweit sie nicht auf Reichszentralbehörden übergingen. Nachdem bereits 1940 die Dienststellen des bayerischen Regierungspräsidenten für die Pfalz in Speyer und des Reichskommissars für das Saarland unter der Firmierung Reichskommissar für die Saarpfalz vereinigt worden waren, wurde dieser - seit 1940 zugleich Chef der Zivilverwaltung in Lothringen - 1941 zum Reichsstatthalter in der Westmark bestellt, womit die Pfalz de facto aus der bayerischen Verwaltung gelöst wurde. Zwar sollte seine Behörde in Saarbrücken konzentriert werden, doch blieben Teile in Speyer, und die Aufsicht über das lothringische Departement Moselle wurde z. T. von Metz aus ausgeübt. Die Folge davon und der erneuten Trennung von Saarland und Pfalz ist, daß Schriftgut dieser Provenienz, das durch Kriegsverluste, aber auch wegen fehlender archivischer Zuständigkeit nach 1945 und beim Saarhochwasser 1947/48 erheblich reduziert wurde, auf mehrere Archive verteilt ist. 
Im Landesarchiv Saarbrücken befindet sich Überlieferung einerseits in einem Bestand „Reichsstatthalter in der Westmark und Chef der Zivilverwaltung in Lothringen“, andererseits als Vorakten in Registraturgut von Ministerien des Saarlandes. Sie stammt aus folgenden Organisationseinheiten:

Personal- und Organisationsamt (i9 Bde Sach-, ca. 180 Personalakten).

Unterabteilung Ia (Allgemeine und innere Angelegenheiten): Kommunalaufsicht (18 Bde Sach-, 23 Bde Personalakten von Bürgermeistern und Kommunalbeamten). Polizei (55 Bde, u. a. betr. Fremdenlegion, Emigranten, Schutzhaft. Ausländerpolizei, Fremdarbeiter, Kriegsgräber, in Akten des Innenministeriums, ca. 360 Personalakten von Gendarmeriebeamten vor allem in Lothringen), kirchliche Angelegenheiten (ca. 250 Bde in Akten des Kultusministeriums, insbesondere über Vermögens- und Bausachen der Kirchengemeinden im Saarland, Kirchensteuer, einige über Juden).

Abteilung III (Gesundheitswesen und Volkspflege): Vorakten des Arbeitsministeriums betr. Gesundheits- und Krüppelfürsorge, Apotheken, Mutterschutzgesetz, Dienstgebäude.

Abteilung IV (Wirtschaft, Arbeit, Landwirtschaft): Wirtschaftsförderung, Kreditwesen und Feindvermögen (7 Bde); Neubildung deutschen Bauerntums (275 Sachakten betr. Siedlungswesen, Umlegung. Organisation der Kulturämter zusammen mit 75 Personalakten im Bestand Landeskulturverwaltung).

Unterabteilung Vb (Höhere Schulen): Aufsicht über höhere Schulen im Saarland (ca. 260 Bde im Bestand Kultusministerium).

Abteilung VIII (Landesforstamt): relativ umfangreiche Überlieferung über Forstbetrieb und Kriegswirtschaftsmaßnahmen, u. a. Einsatz von Fremdarbeitern.

Lediglich Splitter sind vorhanden aus den Zentralreferaten für Rechtssetzung ( 3 Bde) und für politische Polizei (2 Bde), der Abteilung II (Finanzabteilung, 9 Bde) und der Wasserwirtschaftsverwaltung.

Der Bestand im Departementalarchiv Metz (Sous-série 1 AR, Administration civile de Lorraine à Sarrebruck et fonds annexes) enthält vor allem Akten der Metzer Außenstellen (618 Bde). Der Anteil Saarbrückener Akten (77 Bde, 1937-1944) stammt hauptsächlich aus der Abteilung IV, umfaßt aber auch Akten des Verbindungsbüros zur Gauleitung Westmark.

In der Registratur der Bezirksregierung in Neustadt (SP, Best. H 7, vgl. Abschnitt 2.1.2.3.4) sind nur wenige Bände über Räumungs- und Rückführungsmaßnahmen (19391941) und Schulaufsicht erhalten.

Aus den Kreisverwaltungen des Saarlandes liegt Ersatzüberlieferung für die Zeit von 1935 bis 1945 in größerem Umfang von Saarbrücken-Land und St. Ingbert vor, in geringem von Saarlouis (damals Saarlautern), Merzig und St. Wendel (SB).

Lit.: V. RÖDEL: Die Behörde des Reichsstatthalters in der Westmark. 1984. - GRUNDRISS zur deutschen Verwaltungsge schichte. A 7. S. 589 ff.- H. W. HERRMANN: Pfalz und Saarland in den Plänen zur Neugliederung des Reichsgebietes 1933-1941. 1985. - ZEHN STATT TAUSEND JAHRE. 1988. S. 36-59. - F. JACOBY: Die nationalsozialistische Herrschaftsübernahme an der Saar. 1973.

\subsubsection{Reichsstatthalter in Lippe und Schaumburg-Lippe, Detmold}

DT, Best. L 76

Vorhanden sind Akten (1933-1943) über die Ernennung, persönliche Angelegenheiten und das Büro sowie Korrespondenz (u. a. über Erhaltung der Selbständigkeit beider Länder) des Reichsstatthalters Alfred Meyer, der zugleich Oberpräsident von Westfalen und Gauleiter von Westfalen-Nord war (34 Bde, 1933-1941). Die Sachakten (132 
Bde) enthalten Erlasse und Anordnungen und betreffen Ernährung und Landwirtschaft (1933-1938). Kirchenpolitik (1933-1935), Wirtschaft (u. a. Preisüberwachung. Siedlungswesen, Ausbeutung von Bodenschätzen für den Vierjahresplan, Mitteilungen des Reichstreuhänders für den öffentlichen Dienst), Luftschutz und Luftfahr (1933-1938), Gesundheitswesen (1939-1941), Länderfinanzen (1933-1941), kulturelle Angelegenheiten (1933-1938), Landesplanung (1933-1937), Ernennung von Bürgermeistern (19351938) und Aufsicht über die Landesregierung (20 Bde, u. a. Personalunterlagen mit politischen Beurteilungen, Organisation der Polizei, Beschäftigung von „Alten Parteigenossen", vermögensrechtliche Auseinandersetzung mit dem Fürstenhaus). Der in den Akten enthaltene Schriftwechsel mit Dienststellen der NSDAP und ihrer Gliederungen ist gesondert nachgewiesen (Das SCHRIFTGUT der NSDAP, Teil 4).

Lit.: J. SENGOTTA: Der Reichsstatthalter in Lippe 1933-1945. 1976.

\subsection{Staatskanzleien und Gesamtstaatsministerien der Länder}

\subsubsection{Preußisches Staatsministerium}

GStA und ZStA Merseburg, Rep. 90

Mit der Vereinigung der Reichs- und preußischen Ministerien mit Ausnahme des Finanzministeriums verlor die Behörde den größten Teil ihrer Bedeutung als Zentralinstanz und wurde von Göring, der als preußischer Ministerpräsident formal weiter an der Spitze stand, zum Teil für seine Aufgaben als Beauftragter für den Vierjahresplan benutzt; der Staatssekretär Paul Körner diente ihm in beiden Funktionen.

Der Bestand des GStA enthält aus der NS-Zeit Protokolle von Sitzungen der Minister (Annex A, nur 1933 und November, Dezember 1935), Korrespondenz- und andere Akten aus dem Büro Görings (Annex B, ca. 250 Bde, überwiegend 1933 und 1937. mit Einladungen, Glückwünschen, Bittgesuchen und Beschwerden, Presseartikeln und Unterlagen über Ehrenbürgerschaften und andere Ehrungen, Erfindungen, Verfolgung von Juden, Ernennungen - u. a. von Professoren 1944 - und andere Personalangelegenheiten), Handakten des Referenten Gönnert aus dem Stabsamt Görings (Annex Q. 21 Bde mit Einzelvorgängen, meist 1941-1944, u. a. Aufzeichnungen über Besprechungen mit Hitler und Gauleitern 1942, über Geschenke an Göring, Giftgasproduktion, Kriminalstatistiken) und einzelne Sachakten vornehmlich aus folgenden Sachgebieten: - Reichs- und Landesverfassung: Gleichschaltung der Länder (4 Bde, 1933-1934); Ernennung von Sanitätsräten (bis 1938); Ordensverleihungen (2 Bde, bis 1937); Angelegenheiten des Hauses Hohenzollern und der Fürsten von Lippe und Schaumburg-Lippe (4 Bde, bis 1938).

- Reichs- und Staatsbehörden: Geschäftsstil (1933); Repräsentationsverpflichtungen von Ministern (1933-1936); Geschäftsbedürfnisse; Einrichtung von Reichsbehörden (9 Bde, 1933-1941).

- Reichs- und Staatsbeamte: Politisches Verhalten (2 Bde, 1929-1936); Dienstjubiläen (10 Bde, 1937-1938); Ernennung und Laufbahnen (6 Bde, 1933-1939); Personalangelegenheiten einzelner Ministerien, Behörden, Forschungsinstitute, Akademien (ca. 50 Bde, bis 1944); Zwangspensionierungen (Annex H, ca. 70 Bde, bis 1936); Personalveränderungen (Annex O, 87 Bde mit ca. 3000 Einzelvorgängen über Ernennungen, 
Beförderungen, Pensionierungen von höheren Beamten, vor allem Gymnasiallehrern, und Polizeioffizieren, auch Ministerial- und Gestapobeamten ab 1935).

- Landesverwaltung: Hilfen für Ostpreußen und andere Ostprovinzen (ca. 20 Bde, bis 1939); Währungs-, Bank- und Versicherungsangelegenheiten (5 Bde, bis 1940): Vermessungswesen; Volkszählung (bis 1937); Staatshandbücher (bis 1939).

- Verwaltung des Staatsvermögens: Stiftung "Preußenhaus“ (1934-1936); Grundstücks- und Gebäudeverwaltung (1938-1944), u. a. von Görings Jagdhäusern Karinhall (18 Bde), Rominten/Ostpreußen (4 Bde), Burg Veldenstein (5 Bde).

- Monopole, Steuern und Zölle (8 Bde).

- Landwirtschaft, Forsten, Jagden und Fischerei (6 Bde).

- Handel und Gewerbe (6 Bde).

- Eisenbahnen (3 Bde), Kraftfahrzeuge (2 Bde, auch Reichsautobahnen) und Luftverkehr (Eingaben 1893-1939).

- Religions- und Kirchensachen (5 Bde).

- Unterrichtssachen ( 8 Bde betr. Schulen, Hochschulen, Lehrerbildungs- und Nationalpolitische Erziehungsanstalten).

- Einrichtungen zur Fortbildung und Berufsausbildung (4 Bde).

- Wissenschaft und Kunst (12 Bde, u. a. betr. Kaiser-Wilhelm-Gesellschaft bis 1936, Verkaufsabrechnungen für ,entartete Kunst“ 1938-1940, Betrieb und Leitung der Staatstheater, Denkmalpflege).

- Polizei (5 Bde, vor allem Gesundheitspolizei).

- Armen- und Wohltätigkeitssachen: Unterstützungsgesuche (13 Bde, 1933-1937), Ehrenpatenschaften Görings (18 Bde, 1933-1936), Unterstützung kinderreicher Familien (5 Bde).

Einen eigenen Teilbestand bildet die Gestaporegistratur (Annex P) mit Lageberichten und Ereignismeldungen der preußischer Staatspolizeistellen (16 Bde, überwiegend 1934-1936, einzelne bis 1942, Einzelnachweis für das Gebiet der Bundesrepublik im Abschnitt 2.2.4.2.2.1) und - meist nur einzelnen Bänden (1933-1937) - über Organisation (3 Bde), Personalangelegenheiten ( $8 \mathrm{Bde}$ ), Haushalt ( $9 \mathrm{Bde})$, Waffen und Munition (4 Bde), Staatsschutz (3 Bde), NSDAP und Gliederungen ( 9 Bde), Wehrmacht und Wehrverbände (5 Bde), Kirchen und Weltanschauungen ( 7 Bde), Juden und Emigranten (2 Bde), Freimaurer (2 Bde), Kommunismus ( $3 \mathrm{Bde}$ ), Korruptionsfälle ( $2 \mathrm{Bde}$, bis 1941), Ausschreitungen (4 Bde), Schutzhaft (5 Bde, mit Namenslisten) und zahlreiche andere Tätigkeitsgebiete (weitere 24 Bde, in einem Sammelband Berichte Heydrichs an Göring, Vorgänge über Beobachtung des Erzbischofs Gröber 1939-1943).

Ein weiterer Teilbestand (Annex N, 354 Bde, 1934-1944) stammt von der Archivabteilung und enthält Generalakten über Dienststellenverwaltung mit Haushalts- und Personalangelegenheiten (166 Bde), über die 18 einzelnen Archive, die Zentralstelle für Nachkriegsgeschichte, die Publikationsstelle und das Institut für Archivwissenschaft sowie über Kriegsmaßnahmen im Archivwesen.

Ergänzungsüberlieferung enthalten einige Fragmente von Aufzeichnungen Görings (IfZ) und die Dokumente aus dem Nürnberger IMT-Prozeß.

Der Merseburger Teilbestand umfaßt wenige Akten in Privatangelegenheiten Görings (2 Bde, 1937-1943, meist Gesuche um Hilfe bei anderen Behörden 1939-1943), Handakten des Ministerialrats Dr. Gramsch (Presseartikel zur „Volksdeutschen Bewegung“ in Ungarn, Okt.1936), Sitzungsprotokolle 1933-1938 (2 Bde) und Sachakten betr. Grenze zu Sachsen (Behebung von Mängeln bei der Vermarkung und von durch $\mathrm{HJ}$-Angehörige 
verursachten Grenzschäden, 6 Bde, 1933-1936) und Thüringen (4 Bde, 1932-1933), Hamburg-PreuBische Hafengemeinschaft $\mathrm{GmbH}$ und andere hamburgisch-preuBische Gemeinschaftseinrichtungen (1933-1934), Berichterstattung über außergewöhnliche Ereignisse, insbesondere Katastrophen, Unglücke, Luftangriffe (2 Bde, 1937-1941).

Ebenfalls in Merseburg befinden sich die Akten der 1933 zur Verwaltung der Gebäude des preuBischen Abgeordneten- und Herrenhauses unter Aufsicht des Ministerpräsidenten errichteten

\section{Stiftung Preußenhaus}

Sie betreffen allgemeine Verwaltungs-, Organisations- und Personalangelegenheiten (26 Bde, 1933-1944); Haushalts-, Kassen- und Rechnungssachen (26 Bde, 1934-1944); Grundstücks- und Bauangelegenheiten (15 Bde, 1933-1944, auch betr. Amtswohnung des Präsidenten; Inventare und Überlassung von Einrichtungsgegenständen (15 Bde. 1934-1944) und Räumen an Reichs- und preußische Ministerien (8 Bde, 1933-1944) sowie NS-Organisationen und staatlichen Institutionen (15 Bde, 1934-1936).

Lit.: GUIDES to German Records. vol. 5. S. 4-5 (Annex Q). - H. WEISS: Die Aufzeichnungen Hermann Görings im Institut für Zeitgeschichte. 1983. - A. KUBE: Pour le mérite und Hakenkreuz. 1987. - S. MARTENS: Hermann Göring. 1985.

\subsubsection{Bayerische Staatskanzlei}

M, Best. MA

Der umfangreiche Bestand, der an die Überlieferung des Ministeriums der auswärtigen Angelegenheiten angeschlossen wurde, enthält Schriftgut, das jedoch ab 1935 an Bedeutung verliert, aus der Amtszeit der Ministerpräsidenten Ludwig Siebert (1933-1942) und Paul Giesler in folgender Gliederung:

- Auswärtige Angelegenheiten: Allgemeines, Beziehungen zu einzelnen Ländern und deren Vertretungen (214 Bde); Auslandsdeutschtum (11 Bde, bis 1941); Kriegsfolgen des Ersten und Maßnahmen im Zweiten Weltkrieg (18 Bde, u. a. Ministerrat für die Reichsverteidigung, Kriegsschäden, Besatzungsverwaltung).

- Aufbau des Reiches: Verhältnis Reich-Länder (32 Bde, dabei Berichte aus anderen Ländern und preußischen Provinzen); Reichsverfassung, Reichsreform, Hoheitszeichen, Feiertage (33 Bde); Landesverfassung (19 Bde); Organisation der Reichs- (84 Bde, dabei Sammlungen von Erlassen der obersten Reichsbehörden) und Landesverwaltung (282 Bde, dabei Korrespondenz, Reden und Unterlagen über persönliche Angelegenheiten - Ehrungen, Repräsentationsverpflichtungen, Patenschaften, Glückwunschschreiben von Ministern, Reichs- und Gauleitern - Sieberts, Protokolle des Ministerrats); Beamtenrecht und öffentliches Dienstrecht (151 Bde).

- Innere Verwaltung: Grenzangelegenheiten (40 Bde, dabei Zwischenfälle, Einsatz der SA zur Grenzsicherung); Grenzlandfürsorge, u. a. durch Sondermittel der Reichsanstalt für Arbeitsvermittlung und Arbeitslosenfürsorge, für die Bayerische Ostmark (90 Bde), die Pfalz (104 Bde ab 1919) und das Saargebiet (80 Bde ab 1919); Gemeindeverfassung und -verwaltung (21 Bde); Personenstandswesen (19 Bde); Staatsangehörigkeit (29 Bde); Aufenthaltsrecht, Fremdenpolizei, Auswanderung, Ausweisungen (54 Bde); Polizei (70 Bde, dabei Lageberichte, Personalangelegenheiten, Schutzhaft mit Einzelfällen); Gesundheitswesen (79 Bde, dabei Bevölkerungspolitik und Rassenhygiene, Erbgesundheitsgesetz, Nachweis arischer Abstammung, Maßnahmen gegen Juden 1933-1934, Blutschutzgesetz); Lebensmittelpolizei ( 9 Bde); Veterinärwesen (32 Bde); Presse und Literatur (55 Bde, u. a. Schriftleitergesetz, Verbote von Zeitungen und Büchern, Auslandspresse, Angelegenheiten des „Völkischen Beobachters“); Fürsorgewesen (51 Bde, dabei 
auch Winterhilfswerk, NSV, HJ); Verbände und Vereine (35 Bde, dabei SPD, Sekten, Monarchisten, Stahlhelm); Kongresse (8 Bde); Ausstellungen (12 Bde); Lotterien (3 Bde); Statistik (14 Bde); Amtliche Drucksachen, Gesetzblätter (31 Bde); Angelegenheiten des ehem. Königshauses und des Adels (5 Bde): Berichte der Regierungspräsidenten (28 Bde, vgl. Abschnitt 2.1.2.3.4).

- Wirtschaft und Verkehr: Allgemeines, Arbeitsmarkt und Arbeitsrecht, Wohnungsund Siedlungswesen, Städtebau, Preisbildung. Energieversorgung (53 Bde, dabei Berichte des Landesarbeitsamtes Bayern 1934, Einsatz von Fremdarbeitern, RAD- und DAF-Angelegenheiten); Land- und Forstwirtschaft, Jagd, Fischerei (55 Bde); Handel, Industrie, Gewerbe, Bergbau (42 Bde, dabei Gewerbeaufsicht, Außenhandel); Geld-. Bank- und Börsenwesen (41 Bde); $\mathrm{MaB}$ und Gewicht (3 Bde); Versicherungswesen (36 Bde); Straßenbau und -verkehr (7 Bde, u. a. Reichsautobahnbau); Eisenbahnen (13 Bde); Post- und Fernmeldewesen, Rundfunk (7 Bde); Schiffahrt und Kanäle (22 Bde); Luftverkehr (3 Bde); Fremdenverkehr (3 Bde).

- Finanzwesen: Finanzverwaltung (10 Bde); Haushalts-, Kassen- und Rechnungswesen (94 Bde, dabei Spenden und Unterstützungen u. a. für SA- und SS-Leute, Dispositionsfonds des Ministerpräsidenten); Steuerwesen (35 Bde); Kostenwesen (4 Bde); Anleihen (5 Bde); Zollwesen (2 Bde).

- Justiz: Organisation (6 Bde); Zivilrecht (9 Bde); Rechtsangelegenheiten von Deutschen im Ausland und Ausländern im Inland (19 Bde); Strafrecht (31 Bde, dabei Berichte des Oberlandesgerichts München, Verfahren wegen Beleidigung von Ministern und wegen Hoch- und Landesverrat, Strafvollzugsangelegenheiten, Amnestie, Maßnahmen gegen Glücksspiele und Wahrsagerei); Rechtshilfeverkehr mit dem Ausland (20 Bde).

- Kultus: Kirchliche Angelegenheiten (57 Bde, dabei Beziehungen zum Vatikan, Reichskonkordat, politische Betätigung von Geistlichen, Bekennende Kirche, Sekten, Feiertagsrecht); Bildungswesen (alle Schularten, Landjahr, Volksbildung, Universitäten, Professoren und Studenten, 78 Bde); Turn- und Sportwesen (7 Bde, u. a. Deutsche Kampfspiele, Olympische Spiele); Wissenschaftliche Institute, Vereine und Aufgaben (36 Bde, u. a. Deutsche Akademie, Bayerische Akademie der Wissenschafien); Erwerb und Leihverkehr von Büchern und Archivalien (7 Bde); Museen und Sammlungen (27 Bde); Reichskulturkammerangelegenheiten, Kunstpflege, Musik, Tanz. Theater, Festspiele, Passionsspiele, Heimatpflege, Denkmalschutz, Naturschutz (insges. 62 Bde).

- Heer, Marine, Luftwaffe (3 Bde, dabei auch Fremdenlegion).

- Orden und Titel (50 Bde ab 1920).

- Personalangelegenheiten politischen Charakters (21 Bde u. a. über Säuberungsmaßnahmen nach dem 30. Juni 1934, Verhältnis von NSDAP und Wehrmacht 1934-1935, Staatsminister Hermann Esser 1934-1935, Schutzhaftfälle 1933-1934, Gauleitung Mainfranken 1935, Parteizugehörigkeit von Beamten 1941, Kronprinz Rupprecht 1941-1942).

Lit.: WIDERSTAND und Verfolgung in Bayern. Bd. 5. S. 1-124. - B. ZITTEL: Der bayerische Ministertat und seine Protokolle. 1957.

\subsubsection{Württembergisches Staatsministerium}

S, Best. E 130 b

Nur relativ wenige Akten sind in dem 1876 beginnenden Bestand überliefert, die unter dem Ministerpräsidenten Christian Mergenthaler 1933 bis 1945 fortgeführ oder neu angelegt wurden. Sie betreffen vor allem:

Ordensverleihungen. - Vermögensrechtliche Auseinandersetzung mit dem Königshaus (1924-1943). - Volksabstimmung 1933. - Personalien der Minister und Tätigkeit 
der Ministerien (Berichte 1933-1939). - Beamtenrecht (6 Bde). - Verwaltungsgerichtsbarkeit und Dienststrafrecht (3 Bde. 1935-1941). - Eingemeindungen (1936-1937). Turn- und Sportvereine (1923-1945). - Polizei (u. a. Maßnahmen gegen Zigeuner, Fremdarbeiter, Jugendschutzlager, Feiertagsrecht, Feuerschutzpolizei). - Gesundheitswesen und Fürsorge (15 Bde, dabei Fürsorge für Angehörige von Schutzhäftlingen 1933-1934, Landjahr 1935-1944). - Landwirtschaft (3 Bde, dabei Berichte des Reichs. amtes für Agrarpolitik 1933-1942). - Wohnungs- und Siedlungswesen (4 Bde). - Verkehr mit Lebensmitteln (10 Bde). - Wirtschaft, Handel und Handwerk (28 Bde, hauptsächlich Angelegenheiten von Kammern und Sparkassen). - Arbeitsrecht (7 Bde, dabei auch RAD). - Auswanderung und Auslandsdeutschtum (5 Bde). - Unterrichtswesen (5 Bde, u. a. Reichsschulgesetz, Streit um Bekenntnisschulen), Wissenschaft (Technische Hochschule, Ortsgeschichtsforschung) und Kunst (5 Bde). - Kirchliche Angelegenheiten (10 Bde, auch Einzelfälle und Sekten). - Finanzen und Steuern (25 Bde). - Staatshaushalt (11 Bde, u. a. Kürzung der Leistungen für Kirchen, Mittel für die NSDAP, Einziehung von Vermögen). - Finanzen und Steuern (25 Bde). - Eingaben der NSDAP und anderer Organisationen und deren Behandlung (16 Bde). - Reichsverfassung und -behörden (17 Bde) - NS-Kriegsopferversorgung (1933-1939).

\subsubsection{Badisches Staatsministerium}

KA, Best. 233

Aus folgenden Sachgebieten sind Akten vorhanden, die unter dem Ministerpräsidenten Walter Köhler fortgeführt oder angelegt wurden:

- Reichsangelegenheiten: Auswanderung (6 Bde, dabei Auswanderberatungsstelle, 1937-1943); Werbung für die NS-Presse (Maßregelung von Beamten); Schriftleitergesetz (1933-1941); Reichsautobahn (1933-1941).

- Verwaltung und Beamtentum: Reichsstatthaltergesetz (2 Bde, 1933-1938); Gleichschaltung 1933 (5 Bde); Zusammensetzung und Sitzungsprotokolle der Staatsregierung (9 Bde, 1933-1936); Behördenorganisation, Verwaltungsvereinfachung, Verlagerungen im Zweiten Weltkrieg (5 Bde); Entlassung und Erhebungen über politische Zuverlässigkeit von Beamten (20 Bde, Einzelfälle); Unterbringung alter Parteigenossen (10 Bde); Berufsbeamtengesetz (5 Bde); Nachweis arischer Abstammung (4 Bde); politische und weltanschauliche Schulung (5 Bde); Tarifordnung (3 Bde, 1921-1944); Angelegenheiten des Kultusministeriums (30 Bde, dabei Denkschriften zur Lage der Akademien, Hochschulen und Universitäten, Besetzung von Schul- und Kirchenämtern); Personalangelegenheiten der Polizei (15 Bde), des Wachpersonals im Schutzhafilager Kislau, der Landesversicherungsämter und des Verwaltungsgerichtshofs; Anwendung des Berufsbeamtengesetzes bei den Gemeinden ( 5 Bde); Winterhilfswerk und NSV (5 Bde); Organisation der Arbeits-, Luftfahrt-, Vierjahresplan- und Sozialverwaltung und der Reichspropagandaämter (5 Bde); Zivilverwaltung im Elsaß (30 Bde, 1940-1945); Reichswasserstraßenverwaltung (1919-1943); Organisation der Staatsbehörden (30 Bde).

- Gewerbe: Arbeitsrecht und Arbeitseinsatz (20 Bde); Wirtschaftsverfassung (Generalrat der deutschen Wirtschafi, Reichskammer der Technik, 1933-1934); Maßnahmen gegen jüdische Betriebe (1937-1938); Gewerbeaufsicht; Reichswesthilfe (1933-1934); Vierjahresplan, Rohstoffbewirtschaftung (13 Bde, 1936-1942); Elektrizitätsverbund (5 Bde, 1929-1934).

- Kirchen (10 Bde, u. a. betr. Konkordat und Vertrag mit der Landeskirche, katholische Jugendverbände, Bischofswahl, Kirchgeld).

- Krieg (10 Bde betr. Feindvermögen, Produktionslenkung, Arbeitseinsatz). 
- Kunst (5 Bde betr. kulturelle Westhilfe, Denkmalpflege).

- Landwirtschaft (3 Bde betr. Reichsnährstand, Siedlungswesen, Schulwesen).

- Medizinalwesen: Kassenzulassung von Ärzten; Fürsorge für Geisteskranke (19351944); Ehegesundheitsgesetz (1935-1945).

- Polizei (16 Bde, dabei Hilfspolizei 1933-1945, Bekämpfung der Jugendkriminalität 1933-1944, Ausweisungen 1930-1937, Schutzhafteinzelfâlle 1933-1940, Einziehung staatsfeindlichen Vermögens, Berichte über einzelne Vorfälle der Störung von Sicherheit und Ordnung 1933-1943).

- Rechnungs- und Haushaltswesen (10 Bde).

- Rechtspflege (8 Bde, dabei Bildung von Sondergerichten 1933-1938, Reichserbhofgesetz, Rechtsbetreuung durch die NSDAP 1934-1935); Auseinandersetzung mit ehemaligen Fürstenhäusern 1935-1939.

- Schulen: Katholische Lehr- und Erziehungsanstalten (1938-1945); Landwirtschaftsschulen (1935-1941), Nationalpolitische Erziehungsanstalten (1937-1941).

- Stiftungen der Kirchen und von Familien (3 Bde, 1939-1941).

- Versicherungen (2 Bde, 1933-1939).

Lit: H. REHBERGER: Die Gleichschaltung des Landes Baden 1932/33. 1966.

\subsubsection{Hessische Landesregierung}

DA

Der Reichsstatthalter und Gauleiter Jakob Sprenger, der bereits 1933 die zunächst mit Professor Ferdinand Werner und Philipp Jung besetzten Ämter des Staats- bzw. Ministerpräsidenten beseitigt und die bisherigen vier Ministerien mit dem Staatsministerium vereinigt hatte, übernahm 1935 als Führer der Landesregierung die Leitung einer Einheitsbehörde, deren zehn Abteilungen die Kompetenzen der Ministerien erhielten, soweit sie nicht auf das Reich übergegangen waren. Ihr Schriftgut ist durch Kriegsereignisse fast völlig vernichtet worden, die Reste wurden mit den Vorakten der früheren Ressorts vereinigt. Folgende Teilbestände sind überliefert:

Abteilung I, Allgemeine Verwaltung

Abt. G 5 Erhalten blieben vor allem Vorgänge aus der persönlichen Registratur des Amtschefs (ab 1938 Staatssekretärs) Heinrich Reiner. Sie betreffen die Auseinandersetzungen zwischen Werner und Sprenger, dessen Entlassung und anderes aus der Tätigkeit - auch als Reichswanderwart - des Ministerpräsidenten (25 Vorgänge, 1933-1934) und des Staatsministers Jung (3 Vorgänge, 1933-1935), ferner andere Personalangelegenheiten von Parteifunktionären, Beamten und Unternehmern, u. a. Schutzhaftfälle (mit Liste 1934) und Vorwürfe wegen politischer Unzuverlässigkeit (ca. 70 Vorgänge, 1933-1938). Außerdem sind politische Monatsberichte des Reichsstatthalters an den Reichsinnenminister vorhanden (1934 August-1936 Februar). Ergänzungsüberlieferung enthält der NachlaB Jungs (Abt. O 31, dabei Vorgänge über die Ernennung der Staatskommissare 1933 und Tätigkeitsberichte einzelner Abteilungen 1933-1934). Eine Serie der Verordnungen, Runderlasse und Ausschreibungen der Landesregierung (1933-1938) wurde aus Akten der Kreisverwaltungen zusammengestellt (Abt. R 1). Die Tätigkeit des zur Abteilung gehörenden Personalamts ist durch die weitgehend vollständig erhaltenen Besoldungsstammkarten dokumentiert (Abt. G 35 E, 1933-1945). 
Abteilung II, Polizei

Abt. G 12 A

Vorhanden sind Rundschreiben, Tagesbefehle und Anordnungen des Polizeifihrers bzw. des Landespolizeiamts und anderer hessischer Behörden in Polizeiangelegenheiten (26 Bde, 1933-1936), die durch Befehle der Kommandeure der Schutzpolizei (6 Bde, 1939 1944) und der Gendarmerie (2 Bde, 1937-1941) fortgesetzt werden. Aufstellung, Ausbildung und Einsatz der Hilfspolizei sind gut dokumentiert (32 Bde, 1933-1935, dabei Berichte von einzelnen Sonderkommandos). Außerdem sind Personalakten der Polizei überliefert ( 320 Einzelfalle, meist 1920-1937, z. T. bis 1945, in Abt. 12 C).

Abteilung III, Innere Verwaltung

Abt. G 11

Den Hauptteil der Überlieferung bilden Akten über die Verleihung der Rechtsfähigkeit an und die Aufsicht über Vereine (ca. 50 Bde bis 1943) und Stiftungen (ca. 175 Bde bis 1944), darunter Turn- und Gesangvereine, gemeinnützige, z. B. Bau-, Vereine, auch sozialdemokratische und jüdische Vereine (Israelitischer Lehrerverein) und Stiftungen (Kultusvereinigung Offenbach, Hospital Worms), ferner Reichsstatthalter Jakob Sprenger-Stiftung und Adam Opel-Gedächtnisstiftung. AuBerdem sind Unterlagen über die Änderung von Familiennamen (Allgemeines und wenige Einzelfälle, auch von Juden, 9 Bde, 1933-1943), über Bekämpfung von Spionage und Landesverrat (4 Bde, 19331936), Sparkassenaufsicht (1944-1945) und Veterinärwesen (1944-1945) vorhanden. Mit nach 1945 fortgeführten Vorakten in anderen Beständen ist aufgrund der Zerstörung des Dienstgebäudes durch Bomben 1944 nur bedingt zu rechnen.

Abteilung IV, Finanzverwaltung

Abt. G 31

Die im Bestand überlieferten Altregistraturen enthalten nur wenige über 1933 fortgefuihrte Akten, u. a über den Bau und Unterhalt von Kirchen, Pfarr- und Schulhäusern (Abt. G 31 F, bis 1940), Eisenbahnwesen (Abt. G 31 L, Baufinanzierung, Nebenbahnen, bis 1939) und (Sammel- und Einzelfallakten) Personalangelegenheiten der Finanz- und Steuerverwaltung (Abt. G 31 P, bis 1942). Wichtiger sind die im NachlaB des Abteilungsleiters, Ministerialrat Hermann Hesse, überlieferten Unterlagen (Abt. O 24). Sie betreffen vor allem folgende Sachgebiete:

Archiv- und Büchereiwesen, Aktenbenutzung (4 Bde, 1933-1944). - Banken und Geldinstitute (55 Bde, 1933-1945, überwiegend aus Funktion als Staats- bzw. Reichskommissar bei der Hessischen Landesbank und der Landeshypothekenbank). - Bauwesen, insbes. sozialer Wohnungsbau (18 Bde, 1933-1945). - Beamtenangelegenheiten (20 Bde Allgemeines, 10 Bde Einzelfälle, 1934-1945 bzw. 1943). - Elektrizitätsversorgung (10 Bde, 1933-1945, z. T. aus Funktion als Mitglied des Verwaltungsrates der Rheinisch-westfälischen Elektrizitätswerke). - Finanzausgleich, Darlehen und Schulden (16 Bde, 1933-1945). - Fiskalischer Grundbesitz, auch Erwerb und Veräußerung (99 Bde, 1933-1945, dabei Fischereirechte, Waldbesitz, staatseigene Gebäude in Darmstadt, Überlassung von Gebäuden und Grundstücken an die NSDAP 1934-1936). - Fürstenhaus, Abfindung und Vermögensauseinandersetzung (15 Bde, 1933-1944). - Gemeindefinanzen (6 Bde, 1933-1944). - Haushalts-, Kassen- und Rechnungswesen (30 Bde. 1934-1945). - Kriegsfolgelasten, Grundbesitz des Militärfiskus (5 Bde, 1933-1935). Kirchensachen, insbes. Zuwendungen an die evangelische Kirche (1933-1945). - Landeskultur, Umschuldung in der Landwirtschaft (15 Bde, 1933-1944). - Schulwesen (10 Bde, 1933-1944). - Staatsbad Nauheim (15 Bde, 1933-1945, dabei Unterbringung ausländischer Diplomaten und des Reichssenders Frankfurt). - Steuern (15 Bde, 1933 . 1945). - Straßenbau (10 Bde, 1934-1944). - Universitäten (Gießen, TH Darmstadt, 6 
Bde, 1935-1944). - Verwaltungsorganisation (7 Bde, 1934-1944, dabei Aufhebung der drei Provinzen 1937). - Weinbaudomäne (3 Bde, 1942-1943).

Ergänzungsüberlieferung enthalten umfangreiche Akten der Landeshauptkasse (bis 1937 Hauptstaatskasse) Darmstadt (Abt. G 35 mit Teilbeständen 35 C und D) vor allem mit Abrechnungen des Erneuerungsstocks für Land- und Forstwirtschaft, der Hessisch-thüringischen Lotteriegemeinschaft (1933-1941), der Polizeikasse (1934-1938) und der Staatsunterstützungskasse, über verschiedene Stiftungsvermögen zur Förderung von Gewerbe, Kunstgewerbe und Handel, den Landesschulfonds (1933-1936), die Landesplanungsgemeinschaft Rhein-Main (1938-1943), die Hessische Offizierswitwen- und -waisenkasse (1938-1945), Westhilfe und ,Deutsches Volksopfer“ (1940-1945).

Abteilung V, Forstwesen

Abt. G 33 A

Nur wenige Akten der Oberforstdirektion, hauptsächlich betr. Holzeinschlag und andere Rechnungssachen, reichen über 1933 hinaus (ca. 20 Bde), dazu kommen Personalakten (ca 120 Bde, meist nur bis 1938/39, in Abt. G 33 B) und die im NachlaB Hesse überlieferten Vorgänge aus der Finanzabteilung, u. a. über die Villenkolonie Buchschlag bei Frankfurt (15 Bde).

Von den Abteilungen VI, Landwirtschaft, VII, Bildungswesen, Kultus, Kunst und Volkstum, VIII, Arbeit und Wirtschaft, IX, Bauverwaltung, und X, Vertretung Hessens in Berlin ist keine eigene Überlieferung vorhanden, jedoch von Hesse bearbeitete Akten (Domänen-, Kirchenbau- und andere Bausachen) in seinem NachlaB, und weitere Ersatzüberlieferung (über Einsetzung von Staatskommissaren für Landwirschaft, Arbeits- und Mittelstandsfragen 1933, Studentenschaften 1933/34, Landwirtschafts- und Industrie- und Handelskammer) ist im Nachlaß Jung enthalten.

Lit.: D. REBENTISCH: Der Gau Hessen-Nassau und die nationalsozialistische Reichsreform. 1978.

\subsubsection{Oldenburgisches Staatsministerium}

OL, Best. 131

Der Bestand enthält nur wenige nach 1933 unter dem Ministerpräsidenten Georg Joel fortgeführte oder angelegte Akten. Sie betreffen Reichsangelegenheiten (dabei Einsetzung eines Staatskommissars 1933, Vermögensauseinandersetzung mit dem Fürstenhaus 1918-1939), Behördenorganisation (dabei Sachverständiger für Rassenforschung, 1933-1940) und Beamtentum (Einstellung von Nationalsozialisten, Berufsbeamtengesetz 1933-1943, Nachweis arischer Abstammung 1936-1937, Zusammenarbeit mit der Gauleitung Weser-Ems, 1933-1944, Parteigerichtsverfahren 1935-1945). Akten über abgetretene und eingegliedere Gebiete (u. a. Kolonien, Saarland, Protektorat Böhmen und Mähren), Auslandsdeutschtum und Umsiedlung, deutsche Propaganda im Ausland mit Berichten (1938-1939) deutscher Vertretungen befinden sich als Nachakten bei der Überlieferung des Ministeriums für auswärige Angelegenheiten (Best. 132, dor auch Vorgänge über Zusammenarbeit von Landräten und Kreisleitern).

\subsubsection{Braunschweigisches Staatsministerium}

WF, Best. $12 \mathrm{Neu}$

In der Gesamtüberlieferung, die vom Anfang des 19. Jahrhunderts bis zum Ende der Selbständigkeit 1946 reicht, sind während der NS-Herrschaft geführte Akten, die nur einen geringen Teil bilden, nicht gesondert ausgewiesen. Sie betreffen vor allem allgemeine Reichs- und Landesverwaltung (dabei Reichsreform, Gleichschaltung der Länder, einzelne Reichsbehörden), Auslandsbeziehungen (speziell deutsche Konsulate, 
Auslandsdeutschtum, Elsaß-Lothringen und andere eingegliederte Gebiete), Staatshoheitssachen (Flaggen und Wappen, Besuche Hitlers, Feier- und Gedenktage), Personalund Haushaltsangelegenheiten (dabei Kopie der Akten über Ernennung Hitlers zum Regierungsrat aus BDC), ferner Vertretung in Berlin (bis 1939), Gebietsaustausch mit Preußen (Holzminden, Goslar), Kriegsmaßnahmen (Luftschutz, Ehrung von Gefallenen), Sport, Gedenkstärte für Heinrich den Löwen im Braunschweiger Dom; ein Teilbestand dokumentiert die Verleihung von Kriegsverdienstkreuzen (86 Bde, 1940-1945).

Von der Nachrichtenstelle des Staatsministeriums sind Unterlagen über Ausstellungen (u. a. „Gau am Werk“), Tagungen und Kongresse (u. a. Volkskundetag 1938), Presseangelegenheiten, Besuche und Besichtigungen, Rundfunk, Heimatpflege, Werbung für VW-Werk, Reichswerke Hermann-Göring, SS-Musikschule, Germanische SS, Betreuung von Wehrmachtangehörigen, Feiern und andere Veranstaltungen überliefert (insges. 80 Bde). Aus der Zuständigkeit des Ministerpräsidenten für kirchliche Angelegenheiten stammen wenige Generalakten (u. a. betr. Reichskonkordat, Evangelische Kirche).

Ergänzungsüberlieferung enthalten die Akten des Generalstaatsanwalts Braunschweig aus dem Strafverfahren gegen Ministerpräsident Dietrich Klagges wegen Verbrechen gegen die Menschlichkeit (Best. 61 Nds, 120 Bde, 1929-1971).

Lit.: P. AUSMEIER: Klagges. Verbrecher im Hintergrund. (1951).

\subsubsection{Lippische Landesregierung DT, Best. L 80}

AusschlieBlich aus der Zeit der NS-Herrschaft stammen die Akten (57 Bde, Best. L 80 L) aus dem Büro des Staatsministers (Hans Joachim Riecke, ab 1936 Reichsstatthalter Alfred Meyer, Vertreter der Kreisleiter Adolf Wedderwille). Sie betreffen vor allem Personalangelegenheiten (u. a. Bewerbungen, Entlassungen, Einstellung von Parteigenossen, politische Beurteilungen), Presseangelegenheiten, ArbeitsbeschaffungsmaBnahmen und RAD, Siedlungswesen, Verhältnis zu den Kirchen, Handel mit Juden, Banken und Sparkassen, Luftfahrt und Luftschutz.

Aus der Zentralregistratur und den Registraturen der Abteilungen, die durchlaufend vom 19. Jahrhundert bzw. 1924 (Nachakten zu älteren Serien betr. Fürstenhaus bis 1938 in Best. L 75, betr. Fortbildungsschulen und Armenwesen bis 1934/35 in Best. L 79 III, Statistik bis 1948 in L 79 IV, Vorakten der nordmein-westfälischen Regierung Detmold in Best. D 1, vgl. zu Abschnitt 2.1.2.3.1 Minden) bis in die Nachkriegszeit geführ wurden, ist für folgende Sachgebiete Schriftgut aus den Jahren 1933-1945 (ca. 5600 Bde) überliefert:

Innere Verwaltung (Best. L 80 Ia): Staatsangehörigkeit (dabei Anwendung der Nürnberger Gesetze, Aus- und Einbürgerungen); Wahlen und Volksabstimmungen; Volksaufklärung und Propaganda; NSDAP und Organisationen; zivile Reichsverteidigung; Gemeindeverwaltung, -beamte und -finanzen; Strafrecht und -vollzug (dabei Beschwerden gegen Staatsanwaltschaft 1933-1936, Gnadengesuche), Anerbenrecht (1933-1939), Zulassung zur Rechtsanwaltschaft (bis 1935); Vereinswesen (Einzelfälle); Sozialversicherungs- und Versorgungsverwaltung (u. a. Tätigkeit der Hauptfürsorgeund Versorgungsstelle Detmold, RAD-Versorgungsrecht); Sammlungen und Kollekten; Stiftungen; Kirchenaustritte; Denkmalpflege; Naturschutz; Fremdenverkehr, Medizinalverwaltung (u. a. Berichte der Gesundheitsämter 1935-1945 und der Medizinaluntersuchungsstelle Bad Oeynhausen 1936-1944, Erb- und Rassenpflege mit Kursen für Ärzte und Gesundheitspflegerinnen, Aufsicht und erbbiologische Bestandsaufnahme bei Heil- 
und Pflegeanstalten, Durchführung des Erbgesundheits- und des Ehegesundheitsgesetzes mit Monats- und Jahresberichten); Fürsorgewesen (u. a. Winterhilfswerk, Fürsorge für Angehörige von Schutzhäftlingen, Juden, arbeitsunfähige Fremdarbeiter, Müttererholung. Unterstützung von Kinderreichen, Reichsjugendwohlfahrtsgesetz, HJ-Heime, -Dienststrafrecht, -Dienstpflicht, NSV-Gemeindepflegestationen 1936-1938, Arbeitslosenhilfe 1939-1945); Mitwirkung (Best L 80 Id) bei Arbeitsbeschaffungsmaßnahmen (u. a. Reinhardt-Programm, Landeskulturarbeiten, insbes. durch Freiwilligen Arbeitsdienst 1932-1934, mit Berichten des Landesarbeitsamtes Westfalen-Lippe über den Arbeitsmarkt bis 1939), Einsatz von Kriegsgefangenen (1939), bei Verlegung von Rüstungsbetrieben (ab 1943), im landwirtschaftlichen Siedlungswesen, Wohnungs- und Eigenheim-, Reichsautobahnbau (ab 1937).

Personalangelegenbeiten (Best. L 80 Pers): Berufsbeamtengesetz; Mitgliedschaft in der NSDAP, politische Beurteilungen (ab 1936); Fortbildung; Besoldung; Verleihung von Treudienst-Ehrenzeichen (ab 1938).

Polizei (Best. L 80 Ie): Personalwesen (dabei Hilfspolizei 1933-1943), Runderlasse der Staatspolizeistelle Bielefeld (1941-1943), Volkskartei (1939-1943), Ausländerpolizei (6 Bde, 1914-1947), Verbot von Druckschriften (6 Bde, 1933-1939), Einziehung staatsfeindlichen Vermögens (u. a. der „Naturfreunde“), MaBnahmen gegen konfessionelle Jugendgruppen (1937), Wehrwirtschaftsmaßnahmen; eigener Teilbestand (L 80 le P) für Akten des Führers der Landespolizei Lippe betr. Dienststellenverwaltung ( 8 Bde, 1933-1939), Organisation der Polizei (3 Bde, 1933-1938), Verfolgung einzelner Delikte (3 Bde, 1933-1935), auch Einsatzbefehle (1933-1935) und Morgenmeldungen (19331938).

Wirtschaft (Best. L 80 IIa): Reichsnährstand, Umschuldung und Absatzförderung in der Landwirtschaft, Kleinsiedlungen; Bergbau (Schwefelkies- und Erdölgewinnung); Industrie und Handel (mit Berichten der Industrie- und Handelskammer und der Gewerbeaufsichtsbeamten): Einsatz von Fremdarbeitern (ab 1943); Maßnahmen zum Schutz des Kleinhandels (18 Bde, ab 1934); Arbeitszeitregelung; Heimarbeit (1933-1939); Wandergewerbe (3 Bde, 1928-1941); Handwerk (Lehrlingsausbildung, Handwerkerrollen); Vergabe öffentlicher Aufträge; Aufsicht über Sparkassen (38 Bde, 1931-1948); Auswanderung (1925-1937); Wohnungsbauförderung (10 Bde, 1934-1940); Energiewirtschaft, Elektrizitätswerk Wesertal; eigener Teilbestand (L $80 \mathrm{IIa}$ Prü) für Akten der Preisüberwachungsstelle (34 Bde, 1931-1948, u. a. Monatsberichte 1938-1944, Maßnahmen gegen Schleich- und Tauschhandel 1940-1947).

Finanzen (Best. L $80 \mathrm{Ilb}$ ): Anwendung des Reichsleistungsgesetzes (ab 1939); Verteilung von Reichszuschüssen für Wohlfahrtszwecke und Gemeinden (bis 1936); Bewertung landwirtschaftlichen Vermögens; Staatszuschüsse an die Landeskirche; Finanzberichte und Jahresrechnungen (bis 1941); Erhebung von Verwaltungsgebühren (bis 1938). Forstsachen (Best. L $80 \mathrm{IIc}$ ): Personalangelegenheiten, Holzverkauf, Kulturen, Wegebau, Forstschutz; Jagd und Fischerei.

Domänensachen (Best. L 80 IId): Molkereiangelegenheiten; Flugwesen (140 Bde, 19331939); Angelegenheiten der Staatsbäder Bad Salzuflen und Bad Meinberg.

Schulwesen (Best. L $80 \mathrm{III}$ ): Organisation und Verwaltung; Lehrerbildung; Höheres Schulwesen (Jahresberichte der Schulen 1925-1947, nationalpolitische Lehrgänge 19351936, Ausbildungsbeihilfen ab 1938, Erbgesundheitspflege 1933-1936, Berufsbeamtengesetz und politische Beurteilungen, Religions- und Geschichtsunterricht, Einsatz von Luftwaffenhelfern; Berufs- und Fortbildungs-, insbes. landwirtschaftliches Schulwesen, Technikum in Lage, private Handelsschulen. 
Bauwesen (Best. L 80 IV): Luftschutz, Luftfahr (16 Bde, 1934-1948); Organisation der Bauverwaltung (bis 1941); Staatliche Gebäude.

\subsubsection{Schaumburg-lippische Landesregierung, Bückeburg}

SHG, Best. L 4

Bis auf die im April 1945 größtenteils vernichteten Akten über Reichsverteidigungsangelegenheiten und ca. 50 Bände „politischen Inhalts“, die an die britische Militärregierung abgeliefert wurden und verschollen sind, ist die Registratur der Regierung, die der Kreisleiter Karl Heinrich Dreier als Landespräsident leitete, erhalten geblieben. Der Bestand enthält in Serien, die in der Regel von 1909 bis 1949 durchlaufen, Schriftgut aus der NS-Zeit mit relativ hohem Anteil von Schriftwechsel mit obersten Reichsbehörden aus folgenden Sachgebieten:

- Reichsangelegenheiten (47 Bde, 1933-1945); Reichsstatthalter (mit Weisungen an ihn, 1933) und Reichsbehörden; Politische Berichte (3 Bde, 1937-1939); Wahlen und Abstimmungen (5 Bde); Auswanderung, auch von Juden ( 5 Bde); Titel und Ehrungen (6 Bde).

- Landesverwaltung: Allgemeine Staatsverwaltung (3 Bde); Landesregierung und -behörden (67 Bde); Beamten- und Tarifrecht, Personalangelegenheiten (83 Bde); Landesgesetze (1933-1942).

- Reichs- und Staatsangehörigkeit (40 Bde, dabei Widerruf von Einbürgerungen 1934, Reichsbürgergesetz und MaBnahmen gegen Juden 1935-1942).

- Finanzen, Kassen- und Rechnungswesen (93 Bde).

- Landesvermessung und Grenzsachen (35 Bde).

- Kirchen- und Religionsangelegenheiten (20 Bde, dabei Rundschreiben des Reichsministers für die kirchlichen Angelegenheiten 1937. Synagogengemeinden 1934-1940).

- Kreis- und Gemeindeverwaltung (142 Bde).

- Hoch- und Straßenbau (103 Bde, dabei Arbeitsbeschaffungsmaßnahmen 1933).

- Wasserwirtschaft (32 Bde).

- Land- und Forstwirtschaft (117 Bde): Feier des Erntedankfestes (1933-1942); Reichsnährstand (6 Bde, dabei Stimmungsberichte der Landesbauernschaft 1938); Bewirtschaftungsmaßnahmen und Verstöße dagegen: Reichsbeihilfen für die Landwirtschaft.

- Enteignungen, u. a. für militärische Zwecke und den Bau der Reichsautobahn (16 Bde).

- Post und Verkehr (54 Bde, u. a. Überwachung des Luftraums 1936-1939, Segelflugsport)

- Geld-, Kredit- und Sparkassenwesen (71 Bde).

- Rechtspflege (86 Bde, dabei Justizreform 1934, Kriminalstatistik, Errichtung der

Erbgesundheits- und Sondergerichte 1933-1934) und Strafvollzug (22 Bde).

- Personenstandsangelegenheiten (31 Bde).

- Gesundheitspflege (205 Bde, dabei 9 Bde Durchführung des Erbgesundheitsgesetzes) und Veterinärwesen ( 80 Bde).

- Schulwesen: Allgemeines (85 Bde, dabei Rassentrennung 1935-1942, wehrgeistige Erziehung 1940-1944), Angelegenheiten der höheren (116 Bde, dabei Anwendung des Gesetzes gegen die Überfüllung der Hochschulen), Volks- (96 Bde), Privat- (25 Bde) und Berufsschulen (38 Bde).

- Statistik (ca. 300 Bde, dabei Unterlagen über Konferenzen der statistischen Landesämter). 
- Militärwesen (106 Bde): Wehrersatzwesen: Stationierung des Inf. Reg. 18 in Bückeburg: Versorgungsangelegenheiten (Akten der Landesfürsorgestelle für Kriegsbeschädigte und Hinterbliebene, 1920-1946).

- Wirtschaft. Industrie und Handel (134 Bde).

- Handwerk und Gewerbe (155 Bde).

- Versicherungswesen: Sozial- (62 Bde) und Privatversicherung (24 Bde).

- Polizei: Allgemeines (33 Bde, dabei politische Berichte an den Reichsinnenminister 1934. Erlasse des Reichsfiuhrers SS und Chefs der Deutschen Polizei 1937-1945, Einsetzung des Höheren SS- und Polizeifïhrers 1938); Angelegenheiten der Landespolizei (94 Bde), der Gendarmerie (20 Bde), Schutzpolizei (34 Bde), Sicherheitspolizei (38 Bde. dabei 14 Bde betr. Organisation von Gestapo und Kriminalpolizei, 6 Bde betr. Einziehung volks- und staatsfeindlichen Vermögens, ferner Maßnahmen gegen Kirchen 1935-1937, Schutzhaft 1933-1934), Verkehrs- (115 Bde), Sitten- (11 Bde), Fremden(50 Bde), Bau- (25 Bde) und Gesundheitspolizei (12 Bde).

- Kunst, Wissenschaft, Literatur und Presse (75 Bde).

- Wohlfahrtswesen (143 Bde, dabei 3 Bde betr. Auflösung der Arbeitersport- und gesangvereine 1933-1938, 9 Bde betr. HJ, ferner NSV, Winterhilfswerk und Hilfswerk „Mutter und Kind“. Bevölkerungs- und Rassenpolitik 1933-1937, Ausführung des Blutschutzgesetzes 1935-1938, Jugendschutzlager 1940-1944).

- Wohnungs- und Siedlungswesen (82 Bde).

- Erwerbslosenfürsorge (30 Bde) und (Freiwilliger und Reichs-) Arbeitsdienst (20 Bde, 1931-1944).

- Staatsbesitz (ca. 400 Bde): Domänen, Forste, Gewässer, Bergwerke.

Reste von Geheimakten (138 Bde) und Einzelvorgänge (66 Bde) betreffen vor allem Uk-Stellungen (16 Bde, 1936-1945), Bewirtschaftung von Lebensmitteln und Verbrauchsgütern (je ca. 30 Bde), Arbeitseinsatz (dabei Anordnungen des Generalbevollmächtigten für den Arbeitseinsatz, 1941-1944), auch von Kriegsgefangenen (19411944) und Fremdarbeitern (3 Bde, 1940-1944), Luftangriffe (9 Bde), Luftwaffenhelfer und Volkssturm, Maßnahmen gegen Juden (1935-1943) und Kommunisten (1933-1944), kirchliche Angelegenheiten (1933-1942), Spionageabwehr (8 Bde), nationale Verbände (1933-1936), Rassegesetzgebung und Erbgesundheit (1935-1943). Beschwerden über Beamte (3 Bde, 1933-1935), Einstellung von Parteigenossen in den öffentlichen Dienst (1933-1938), Ehrung von Künstlern und Wissenschaftlern (1939-1942).

\subsubsection{Staatsverwaltung Hamburg}

$\mathrm{HH}$

Die Überlieferung der obersten staatlichen Behörden der Hansestadt aus der NS-Zeit ist dadurch schwer zu ermitteln, daß erst 1938 eine Trennung zwischen der Staatsverwaltung unter dem Präsidenten und Staatssekretär Georg Ahrens als Vertreter des Reichsstathalters und der Kommunalverwaltung unter dem Bürgermeister Karl Vincent Krogmann erfolgte, staatliche Aufgaben aber auch auftragsweise von der Stadt wahrgenommen wurden und die Akten in den Registraturen überwiegend vor 1933 angelegt und nach 1945 fortgeführt wurden, so daB für die Bestandsbezeichnungen in der Regel nicht die bei Kriegsende geltenden Namen der Provenienzstellen verwendet werden. Schriftgut aus den damals bestehenden Abteilungen I für allgemeine Angelegenheiten (mit Personalangelegenheiten, Haushalt, Rechts- und Religionsangelegenheiten, Gesundheits- und Vermessungswesen, Reichsverteidigung), 2 (Konsularabteilung), 3 für die Polizei (unter dem Höheren SS- und Polizeiführer, vgl. Abschnitt 2.2.4.1), 4 für Schulen und Hochschulen, 5 für Wirtschaft, Landwirtschaft und Soziales. 6 für Verkehr und Bauwesen 
ist in nachstehenden Beständen zu erwarten, während die Überlieferung der Abteilung 8 (Landeswirtschaftsamt) im Abschnitt 6.4.1, des Landesjugendamtes (aus Abteilung 1) im Abschnitt 2.1.2.2.3 berücksichtigt ist und die staatliche Finanzverwaltung beim Landesfinanzamt (Abschnitt 5.4) lag; von den Abteilungen 7 (Wasserstraßendirektion) und 9 (Hauptvermessungsabteilung VI) scheint es keine Akten zu geben.

Akten von Bürgermeister Krogmann über Wirtschaftsangelegenheiten (1934-1936, u. a. Arbeitsbeschaffung, Industrieförderung, Wohnungsbau), befinden sich mit anderen Unterlagen von ihm (u. a. Tagebücher 1933-1944) in seinem Nachlaß (HH, Familienarchiv Krogmann I), Denkschriften und Korrespondenz zur Wirtschaftspolitik in der Forschungsstelle für die Geschichte des Nationalsozialismus in Hamburg. Für Akten von Senator Ahrens als Staatskommissar für die Deutsche Schauspielhaus AG und Neue Schauspielhaus GmbH (1933-1942) wurde der Bestand 363-7, von Staatsrat Krönig über Luftverkehr (1929-1934) der Bestand 371-11 gebildet.

\section{Innere Verwaltung}

$\mathrm{HH}$, Best. 113.2

Aus dem Büro des Senators Alfred Richter sind aus der Zeit von 1933 bis 1939 neben Unterlagen über seine persönlichen Angelegenheiten (mit Schriftwechsel und Reden) und seine Funktionen in der NSDAP, Beiräten (u. a. für Luftschutz, Energieversorgung) und bei der Landesdienststelle Hamburg des Deutschen Gemeindetages Korrespondenz mit dem Reichsstatthalter, politische Lageberichte und Akten aus folgenden Sachgebieten vorhanden: Verfassung und Verwaltung (1933-1938, dabei GroB-Hamburg-Gesetz); Personalangelegenheiten; Polizei; Gesundheits- und Fürsorgewesen (dabei Sippenforschung, Erb- und Ehegesundheitsgesetz, HJ); Sport (1934-1939); Verwaltung des Landgebiets; Kultur (1935-1938); Wohnungs- und Siedlungswesen (1935-1938); Wirtschaft (u. a. Vierjahresplan, AusschluB der Juden).

\section{Staatsverwaltung, Allgemeine Abteilung}

HH, Best. 113-5

Die aus drei Referaten überlieferten Akten betreffen Verwaltungsorganisation (19371945), Dienststellenverwaltung (1938-1945), Verleihung von Auszeichnungen (19381945), Fremdenverkehr (1936-1944), Personalangelegenheiten (1935-1945, dabei auch Aus- und Fortbildung, Tarifrecht), allgemeine Rechtsangelegenheiten und Prozesse (1937-1945), Aufsicht über Vereine, Stiftungen und Versicherungen (1933-1945) sowie Standesämter (1934-1946), Wasserrecht (1928-1943), Kirchen und Religionsgemeinschaften (1934-1949), Reichsverteidigung.

\section{Senatskommission für die Reichs- und auswärtigen Angelegenheiten}

HH, Best. 132-1 II Im Bestand sind Vorgänge bis 1936/37, teilweise bis 1945 aus folgenden Sachgebieten überliefert: Gleichschaltung der Länder (1933); Auslands- und ausländische Vertretungen; Gesandtschaft in Berlin; Handels-, Schiffahrts- und Konsularverträge (bis 1945); Staatsbesuche und Kongresse; Reichsfinanzen (bis 1934); Luftfahrt; Angelegenheiten der inneren Verwaltung; Presse (bis 1934).

\section{Senatskanzlei, Verwaltungsabteilung}

HH, Best. 131-3

Folgende Aktengruppen enthalten Vorgänge aus der NS-Zeit:

Organisation und Rationalisierung der Verwaltung; Dienststellenverwaltung; öffentliches Dienstrecht; Berufung und Personalangelegenheiten der Senatoren (bis 1938); Durchführung der Sitzungen des Senats (Protokolle mit Anlagen 1933-1945 im Best. 
131-2); Zuwendungen und Auszeichnungen (bis 1939), Angelegenheiten des Reichsstatthalters und des Bürgermeisters (bis 1938); Pressesachen (bis 1937); Verkehr mit dem Deutschen Gemeindetag.

Senatskanzlei, Präsidialabteilung

HH, Best. 1314 Zum Bestand gehören Akten über Bildung und Stellung des Senats (bis 1943), Geschäftsordnung (bis 1937), persönliche Angelegenheiten von Senatoren (bis 1943), Reichsverfassung (bis 1936), Hoheitszeichen, Grenzangelegenheiten (bis 1943), Militärwesen, Feiertage und staatliche Veranstaltungen (auch Kongresse, Sportveranstaltungen), Ehrenbürgerrecht und andere Ehrungen und Auszeichnungen, Glückwünsche und Beileidskundgebungen, Denkmäler und über Angelegenheiten ständiger Senatskommissionen und der Fachverwaltungen, u. a. Organisation, Personalwesen, Aus- und Einbürgenungen, Polizei, Handel und Gewerbe (dabei Arisierung), Gesundheit und Soziales, Schul- und Hochschulwesen (bis 1942 bzw. 1937), Finanzen und Zölle, Schifffahrt, Strom- und Hafenbau (bis 1936), Arbeitgeber- und Arbeitnehmerorganisationen (bis 1937, Geld- und Kreditinstitute (bis 1936), Wirtschaftsförderung (bis 1938), Verkehr (bis 1942), Luftschutz (bis 1942), Wohnungsfürsorge (bis 1942), Sammlungen und Spenden (bis 1941), Kultur (Theater, Musik, Film, Museen, bis 1939), Kirchen (bis 1937).

Staatsamt

$\mathrm{HH}$, Best. 131-6

Die Akten des Amtes, das nur von 1933 bis 1938 bestand, enthaiten Vorgänge über die innere Verwaltung (mit Polizei und Gesundheitswesen), Finanzverwaltung (Haushalt, Steuern, Vermögen und Schulden), Wirtschaft, Technik und Arbeit (mit Berichten, auch Akten über Außenhandel, Preisbildung, Wohnungsbau, Baupolizei, Arbeitsdienst, Wasserstraßen, Schiffahrt und Häfen), Schul- und Bildungswesen (mit Kunst und Kultur), Justiz (bis 1935), Landwirschaft und Fischerei.

Senatskanzlei - Personalabteilung

HH, Best. 131-10 I und II Akten aus der NS-Zeit betreffen vor allem Beamtenrecht, Besoldungs- und Tarifrecht, Verwaltungsorganisation, Verhältnis zwischen Verwaltung und Bevölkenng und zur NSDAP, spezielle Angelegenheiten der Angestellten im Gesundheitswesen (bis 1936), in Körperschaften, öffentlichen Betrieben und des wissenschaftlichen Hilfspersonals (bis 1934), Vorbereitung und Auswirkung des GroB-Hamburg-Gesetzes und des Gesetzes über die Verfassung und Verwaltung (1935-1945).

Polizeibehörde

HH, Best. 331-1 I

Der Bestand enthält aus der Abteilung 3 der Staatsverwaltung Akten über die Organisation aller Polizeisparten, auch der Wasserschutz- und Schiffahrtspolizei, Personalangelegenheiten einschl. Ausbildung, Ausrüstung und Bewaffnung, Luftschutz und Luftangriffe, Aufstellung von Polizeibataillonen und Abordnungen in besetzte Gebiete.

Sozialbehörde

HH, Best. 351-10 I

Zum Bestand (Vorakten der Arbeitsverwaltung bis 1934/35 auch im Best. 356-2) gehört Schriftgut aus folgenden Sachgebieten:

Staats- und Verwaltungsaufbau (dabei über den Gaureferenten für Sozialpolitik, 1939-1945). - Dienststellen- und Personalverwaltung (dabei Jahresberichte, auch von Oberfürsorgerinnen im AuBendienst, Beschwerden). - Bestattungswesen (dabei russische Kriegsgefangene und kriegsgerichtlich Verurteilte). - Statistik (auch Reichsstati- 
stik und Wohlfahrtsstatistik für Norddeutschland). - Aufsicht über staatliche und private Wohlfahrtsanstalten (u. a. Anwendung des Erbgesundheitsgesetzes). - Kriegsopferfürsorge. - Gesundheitsfürsorge (dabei Rassenhygiene, Erb- und Ehegesundheitsgesetz, Maßnahmen für Tuberkulose-, Geistes-, Geschlechtskranke, Alkoholiker und Rauschgiftabhängige). - Stiftungen und Organisationen der freien Wohlfahrtspflege (u. a. NS-Rechtsbetreuungsstellen, NSV, Winterhilfs- und andere Hilfswerke, Deutscher Verein für öffentliche und private Fürsorge). - Fürsorge für Bettler, Prostituierte, Erbkranke, Opfer von Luftangriffen. - Arbeitsverwaltung (Organisation, Vermittlungswesen, Sozialversicherung, Arbeitsbeschaffungsmaßnahmen, dabei Bau der Reichsautobahn, Einsatz des Freiwilligen und Reichsarbeitsdienstes).

Oberschulbehörde

HH, Best. 361-2

Die Überlieferung der 1870 eingerichteten Registratur enthält (Best. Oberschulbehörde I) Behörden- und Konferenzprotokolle und Lehrermatrikeln bis 1937 bzw. 1939 sowie Einzelfallakten über Schulverwaltungsbauten, in weiteren Teilbeständen (Oberschulbehörde VI) ab 1932 (einzelne Bände bis 1935 auch in Best. Oberschulbehörde V) und über 1945 hinaus Akten betr. Verwaltungsangelegenheiten, allgemeine Schulangelegenheiten (dabei Gesetzgebung, Schulgliederung, Unterricht, Prüfungswesen, Schülerfürsorge, Lehrerbildung, Volksbildung, Privatunterricht, Berufsschulangelegenheiten). Über das höhere Schulwesen (Oberschulbehörde II) sind zum Teil bis 1945 fortgefuhrte Akten überliefert, die Lehrer, Unterricht, Lehrmittel und Bausachen einzelner Gymnasien betreffen. Die über Beaufsichtigung des Volksschulwesens (Oberschulbehörde III) und der Schulen im Landgebiet (Oberschulbehörde IV) entstandenen Akten reichen in Einzelfällen bis 1934 bzw. 1936.

Hochschulverwaltung

HH, Best. 361-5 (Hochschulwesen II) Die Akten des Bestandes betreffen vor allem die Universität und deren Institute und Kliniken, ihre Organisation, Finanzierung, Bauten, Besetzung der Professoren- und anderer Stellen, Zulassung zum Studium und Prüfungen, Lehraufträge (dabei Wehrtechnik), Auslandsbeziehungen, Angelegenheiten der Studentenschaft (auch NS-Studentenbund, andere Vereinigungen, Sport), einzelne Forschungsvorhaben, Studienreisen, Veröffentlichungen und Veranstaltungen; außerdem sind Unterlagen über Volkshochschule, andere Volksbildungseinrichtungen und die Förderung wissenschaftlicher Vereine vorhanden.

Staatsverwaltung - Schul- und Hochschulabteilung

HH, Best. $361-7$

Überliefert sind - überwiegend ab 1938 - Akten aus der Zuständigkeit für die Schulaufsicht im allgemeinen (dabei Kriegseinsatz von Schülern und Lehrern), Lehrerbildung (dabei Pädagogisches Institut, 1943-1945), für die höheren, Volks-, Mittel- und Sonderschulen (auch Hauptschulen, 1940-1944, und Lehrerbildungsanstalten, 1939-1948) sowie Berufs- und Fachschulen (dabei Berufspädagogisches Institut, 1941-1946, und Reichsseefahrtsschulen, 1932-1946) und den Unterricht an ihnen, außerdem Anweisungen in Hochschulangelegenheiten.

Lit: H. P. IPSEN: Hamburgs Verfassung und Verwaltung. 1956. - C. V. KROGMANN: Es ging um Deutschlands Zukunft 1932- 1939. 1976. - A. EBBINGHAUS: Fürsorgerinnen in Hamburg 1933-1939. 1987.

\subsubsection{Bremer Senatskanzlei}

HB, Best. 3

Im Bestand ist Schriftgut des Senats und von Fachverwaltungen ohne eigene Registraturen von 1875 bis in die Zeit nach 1945 vereinigt. In folgenden Aktengruppen ist 
die NS-Herrschaft, die durch die Regierenden Bürgermeister Richard Marken (19331934), Otto Heider (1934-1937), Heinrich Böhmcker (1937-1944) und Richard Duckwitz (1944-1945) ausgeübt wurde, mit Vorgängen dokumentiert:

- Senat und Inneres: Zusammensetzung des Senats; Verwaltungsorganisation und -reform; öffentliches Dienst- und Tarifrecht, Personalangelegenheiten; Hoheitszeichen; Feiern; Auszeichnungen und Ehnungen; Unterrichtung der Öffentlichkeit (ab 1936); Förderung der Wissenschaft; Statistik; Personenstandswesen; Auswanderung; Verwaltungspolizei, Luftschutz; Verwaltung der Landgemeinden; Deich- u. a. Zweckverbände; Parteien (SPD, KPD, NSDAP), Vereine und Gewerkschaften; Maßnahmen gegen Juden. - Auswärtige Angelegenheiten, Militärwesen: Konsularische Beziehungen; Staatsverträge; Staatsbesuche; Verhältnis zum Reich und den Reichsbehörden sowie anderen deutschen Ländern (u. a. Neuaufbau des Reiches, 1933-1945, Angelegenheiten des Gauleiters und Reichsstatthalters, 1933-1944, der Reichskulturkammer, 1933-1942, Erbund Rassenkunde).

- Verfassung, Recht und Justiz: Staatsverfassung und Gesetzgebung; Gerichte und Staatsanwaltschaften; Strafverfahren und -vollzug; Gnadenwesen; Ausweisungen; Rechtsanwälte und Notare.

- Wirtschaft, Handel und Arbeit: Industrie- und Handelskammer, Ausstellungen, Messen und Märkte; Gewerbesachen; Maße und Normen; Land- und Forstwirtschaft; Arbeitsvermittlung, Arbeitslosenversicherung und -fürsorge; Angelegenheiten freier Berufe im Handel (u. a. Makler, Wirtschaftsprüfer).

- Häfen, Schiffahrt und Verkehr: Hafenabgaben; See- und Binnenschiffahrt; Schiffsunfälle; Seezeichen; Lotsenwesen; Eisen- und Straßenbahnen; Luftfahrt; Post und Fernmeldewesen.

- Finanzen: Reichs- und Staatsfinanzen; Banken und Sparkassen; Zölle; Münzwesen: Lotterien.

- Bauwesen: Straßenbau und Stadtplanung; Brücken; öffentliche Gebäude; Gartenbau: Energieversorgung; Wohnungsbau und Siedlungswesen; Vermessungswesen.

- Kultur, Bildung und Kirche: Pressesachen; Verlagsrecht: Bibliotheken und Museen: Bau- und Naturdenkmäler; Theater und Konzerte; Schul- und Fachschulangelegenheiten: Beziehungen zu den Kirchen.

- Soziales, Jugend, Sport und Gesundheitswesen: Wohlfahrtsleistungen; Jugendpflege; Kindergärten und -heime; Badeanstalten: Medizinalverwaltung; Apothekensachen; Bekämpfung der Trunksucht; Tierschutz.

Eine ergänzende Überlieferung besteht in wenigen erhaltenen Akten des Bestandes

Bremisches Staatsamt

HB, Best. 4,113

Sie enthalten ein Tagebuch der Stadt Bremen (1937 Dez. - 1943 Juni), Tätigkeitsberichte von Behörden und kulturellen Einrichtungen (39 Bde, 1933-1944), Sitzungsprotokolle Markerts als Reichskommissar für Bremen (1933) und Akten über die Gebietsreform (2 Bde, 1936-1941), den Kirchenkampf (1933-1942), Personalangelegenheiten (mit Einzelfällen) und über einzelne Firmen (6 Bde, 1936-1942).

\subsubsection{Lübeckische Senatskanzlei}

HI, Neues Senatsarchiv

Der Bestand enthält vor allem in folgenden Sachgnuppen Akten aus der Zeit von 1933 bis zum Ende der staatlichen Selbständigkeit Lübecks 1937 (z. T. mit Nachakten der vom vorherigen Senatspräsidenten Dr. Otto-Heinrich Drechsler weiterhin geleiteten Stadtverwaltung): 
- Reichsverwaltung: Maßnahmen anläßlich der nationalsozialistischen Machtergreifung (dabei Akten des Reichskommissars für Lübeck Dr. Friedrich Völızer, insbes. über Wirtschaft und Gewerkschaften, 1933), Reichsreform, Propaganda, auch Berichte des Vertreters Lübecks bei der Reichsregierung (1933-1935).

- Verkehr mit anderen Staaten (1933-1938): Westeuropa, Skandinavien, Danzig.

- Staatsverwaltung: Neuaufbau des Reiches (1936), Verwaltungsvereinfachung, Reichs- und Staatsangehörigkeitsrecht, Dienststellenverwaltung der Senatskanzlei, auch Handakten des Staatsrats Curt Helm (1933-1936).

- Innere Verwaltung: Organisation der Polizei; Feiertagsrecht; Einziehung staats- und volksfeindlichen Vermögens (bis 1938); Schutzhaft und Strafvollzug; Maßnahmen gegen Zigeuner, Aufsicht über Vereine (u. a. Gewerkschaften, Reichsbanner); Reichsautobahnbau; Erbgesundheit und Rassenhygiene; Kommunalaufsicht; Tagungen und Kongresse. - Justiz: Überleitung auf das Reich (bis 1935), Übersicht über politische Strafprozesse und Verfahren gegen Nationalsozialisten (1933-1934), Amnestien (1933-1934), Personalangelegenheiten (Ausbildung, Rechtsanwaltschaft).

- Kirchen, Schulen, Kunst und Wissenschaft (nur einzelne Bde): Auseinandersetzungen in der evangelischen Kirche (1933-1938, mit Berichten der Staatspolizeistelle Lübeck 1936-1937); Angelegenheiten der Hochschule für Lehrerbildung (1936), der Nordischen Gesellschaft (1933-1940) und der Presse (11 Bde, dabei Mitteilungen der Nachrichtenstelle bis 1939).

- Luftverkehr (14 Bde, 1933-1937).

Lit:: G. SCHNEIDER: Gefährdung und Verlust der Eigenstaatlichkeit der Freien und Hansestadt Lübeck und seine Folgen. 1986.

\subsection{Preußische Oberpräsidien und Provinzialverwaltungen}

Die Stellung der Oberpräsidenten als Kommissare der Staatsregierung für ihre Provinz, die bereits 1932 verstärkt worden war, blieb unter der nationalsozialistischen Herrschaft formal erhalten, und zusätzlich wurden sie 1934 auch zu ständigen Vertretern der Reichsregierung bestellt; sie übernahmen außerdem die Leitung der Provinzialselbstverwaltung, wenn auch das Amt des Landeshauptmanns bestehen blieb, und erhielten neue Zuständigkeiten bei der Preisbildung, in der Wasserwirtschaft und der Medizinalverwaltung. Trotz ihrer Eingliederung in die Oberpräsidien bewahrten die Provinzialschulkollegien (vgl. Abschnitt 4.4.1.3) und Landeskulturämter dagegen faktisch ihre Selbständigkeit.

Lit.: K. TEPPE: Die preuBischen Oberpräsidenten 1933-1945. 1985.

\subsubsection{Oberpräsidium von Schleswig-Holstein, Kiel SL, Abt. 301}

Ein erheblicher Teil der laufenden Registraturen wurde durch Luftangriffe vernichtet, so daß die Überlieferung vielfach um 1933/34 endet. Aus dem Büro des Oberpräsidenten und Gauleiters Hinrich Lohse, der während seiner Abordnung als Reichskommissar für das Ostland von Regierungspräsident Vöge vertreten wurde, sind Akten aus folgenden Sachgebieten vorhanden: 
Baupolizei, Wohnungsbau und Siedlungswesen (bis 1939). - Beamtenrecht, Personalangelegenheiten (bis 1939, Kreisverwaltung bis 1934). - Feuerversicherung (bis 1936). - Eisenbahnen (bis 1935). - Haushalt und Finanzen (bis 1936). - Landwirtschaftliches Kreditwesen (bis 1938). - Sparkassenwesen (bis 1938). - Kirchliche Angelegenheiten (bis 1937).

Die Akten der Fachabteilungen betreffen vor allem folgende Angelegenheiten:

Dienststellenverwaltung (bis 1936). - Wahlen und Volksabstimmungen (bis 1935). Wandergewerbe (bis 1937). - Preisbildung (Preisbildungsstelle, 1935-1936). - Dampfkesselüberwachung (bis 1935). - Arbeitsbeschaffung (bis 1936). - Handelskammern (bis 1937). - Schiffahrt (bis 1937). - Viehmärkte (bis 1939). - Konsulate (bis 1938). - Justiz (bis 1936). - Kunst und Wissenschaft (bis 1938). - Natur- und Denkmalschutz (bis 1937). - Deich- und Wasserbau, Meliorationen (bis 1936). - Förderung der Landwirtschaft (bis 1940), Tierzucht (bis 1936), landwirtschaftliches Schul- und Verbandswesen (bis 1937), Grundstücksverkehr (bis 1937), Erntehilfe (bis 1938), Handel mit landwirtschaftlichen Produkten, Kleingärten (bis 1938), Fischerei (bis 1939). - Lotterien (bis 1937). - Medizinalverwaltung (bis 1937, außerdem Akten des Leitenden Medizinalbeamten betr. Notdienst und Betreuung von Bombengeschädigten, 1942-1945), Rettungsdienst (bis 1935), Wasserversorgung, Bestattungswesen (bis 1935); Lebensmittelüberwachung (bis 1935), Irren- und Heilanstalten (bis 1934), Apotheken (bis 1934), Veterinärwesen (bis 1937). - Jugendpflege (bis 1938). - Wohlfahrtspflege (bis 1938). - Militärwesen (bis 1938). - Versicherungsämter (bis 1938). - Regienungsinstruktionen in allgemeinen Verwaltungs- und Beamtensachen (bis 1939). - Vorzensur (bis 1935). - Entschädigungen für Ausgewiesene (bis 1936). - Allgemeine politische Lage (mit Berichten, 1935-1936) und Parteien (bis 1936, NSDAP bis 1939). - Luftschutz und Luftangriffe (1939-1944, dabei Berichte des Polizeipräsidenten in Kiel ab 1941). Luftverkehr (bis 1935). - Reichsbeihilfen (bis 1938). - Verhältnisse in Nordschleswig, insbes. Vereine und Volksbildung (bis 1936). - Verkehrspolizei (bis 1937). - Post (bis 1936). - Theater (bis 1937). - Pressewesen, Verbote (bis 1937). - Statistiken (bis 1935). - Steuern und Zölle (bis 1939). - Fideikommisse, Stiftungen (bis 1938). - Rundfunk (bis 1934). - Aufsicht über Provinzialselbstverwaltung (bis 1937). - Schulwesen (bis 1935). - Sportförderung (bis 1936). - Staatsangehörigkeit, Einbürgerungen (bis 1937). - Straßenbau (bis 1938, insbes. Arbeitsbeschaffungsmaßnahmen (mit Akten des Provinzialrates bis 1937 ).

Lit.: K. JÜRGENSEN: Die Gleichschaltung der Provinzialverwaltung. 1983.

\subsubsection{Provinzialverwaltung Schleswig-Holstein}

SL, Abt. 371

Den Hauptteil der Überlieferung bilden Akten der StraBenbauverwaltung mit Jahresberichten (bis 1937), Erlassen des Generalinspektors für das deutsche Straßenwesen (1935-1944), Unterlagen über den Bau der Reichsautobahn (1934-1944) und von Radwegen (1927-1952), Arbeitsbeschaffungsmaßnahmen (1933-1936), Straßenplanung, -vermessung und -entwässerung (1933-1949). Außerdem sind einzelne Akten über Personalangelegenheiten (bis 1940), Haushalt (bis 1942), Abgaben (bis 1937) und Finanzstatistik (1933-1937), Versicherungsangelegenheiten (bis 1942 mit Jahresberichten der Provinziallebensversicherungsanstalt bis 1940), des Landeskonservators (bis 1940) und der Verbindungsstelle Berlin (1941-1942) vorhanden (zum Landessippenamt vgl. Abschnitt 2.1.2.2.1). 
Lit: K.-D. GRUNWALD: Die Provinzialverwaltung und ihre Organe in der preuBischen Provinz SchleswigHolstein. 1971.

\subsubsection{Oberpräsidium von Hannover}

H, Best. Hann. 122a

Akten aus der NS-Zeit, in der von 1933 bis zu seinem Tod 1941 der Stabschef der SA Viktor Lutze und dann der Gauleiter von Südhannover-Braunschweig Hartmann Lauterbacher an der Spitze der Behörde standen, sind vor allem in folgenden Sachgruppen (einzelne Nachakten auch aus Registraturen der Staatskanzlei und des Innenministeriums von Niedersachsen, Best. Nds. 50 und Nds. 100) enthalten:

- Hoheitssachen, Staatsverfassung: Wahlen und Volksabstimmungen (1933-1938); Neuaufbau des Reiches; Grenzangelegenheiten und -veränderungen, insbes. in Verbindung mit Erzbergbau im Raum Salzgitter (1933-1942); Orts- und StraBennamen (19331944); Verleihung von Orden (u. a. Ehrenzeichen für deutsche Volkspflege, Kriegsverdienstkreuz und -medaille) und von Titeln; Ehrenpatenschaften und -geschenke; Begnadigung für Vergehen und Verbrechen; Staatsangehörigkeit, Auswanderung, Einbürgerung und Entlassung; Hoheitszeichen (Flaggen und Wappen).

- Auswärtige Angelegenheiten: Konsularische Vertretungen (1933-1944); Legalisation von Urkunden.

- Haushalts-, Kassen- und Rechnungswesen: Rechnungswesen der Kultus-, Wirtschafts-, Landwirtschafts- und inneren Verwaltung (1933-1943) mit Vorschriften der Außenabteilung Hamburg des Rechnungshofes des Deutschen Reiches.

- Steuern: Einkommen-, Kraftfahrzeug- und andere direkte Steuern, Finanzstatistik (1933-1944).

- Staatsbehörden: Allgemeines (meist bis 1944, darunter Dienstvorschriften, Berichte über besondere Ereignisse, Akten betr. Tarifrecht, Kompetenzkonflikte, Gebühren, Enteignungen, Presseveröffentlichungen); allgemeine Landesverwaltung (Verwaltungsorganisation und -vereinfachung bis 1945, Pläne zur Neugliederung des Reiches bis 1934, NSDAP und Organisationen 1934-1945, dabei Errichtung von NS-Gemeinschaftshäusern 1941); Personalangelegenheiten der höheren Beamten und Angestellten (Sammelakten, Personalbögen); Personalangelegenheiten, Haushalt und Organisation des Oberpräsidiums, überwiegend bis 1938, dabei Nachweisungen über Mitgliedschaft in der NSDAP, Dispositionsfonds des Oberpräsidenten; Angelegenheiten des Provinzialrats; Organisation, Personalangelegenheiten und Dienststellenverwaltung der Regierungen (bis 1942), Bezirksverwaltungsgerichte (bis 1943), Landratsämter (bis 1945, mit Unterlagen über Konferenzen der Landräte), Polizeibehörden (bis 1945, auch Geheime Staatspolizei bis 1941), Finanz- und Steuerverwaltung, Strafanstalten und Polizeigefängnisse (bis 1944, mit Runderlassen), Staats- und Kommunalarchive (bis 1945, mit Jahresberichten), der Provinzialbibliothek, des Provinzialschulkollegiums (bis 1936), der Medizinal(bis 1942), Veterinär- (bis 1945, dabei Verfahren vor dem Tierärztlichen Bezirksgericht Hannover 1941-1943), Bau- (bis 1943), Landeskultur- (bis 1938), Vermessungs(bis 1945), Domänen- und Forstverwaltung (bis 1945) sowie der Seeämter Emden (bis 1936) und Hamburg (bis 1943), der WasserstraBenverwaltung (bis 1945), der Klosterkammer Hannover (bis 1945), der Eichämter (bis 1945) und Reichsbahndirektionen (bis 1936).

- Beamte: Beamtenrecht (bis 1945, dabei Berufsbeamtengesetz, politisches Verhalten, Ausschluß aus der NSDAP 1935-1937, Disziplinaruntersuchungen bis 1942); Besoldung und Versorgung (bis 1944); Ausbildung und Prüfung; Abordnungen in besetzte Gebiete (1939-1945). 
- Kommunalverwaltung: Allgemeines (überwiegend bis 1945), u. a. Gemeindeverfassung, Gemeindefinanzen, -steuern und -abgaben, Grenzänderungen, Personalangelegenheiten vor allem der leitenden Beamten und Ratsherren, Bildung von Zweckverbänden, Kontrolle der Emährungs- und Wirtschaftsämter 1940-1945; Aufsicht über die Provinzialverwaltung (bis 1945), die Landeskreditanstalt (mit Monatsberichten 1933-1945), Heil- und Pflegeanstalten (bis 1944), die Ostfriesische Landschafi und andere Provinziallandschaften, deren Kredit- und Versicherungsinstitute (bis 1945) und über die Kreiskommunalverwaltungen (bis 1944) und Stadtgemeinden (bis 1945, vor allem .,Stadt des KdF-Wagens“ Wolfsburg und "Stadt der Hermann-Göring-Werke“ Salzgitter).

- Polizei: Organisation (bis 1945) und Personalangelegenheiten (in Nds. 50 und 100): Einziehung staatsfeindlichen Vermögens (1942-1945); Maßnahmen gegen Zigeuner und Asoziale (bis 1939); Sittenpolizei (bis 1945); Glücksspiele und Sammlungen (bis 1945); Verkehrspolizei (bis 1945); Tierschutz (bis 1940); Aufsicht über Presse und Bibliotheken (mit Berichten der Staatlichen Beratungsstelle für das Volksbüchereiwesen Hannover, 1934-1937); Maßnahmen gegen politische Gegner (1933-1934); Ausländerpolizei (bis 1945); Kriminalstatistik und Verbrechensbekämpfung (bis 1942); Verfolgung der Jugendkriminalität (bis 1944); Feuerschutzpolizei und freiwillige Feuerwehren (bis 1945, mit Runderlassen).

- Gesundheitswesen: Allgemeines (bis 1945, u. a. Förderung der Rassenhygiene, Einrichtung von Eheberatungsstellen, Volkspflegeschulen, Gesundheitserziehung); Bekämpfung von Infektionskrankheiten (überwiegend bis 1942); Verkehr mit Nahrungs- und GenuBmitteln (bis 1945); Säuglings- und Kinderfürsorge (bis 1945); Angelegenheiten der Heil- und Heilhilfsberufe (bis 1943, dabei Kammern und Ehrengerichte, Einsatz russischer Ärzte in Gefangenenlagern 1942-1943), der Apotheken (bis 1944) und Krankenanstalten (bis 1942); Organisation der Medizinalverwaltung (bis 1945, dabei Mitteilungen des Reichsgesundheitsführers 1943-1945, Jahresgesundheitsberichte 1942-1944). - Kunst und Wissenschaft: Urheberrecht (bis 1945); bildende Kunst (Preise, Ausstellungen, Ankäufe, bis 1944); Musik (Chorgesang, Niedersachsenorchester, Musikschulen bis 1944); Theater (Niedersächsische Landesbühne, bis 1945); Reichskulturkammer und einzelne Kammern (bis 1944); Rundfunk (NORAG bis 1934); Museen, Vereine und Institute (u. a. Forschungsstelle "Deutscher Bauernhof", bis 1943); Natur- und Denkmalschutz (bis 1944); Förderung wissenschaftlicher, vor allem historischer Forschungen (bis 1943).

- Personenstandswesen: Eheschließungen (bis 1945); Sicherung der Register und Kirchenbücher (1942-1944); Ausführung des Blutschutzgesetzes (1936-1945).

- Statistik: Allgemeines (bis 1944), Volks- und Berufszählung (1939-1944).

- Kirchliche Angelegenheiten: Aufsichtsrecht des Staates und Kirchenverfassung im allgemeinen, der lutherischen, reformierten und katholischen Kirche (bis 1945); Kirchenaustritte (1942-1945); Glockenablieferung (1942); Kirchenbehörden und -beamte (Bischöfe, Domkapitulare, Mitglieder des Landeskirchenamtes, bis 1945); Staatszuschüsse und Kirchenvermögen (bis 1943); Angelegenheiten einzelner Kirchengemeinden, vor allem Bausachen, und Pfarrer (bis 1944); Orden und Klöster (bis 1945); Rechtsverhältnisse der Juden (bis 1943), Landrabbinate und Synagogengemeinden (bis 1939). - Stiftungen: Allgemeines und einzelne Stiftungen (bis 1945, dabei Adolf-Hitler-BadPyrmont-Stiftung 1933).

- Gemeinnützige Anstalten und Vereine, Wohlfahrtspflege: Jugendpflege (dabei HJ, Landjahr, Kinderlandverschickung bis 1945); Wohnungsbau und Siedlungswesen (bis 
1944, dabei Anordnungen des Generalbevollmächtigten für die Regelung der Bauwirtschaft 1941-1944, Deutsches Wohnungshilfswerk 1944, Errichtung von Lagern für Fremdarbeiter 1943-1944); Organisation der Wohlfahrtspflege (dabei NSV und Winterhilfswerk); Reichsarbeitsdienst (1938-1945); einzelne Anstalten und Vereine (u. a. Arbeiter-Samariter-Bund 1933, Freimaurerlogen, Innere Mission und andere evangelische Vereine, Reichsluftschutzbund ab 1935, Reichskriegerbund „Kyffhäuser“ 19381940, Schützenvereine).

- Versicherungswesen: Allgemeines, einzelne Zweige der Sozialversicherung und Aufsicht über private Versicherungen (bis 1945).

- Aufsicht über Banken und Sparkassen (dabei Jahresberichte von Bausparkassen 1938-1941, „Eisernes Sparen“ 1941).

- Gewährung von Unterstützungen: Notstandsarbeiten, insbes. im Emsland (19381942); Fürsorge für kinderreiche Familien und Mütter (bis 1939); Ehestandsdarlehen (1933-1944); Entschädigung von Kriegssachschäden (1942-1946).

- Schul- und Hochschulwesen: Organisation des Volksschulwesens (bis 1945); Jugendspiele (bis 1936); Religionsunterricht (bis 1943); Trennung von Schul- und Kirchenstellen (bis 1943); Schulaufsicht (bis 1939); Gebäude, Lehr- und Lernmittel (bis 1943); Lehrerbildungsanstalten (bis 1944); höhere und Mittelschulen (bis 1945, dabei Nationalpolitische Erziehungsanstalten und Adolf-Hitler-Schulen); Privatschulen, Sonderschulen (bis 1939); Personalangelegenheiten der Lehrer (bis 1944, dabei Disziplinaruntersuchungen bis 1943); Angelegenheiten der Technischen Hochschule Hannover (mit Personalien bis 1945, Langemarckstudium 1943), wenige Vorgänge über Universität Göttingen und Tierärztliche Hochschule Hannover.

- Straßen- und Brückenbau (bis 1945), Eisenbahnverkehr (bis 1943, dabei Tarife bis 1940, StraBenbahnen bis 1940), Post und Fernmeldewesen (bis 1945, dabei auch Rundfunk und Fernsehen), Schiffahrt und Strombau (bis 1944, dabei Arbeitsbeschaffung für Werften 1932-1942, Anlage von Talsperren bis 1939, Seekriegsrecht bis 1940, Ausbau von Häfen und Kanälen bis 1941).

- Land- und Forstwirtschaft: Förderung der Landwirtschaft, Kreditwesen (1936-1944); Höferecht (bis 1942); Bewirtschaftung von Milch, Futtermitteln, Obst und Gemüse (1942-1943); Jagdsachen (bis 1944); landwirtschaftliche Lehranstalten (bis 1945); Feldpolizei (bis 1941); Deichwesen, Meliorationen (bis 1944); Verbandswesen (Landwirtschaftskammer, Landesbauernschaft, bis 1943); Bekämpfung von Viehseuchen (bis 1945); Gewässerkunde.

- Handel und Gewerbe: Arbeitslosenversicherung (bis 1945); Arbeitseinsatz (19431945, dabei Lageberichte des Landesarbeitsamtes Niedersachsen, Heranziehung zum Befestigungsbau 1944-1945); Preissenkungsmaßnahmen (1936-1945); Errichtung der Gauwirtschaftskammern (1943-1945); Fremdenverkehr (1936-1944).

- Reichsverteidigung: Manöver und Schießübungen (bis 1945); Kriegsgräberfürsorge (bis 1944); Auszeichnungen für Teilnehmer am Ersten Weltkrieg (1936-1937); Fürsorgeund Versorgungsangelegenheiten (bis 1944); Einsatz von Kriegsgefangenen (19401945); Rüstungswirtschaft (1942-1945); MaBnahmen nach Luftangriffen (1941-1945); Garnisonen (1935); Zusammenarbeit SA und Wehrmacht (1939-1944); Heranziehung zum Dienst in der Wehrmacht (auch von Wehrmachthelferinnen), im RAD, im Luftschutz, bei der Stadt- und Landwacht und im Volkssturm (1935-1945) und Uk-Stellung (mit Personallisten); Unterbringung von bombengeschädigten Betrieben durch das Gauquartieramt (1943-1944). 
- Justiz: Besetzung der Schöffen- und Schwurgerichte (bis 1940); Personalangelegenheiten (bis 1945); Grundbuchsachen (bis 1945).

- Vermessungswesen (bis 1945) und Landesplanung (1937-1945).

\subsubsection{Provinzialverwaltung Hannover}

H, Best. Hann. 151

Ein erheblicher Teil der Akten, die 1945 noch vorhanden waren, darunter solche der Abteilung für die Heil- und Pflegeanstalten, ist seitdem verschwunden, so daB sich die Überlieferung der NS-Zeit auf Unterlagen aus folgenden Sachgebieten beschränkt:

Personalangelegenheiten (1933-1939). - Straßen-, Wasser- und Wohnungsbau (5 Bde, bis 1942). - Landwirtschaft, vor allem Lehranstalten (32 Bde, bis 1946). - Kulturund Heimatpflege, Denkmalschutz (16 Bde, bis 1947). - Kunst und Wissenschaft (u. a. 5 Bde betr. Provinzialbibliothek bis 1942, 13 Bde betr. Landesmuseum 1937-1947, 6 Bde betr. Niedersächsische Landesbühne 1939-1946, Korrespondenz des Landesleiters für Schriftum Südhannover-Braunschweig mit der Reichsschriftumskammer 1941-1943, Berichte der Provinzialstelle für Niedersächsische Familienkunde). - Umschulung von Kriegsversehrten (3 Bde, 1944-1945). - Wirtschaftsförderung, ErschlieBung von Bodenschätzen (18 Bde, bis 1943); Energieversorgung (10 Bde, bis 1946); Handwerk, Fachschulen (4 Bde, bis 1943); Schiffahrt (8 Bde, bis 1945). - Bekämpfung und Schadensausgleich bei Viehseuchen (50 Bde). - Aufsicht über die Landeskreditanstalt und andere Banken (38 Bde), Provinzialversicherung und andere Versicherungen (32 Bde) und über die Provinzialfeuerwehrschule Celle (5 Bde, 1939-1946). - Bienenzucht, insbes. Landesinstitut für Bienenforschung (13 Bde).

Nachakten über den Provinzialrat (1937-1938) und über die Provinzialverwaltung (bis 1936) sind aus der Registratur des ab 1933 nicht mehr tätigen Provinziallandtags (Best. Hann. 150) überliefert. Ersatzüberlieferung bieten die Unterlagen aus einem Verfahren gegen den Landeshauptmann Geßner und zwei Landesräte wegen Beihilfe zur Ermordung von Geisteskranken (JUSTIZ UND NS-VERBRECHEN, Nr. 226).

Lit.: T. SUESSE, H. MEYER: Die Konfrontation niedersächsischer Heil- und Pflegeanstalten mit .EuthanasiemaBnahmen" des Nationalsozialismus. 1984.

\subsubsection{Oberpräsidium von Westfalen, Münster}

MS

Die Überlieferung aus den Jahren 1933 bis 1945, in denen das Amt des Oberpräsidenten, das zunächst Ferdinand Frhr. von Lüninck bekleidet hatte, ab 1938 dem Gauleiter von Westfalen-Nord und Reichsstatthalter in beiden Lippe Alfred Meyer übertragen war, stammt vornehmlich aus folgenden Sachgebieten:

- Dienststellenverwaltung: Organisation (bis 1946); Personalangelegenheiten (bis 1949); Haushalts-, Kassen- und Rechnungswesen (bis 1950); Aufsicht über den Provinzialrat (bis 1944).

- Hoheitsangelegenheiten: Wahlen und Volksabstimmungen (bis 1942); Staatsangehörigkeit (bis 1946, dabei Listen über Ausbürgerung und Widerruf bis 1937, Deutsche Volksliste 1944-1945), Ein- und Auswanderung (bis 1937, mit Listen von Rückwanderern); Verleihung von Kriegsverdienstkreuzen (20 Bde, 1939-1944).

- Kommunalverwaltung: ProvinzialausschuB (1933) und -verwaltung (bis 1940); Ernennung von Landräten (20 Bde, 1933-1944), deren Konferenzen (1933-1944) und Organisation der Kreisverwaltungen (1934-1944); Aufsicht über Gemeinden (bis 1946, dabei Beauftragte der NSDAP 1935-1940, Nachweis jüdischer Angestellter 1935-1940, Gemeindefinanzen und -steuern, Zuweisungen an die NSDAP 1936-1944). 
- Kirchen und Schulen: Auseinandersetzung mit der katholischen Kirche, insbes. Bischof Graf von Galen, Verbot von Vereinen, Beschlagnahme von Vermögen (19371945); Berichte über die evangelische Kirche (ab 1935); Maßnahmen gegen Sekten (1936-1937); Überwachung von Geistlichen; Finanzwesen der Kirchen (bis 1943); HJ und konfessionelle Jugend (1935); private höhere Schulen (ab 1938); Genehmigung von Schulbüchern (1937-1946); Ausbildung und Entlassung von Lehrern (1939-1946); jüdische Gemeinden (1934-1937).

- Polizei: Organisation (u. a. Einsetzung des Inspekteurs der Sicherheitspolizei, politische Referenten der Gestapo 1938-1942, Erlasse des Reichsführers SS und Chefs der Deutschen Polizei 1940-1944); Überwachung von Ausländern, Fremdarbeiter (19261937, 1944-1945); Verbot von Druckschriften (1933-1943); Maßnahmen gegen die nationalpolnische Bewegung (1933-1937), reaktionäre Organisationen (1932-1938), Kirchen und kirchliche Einrichtungen (20 Bde); Verhängung von Schutzhaft (Listen, 19361937) und ÜberwachungsmaBnahmen (1930-1942); Maßnahmen gegen Zigeuner (bis 1936); Sittenpolizei (bis 1935); Stadt- und Landwacht (1942-1943); Luftschutz und Luftangriffe (1940-1945, dabei 7 Bde Schadensmeldungen des Befehlshabers der Ordnungspolizei); Luftpolizei (bis 1934).

- Justiz: Schulung durch den NS-Rechtswahrerbund (1937-1944), Liste von Rechtsanwälten (1940-1942).

- Militär. Erfassung und Musterung von Wehrpflichtigen (1935-1936, Akten des Reichsverteidigungskommissars vgl. Abschnitt 2.1.1.3, des Chefs der Zivilverwaltung Abschnitt 8.3.3).

- Land- und Forstwirtschaft: Bodennutzungserhebung (1935-1944); Beihilfen aus dem Reichslandeskulturfonds (20 Bde, 1936-1943); Kreditwesen, Entschuldung (19361945); Fortbildungsschulen (4 Bde, 1938-1949); Arbeitseinsatz, auch von Fremdarbeitern (1938-1941); Förderung des Anbaus einzelner Pflanzenarten (20 Bde); Forst-, Jagdund Fischereisachen.

- Siedlungswesen, Wasserbau: Durchführung von Kleinsiedlungsprojekten (19381947); Landesplanung (1936-1945); Wohnungsbau (bis 1945, mit Bilanzen einzelner Bauträger 1936-1939); Wasserwirtschaftsverbände, insbes. Ruhrtalsperrenverband.

- Wirtschaft: Lageberichte (6 Bde, 1937-1941, auch der Industrie- und Handelskammer Ostwestfalen 1933-1936); Industrie (2 Bde, 1933-1935); Arbeitsmarktlage (1937-1943); Reichstreuhänder der Arbeit (3 Bde, 1933-1937); Lage einzelner Wirtschaftszweige (20 Bde); Lehrlingsausbildung im Handwerk (1937-1942); Jahresberichte der Handwerkskammer Dortmund (1935-1937); Gewerteaufsicht (bis 1943); Förderung des Einzelhandels; Bergbau (bis 1940, u. a. Besetzung der Bergausschüsse auch für die Bezirke Bonn und Clausthal-Zellerfeld 1934-1937, Berichte des Rheinisch-westfälischen Kohlensyndikats 1934-1937, Wiederaufnahme des Betriebs in stillgelegten Zechen); Preisüberwachung (9 Bde); Kreditwirtschaft (1935-1946); Versicherungswesen (bis 1944).

- Verkehr. Straßenverkehr und -bau (bis 1946, dabei Planung für Reichsautobahn 1936); Eisenbahnen (bis 1937); Schiffahrt (bis 1946); Flughafen Dortmund (bis 1937).

- Statistik: Volks-, Berufs- und Betriebszählungen (1932-1942).

- Wissenschaft und Kunst: Universitäten und wissenschaftliche Veröffentlichungen (bis 1946); Archive, Bibliotheken und Museen (bis 1945); Förderung von Vereinen (bis 1946); Denkmalpflege (bis 1946), Schäden an Kulturgut (ab 1940); Naturschutz (bis 1940); Theaterangelegenheiten (1931-1938, u. a. Richard-Wagner-Festwochen Detmold 1935-1938). 
- Medizinalwesen: Organisation der Medizinalverwaltung (bis 1946. dabei Ernennung eines Leitenden Medizinalbeamten beim Oberpräsidium 1942-1944); Ärztekammer und ärztliche Ehrengerichtsbarkeit (bis 1936); Behandlung geisteskranker Ausländer (5 Bde, 1931-1942).

- Fürsorge und Wohlfahrt: Sport und Jugendpflege (1936-1943); Unterstützung von Veranstaltungen der Hitlerjugend (1938-1944); Organisation des Landjahrs (10 Bde); Arbeitsbeschaffungsmaßnahmen, wertschaffende Arbeitslosenfursorge (1933-1941, u. a. Vergabe von Mitteln aus dem Reinhardt-Programm); Sammlungen und Lotterien (bis 1946).

LiL: U. SCHNORBUS: Quellen zur Geschichte der Juden. 1983. S. 109-110. - K. TEPPE: Die Oberpräsidenten der Provinz Westfalen 1919-1945. 1982.

\subsection{Provinzialverwaltung Westfalen}

LVW MS

Den gröBten Teil der Überlieferung aus der NS-Zeit (ca. 2700 Bde, 1933-1945) bilden Akten der Hauptverwaltung (Best. C 10 und C 11, ca. 1000 Bde); dazu gehören Unterlagen zur Verfassung der Provinz und ihren Organen (ca. 120 Bde) mit Vorgängen über die Stellung der NSDAP (11 Bde) und deren Veranstaltungen (20 Bde) und Erlassen von Reichsbehörden (10 Bde, u. a. betr. Kolonialdienst, Umsiedlung von Volksdeutschen, Deutschen GruB). Außerdem sind Akten über die Dienststellenverwaltung und Personalangelegenheiten (Best. C 11 mit 15 Bden betr. Heil- und Pflegeanstalten, 17 Bden betr. andere medizinische Einrichtungen und 23 Bden betr. Versicherungen und verschiedene Anstalten, z. B. Heime). Weitere Bestände stammen aus folgenden Zuständigkeiten:

Hochbau (C 13, 10 Bde).

Kämmerei (C 20, 291 Bde): Organe (Provinzialausschuß und -rat) und Verwaltung (77 Bde); Finanz- (37 Bde), wirtschaftliche (29 Bde) und Verkehrseinrichtungen (35 Bde); Arbeitsbeschaffungsmaßnahmen und Strukturhilfen (36 Bde), sonstige Förderungsmaßnahmen (30 Bde, u. a. Leistungen an die NSDAP, Ostsiedlung); soziale und medizinische (37 Bde) sowie Bildungseinrichtungen (10 Bde).

Liegenschaftsverwaltung (C 21, 230 Bde, davon 21 betr. landwirschaftliche Güter, 69 betr. Heil- und Pflegeanstalten).

Wirtschaftspflege (C 30, 168 Bde).

Wasserwirtschaft und Emsausbau (C 33, 69 Bde).

Straßenbau (C 40 III, 134 Bde).

Kulturpflege (C 70, 280 Bde): Dienststellenverwaltung und Personalangelegenheiten (31 Bde), Allgemeines (41 Bde, u. a betr. NS-Kulturgemeinde und Gaukulturämter Westfalen-Süd und -Nord, 1933-1938 bzw. 1944, 7 Bde über die Deutsch-niederländische Gesellschaft, 1932-1944), Landesmuseen (39 Bde) für Vor- und Frühgeschichte (mit Ausgrabungen und Gauarbeitsgemeinschaft Vorgeschichte), für Kunst- und Kulturgeschichte und für Naturkunde, Provinzialinstitut für Landes- und Volkskunde (14 Bde), Archivpflege (5 Bde), Baudenkmalpflege (6 Bde), Landesforschung, insbes. durch historische Vereine, auch Rassenforschung (14 Bde), Kunstförderung (11 Bde), Wissenschaft (8 Bde, vor allem betr. Universität Münster), Naturschutz (18 Bde), Heimatpflege durch Vereine und Publikationen (23 Bde), Volksbildung (18 Bde, dabei Theater-, Orchester-, Büchereiangelegenheiten).

Vom Provinzialinstitut für westfälische Landes- und Volkskunde selbst sind Korrespondenzen (16 Bde) und Unterlagen über Ausschüsse und Kommissionen (6 Bde), 
Tagungen (4 Bde), Publikationen (39 Bde) und deutsch-niederländische Beziehungen (3 Bde) vorhanden.

Ergänzungsüberlieferung bietet der Nachlaß des Landeshauptmanns von 1933 bis 1944 Karl Friedrich Kolbow (69 Bde) mit umfangreichem Schriftwechsel mit den Gauleitungen Westfalen-Nord und Westfalen-Süd und anderen NS-Dienststellen (13 Bde) sowie mit dem Oberpräsidenten und staatlichen wie kommunalen Behörden (14 Bde), auBerdem mit Akten in Angelegenheiten der Landesversicherungsanstalt (15 Bde), des Deutschen Gemeindetages (9 Bde) und persönlichen Unterlagen (dabei Anstellungsgesuche von aiten Parteigenossen). Der NachlaB von Ernst Kühl, 1928 bis 1948 Landesrat und Kämmerer (Best. N 3, 41 Bde), enthält Vorgänge über die Neugliederung des Reiches (2 Bde) und über die NSDAP (3 Bde).

Lit: K. TEPPE: Provinz - Partei - Staat. 1977. - K. TEPPE: Selbstverwaltung und Herrschafisordnung. 1987. - K. DITT: Raum und Volkstum. 1989.

\subsubsection{Oberpräsidium von Hessen-Nassau, Kassel MR, Best. 150}

Das laufende Schriftgut der Behörde, die ab 1944 infolge der Aufteilung der Provinz in die beiden Provinzen Kurhessen und Nassau nur noch für den Regierungsbezirk Kassel zuständig war, ist im Oktober 1943 bei einem Luftangriff vollständig vernichtet worden; die Tätigkeit des Oberpräsidenten Philipp Prinz von Hessen von 1933 bis 1943 und seiner Nachfolger Regierungspräsident Emst Beckmann und für Kurhessen Gauleiterstellvertreter Karl Gerland ist daher nicht dokumentiert.

Der Bestand enthält nur einzelne in den ersten Jahren nach 1933 fortgefuihrte Akten über Verwaltungsvereinfachung (1933), die Bevollmächtigten des Obersten SA-Führers bei den Verwaltungsbehörden (1933-1934), den Haushalt der Landkreise (1935) und über ärztliche Ehrengerichtsverfahren (1933-1935). Außerdem sind ab 1944 neu angelegte Vorgänge über die Trennung der Provinzen, über die Gymnastikschulen „Loheland“ und Schwarzerden sowie Archivangelegenheiten vorhanden.

Lit.: REPERTORIEN des Staatsarchivs Marburg - Bestand 150. 1967. - K. DÜLFER: Die Regierung in Kassel. 1960.

\subsubsection{Provinzialverwaltung Hessen-Nassau}

Ein Bestand mit der älteren Überlieferung (MR, Best. 220) konnte nur durch Restakten über StraBenbau (3 Bde, 1935-1945) ergänzt werden. Weitere Aktenreste sind in Schriftgut des Bezirksverbands Hessen gelangt (LWV KS, vgl. Abschnit 2.1.2.3.3), der ebenfalls von dem Landeshauptmann Traupel geleitet wurde und im selben Gebäude untergebracht war. Eine Sammlung von Erlassen der Provinzialverwaltung ist in Akten der Landesbibliothek (MR, Best. 223, 3 Bde, 1934-1944) erhalten.

\subsubsection{Oberpräsidium der Rheinprovinz, Koblenz KO, Best. 403}

Der Bestand enthält nur einzelne nach 1933 fortgeführte oder neu angelegte Aktenbände. Dazu gehören auch Reste von Korrespondenz (1935-1937) des Oberpräsidenten und Gauleiters von Essen Josef Terboven, der wegen seiner Ernennung zum Reichskommissar in Norwegen ab 1940 vom Regierungspräsidenten Karl Eugen Dellenbusch vertreten wurde. Lageberichte (1934-1936) Terbovens und seines Vorgängers Hermann Frh. von Lüninck sind in Kopien (Best. 717) überliefert, Korrespondenz Lünincks (19331935) enthält dessen Nachlaß (Best. 700,41). Zu den Sachakten gehören einige über 
die NSDAP und ihre Gliederungen (8 Bde, 1933-1935, dabei Maßnahmen am 30. Juni 1934), über das Verhältnis von Staat und katholischer Kirche (13 Bde, 1933-1937), über die Lage im Saargebiet (5 Bde, 1933-1935) und Eupen-Malmedy (4 Bde, 1933-1936), Separatismus (2 Bde bis 1935), die Rheinische Gesellschaft für Deutsche Kultur (4 Bde, 1933-1934) und Überwachung der Presse (7 Bde, bis 1936). Im übrigen stammen sie hauptsächlich aus folgenden Zuständigkeiten:

- Beamtenrecht. öffentliches Dienstrecht (dabei Anwendung des Berufsbeamtengesetzes 1933-1942).

- Kommunalaufsicht (dabei 15 Bde betr. Personalangelegenheiten, Ernennung der Mitglieder des Provinzialrates 1933-1944, Aufsicht über Sparkassen, Provinzialversicherungsanstalt 1935-1938 und Gemeindeversorgungskasse 1938-1939).

- Landwirtschaft (dabei 20 Bde betr. Arisierung landwirtschaftlichen Besitzes in den Kreisen Bernkastel und Zell 1938-1944, Statistik 1936-1944, Natur- und Landschaftsschutz 1938-1942, Meliorationen und Landeskultur, Beihilfen aus dem Westfonds bis 1942, Siedlungswesen 1936-1943, Tierschutz 1936-1938, Forstsachen 1936-1942, Jagdund Fischereisachen bis 1944).

- Wirtschaft (dabei Arbeitslosenversicherung und Arbeitsbeschaffung bis 1939, Sozialversicherung bis 1938).

- Vermessungswesen (1936-1939).

- Wasserbau- und -wirtschaft (bis 1944).

- Apothekensachen (bis 1936).

- Rheinschiffahrtsangelegenheiten (bis 1942).

Lit.: INVENTAR DER QUELLEN zur Geschichte der Juden. S. 47-78. - H. ROMEYK: Verwaltungs- und Behördengeschichte der Rheinprovinz 1914-1945. 1985. S. 153-170.

\subsubsection{Provinzialverwaltung der Rheinprovinz, Düsseldorf}

LVR Brauweiler

Die Registraturen wurden im Zweiten Weltkrieg im Landeshaus fast vollständig vernichtet. Der Bestand enthält neben Protokollen der Konferenzen der Landesdirektoren (2 Bde, 1933-1937) und Resten von Unterlagen über Personalangelegenheiten (bis 1934), Dienststellen- und Kassenverwaltung (bis 1941), Kindergesundheitspflege (bis 1938) und Stiftungen (bis 1935) aus der NS-Zeit hauptsächlich Akten der Kulturabteilung, die in der Regel Ende des 19. Jahrhunderts einsetzen. Sie betreffen Haushalt (6 Bde, bis 1945), Pressemitteilungen (4 Bde), den Literaturpreis (8 Bde, 1937-1944), Kriegszerstörungen (4 Bde, 1940-1945), Rückforderung von Kulturgut aus Westeuropa (1940-1945), Förderung der Hochschulen Aachen, Bonn, Düsseldorf und Köln und wissenschaftlicher Institute (45 Bde, dabei Deutsches Institut Paris 1942-1945), Volksbildung (11 Bde), Rheinisches Landestheater u. a. Theaterangelegenheiten (17 Bde), Ausstellungen ( 6 Bde), wissenschaftliche Publikationen und Gesellschaften ( 90 Bde u. a. über einzelne Geschichts-, Kunst-, Gebirgs- und Wander-, Musikvereine, darunter Reichsbund Volkstum und Heimat, Bund deutscher Westen), Denkmalpflege und Kunstdenkmäleraufnahme (56 Bde allgemein, ca. 300 Bde über Einzelmaßnahmen), Naturund Landschaftsschutz (ca. $60 \mathrm{Bde}$, insbes. Tätigkeit des Provinzialbeauftragten für Naturschutz), Ausgrabungen und Bodendenkmalpflege (58 Bde), Landesmuseen Bonn und Trier (25 Bde), Förderung des Museumswesens, vor allem von Heimatmuseen (ca. 160 Bde, dabei 2 Bde betr. Ankäufe in Belgien und Frankreich 1940-1944), Aufbau eines „Archivs zur Rheinlandbesetzung“ (20 Bde, 1938-1941). Ein „Kriegsarchiv“ (24 
Bde) dokumentiert feindliche Flugblätter, die Wirkung von Luftangriffen besonders auf Einrichtungen der Provinzialverwaltung, Briefwechsel mit Wehrmachtangehörigen, die Metallspende und den Arbeitseinsatz für kriegswichtige Zwecke.

In geringerem Umfang erhalten blieben nach 1933 geführte Akten der für Psychiatrie und erweiterte Armenpflege zuständigen Referate (ca. 40 Bde, dabei aber Berichte, 8 Bde betr. Erbgesundheitspflege, -biologie und „Euthanasie“, vgl. auch unten Abschnitt 2.3.2.2, 3 Bde betr. Strafverfahren gegen Franziskanerbrüder Waldbreitbach 1937-1946) und über die Förderung der Landeskultur, vor allem über Beihilfen aus Mitteln der Deutschen Bodenkultur A.G. und des Reichslandeskulturfonds (25 Bde), ferner über den Einsatz von FAD und RAD (5 Bde, 1933-1942).

Der NachlaB des Landeshauptmanns von 1933 bis 1945, des ersten Gauleiters der NSDAP im Rheinland Heinz Haake, enthält aus seiner amtlichen Tätigkeit nur wenige Unterlagen über das Saarland (1934-1935), Reisen in die besetzten Westgebiete (19401941), eine Auseinandersetzung mit Todt (1939-1940), die Mitgliedschaft in Gremien der Wirtschaft (6 Bde, 1937-1940) und der Kultur, Reste von Korrespondenz, u. a. mit dem Deutschen Gemeindetag, und einzelne Redemanuskripte, Zeitungsausschnitte ( 9 Bde, 1935-1941).

Lit: W. F. WERNER, R. Kahlfeld: Psychiatrie und Erweitene Armenpflege. 1989. - H. LADEMACHER: Von den Provinzialständen zum Landschaftsverband. 1973. - H. ROMEYK: Verwaltungs- und Behördengeschichte der Rheinprovinz. 1985. S. 281- 310.

\subsection{Behörden für auswärtige Angelegenheiten}

\subsubsection{Auswärtiges Amt}

AA

ZStA, Best. 09.01

Obwohl erhebliche Teile der laufenden Registraturen des Amtes während des Zweiten Weltkriegs vernichtet wurden, verwahrt das Auswärtige Amt in Bonn in seinem Politischen Archiv noch umfangreiche Bestände auch aus der Zeit des Nationalsozialismus, neben denen die entsprechende Überlieferung im Zentralen Staatsarchiv Potsdam von geringerer Bedeutung ist. Bei den Mengenangaben ist allerdings zu berücksichtigen, da $B$ es sich vielfach nur um dünne Hefte handelt. Außerdem liegt nicht selten Doppelüberlieferung dadurch vor, daB mehrere Ausfertigungen oder Kopien von Schriftstücken sowohl nach geographischen als auch nach sachlichen Gesichtspunkten abgelegt worden sein können. Ein großer Teil der Ausfertigungen von Verträgen mit anderen Staaten und der Ratifikationsurkunden dazu ist in einer besonderen Sammlung vereinigt. Zu berücksichtigen ist ferner, daB durch eine Reorganisation des Amtes und der Registraturen 1936 für die Zeit des Nationalsozialismus zwei Registraturschichten entstanden sind, jedoch jeweils mit Vor- und Nachakten; Mengenangaben für Überlieferung vor 1936 beziehen sich nur auf Aktenbände, die nach 1933 fortgeführt oder angelegt wurden. Das Schriftgut stammt von folgenden Organisationseinheiten nach dem Stand von 1943:

\section{Ministerbüro}

Im Politischen Archiv sind aus dem Büro Neuraths und Ribbentrops Akten in Organisations- und Personalangelegenheiten (3 Bde, bis 1935), Kabinettsachen, An- 
gelegenheiten anderer Ressorts (55 Bde, bis 1938), Länderakten (23 Bde bis 1935, 32 Bde 1936-1943) und zur Innen- und Wirschaftspolitik (34 Bde, bis 1935, z. T. bis 1937) im Original überliefert. Aus der Zeit von 1938 bis Mai 1943 ist ein Mikrofilm vorhanden, auf dem wichtige Vorgänge gesichert worden waren (ca. 10000 Aufnahmen. dabei auch 4 bzw. 7 Vorgänge von 1936 und 1937); wiedergegeben sind darauf vor allem Aufzeichnungen über Gespräche Ribbentrops, aber auch Hitlers mit Diplomaten, Denkschriften leitender Beamter, ausgewählte Drahtberichte und Weisungen, Memoranden und Noten, ferner Schreiben anderer oberster Reichsbehörden, u. a. des Chefs der Sicherheitspolizei und des SD, und sie betreffen insbesondere die Beziehungen zu GroBbritannien, Italien, dem Baltikum, der Sowjetunion (u. a. Nichtangriffspakt 1939) und Südosteuropa. Weitere Aufzeichnungen über Gespräche (17 Bde Originale, 19401944) und einige Handakten (14 Bde, 1929-1944) stammen vom letzten Leiter des Ministerbüros und vorher des Sprachendienstes, dem Gesandten Paul Otto Schmidt. Die Akten der Dienststelle Ribbentrop der NSDAP sind in Abschnitt 9.1 .02 berücksichtigt.

In Potsdam befindet sich neben Handakten Neuraths (39 Bde, 1928-1944) und Akten des Hauptreferates Presse (48 Bde, 1935-1942) vor allem das persönliche Pressearchiv Ribbentrops (1 006 Bde, 1934-1943, davon 126 Bde Fotos aus der deutschen und internationalen Presse).

\section{Büro des Staatssekretärs}

Der Bonner Bestand enthält Länderakten (ca. 200 Bde, 1937-1944, überwiegend ab 1942) und Akten betr. Rheinlandbesetzung 1936 (9 Bde), Krieg und Friedensverhandlungen (12 Bde, 1940-1944), Aufzeichnungen, vor allem über Gespräche mit Diplomaten, und politischen Schriftwechsel, auch mit dem Minister, der Staatssekretäre Bernhard Wilhelm v. Bülow (1930-1936, 11 bzw. 13 Bde, auBerdem 15 Bde betr. Protokollund persönliche Angelegenheiten), Hans Georg v. Mackensen (1937/38, 3 bzw. 4 Bde), Ernst Frh. v. Weizsäcker (1938-1943, 30 bzw. 28 Bde). Von Staatssekretär z. B. V. Wilhelm Keppler sind wenige Akten über seine Tätigkeit beim AnschluB Österreichs (7 Bde, 1937-1938), über die Slowakei (2 Bde, 1939-1940) und über Indien (6 Bde, 1940-1944) vorhanden (ein Nachlaßrest, 8 Bde, 1934-1953, auch BA, Kl. Erw. 537). Zur Überlieferung des Chefs der Auslandsorganisation der NSDAP und Staatssekretärs Bohle vgl. Abschnitt 9.1.17.

\section{Büro des Unterstaatssekretärs}

Die Akten (im AA) des politischen Unterstaatssekretärs (1938-1943) Ernst Woermann betreffen vor allem ausländische Staats- u. a. Besucher (18 Bde, 1936-1940), den Krieg (18 Bde, 1939-1942), Beziehungen zu einzelnen Ländern und Gebieten (ca. 100 Bde, 1937-1943) und enthalten Reste seiner diplomatischen Aufzeichnungen (7 Bde, 1942).

Büros der Botschafter z. B. V.

Überliefert sind in Bonn Handakten der Botschafter Karl Ritter über einzelne Länder (ca. 100 Bde, überwiegend 1940-1944, dabei 8 Bde betr. Frankreich, 1941-1945, 10 Bde Sowjetunion, 1939-1944, 12 Bde Tschechoslowakei, 1938-1939) und Sachgebiete (24 Bde, 1940-1945, vor allem über Organisation und Kriegführung) und Walter Hewel, des Vertreters von Ribbentrop im Führerhauptquartier, über innenpolitische und Parteiangelegenheiten (12 Bde, 1938-1942, dabei 3 Bde eines Registers der Vorlagen bei Hitler, 1940-1942, außerdem Privatakten). 


\section{Personal- und Verwaltungsabteilung}

Nur Reste der laufenden Personal- und Haushaltsakten haben die Luftangriffe überstanden. Dazu gehören im Bonner Bestand 1944 neu angelegte Personalbögen von 330 Beamten des höheren Dienstes, Unterlagen über einzelne Stiftungen und Spenden zu besonderen Anlässen (1933-1939), Zahlungen an Hilfs- und ähnliche Vereine für Deutsche im Ausland und in Einzelfälen (1933-1940), finanzielle Angelegenheiten einzelner Botschaften, Gesandtschaften und Konsulate (1933-1940). Als Quelle für die Behördengeschichte ist die Registratur des Politischen Archivs (mit Ausweichstelle Friedland) und Historischen Referats von Bedeutung. Sie enthält auch Akten über die Sicherung und Übernahme von Schriftgut, die Benutzung deutscher Archive durch Ausländer (14 Bde, 1933-1944), ausländische und deutsche Aktenpublikationen und die Prüfung von Manuskripten (26 Bde, 1939-1944, dazu zahlreiche eingereichte Arbeiten, z. T. in Druckfahnen), die Archive in Österreich, der Tschechoslowakei, Polen, Norwegen, Belgien, den Niederlanden und Luxemburg (1938-1944).

Der Hauptteil der in Potsdam überlieferten Akten entstand im ehemaligen Hauptbüro der Abteilung (200 Bde) und umfaßt im wesentlichen Berichtsverzeichnisse der Gesandtschaften und Konsulate (115 Bde) und Tagebücher, Sach- und Namensregister (68 Bde), ferner eine Serie von Hauserlassen und Haushaltsakten. Weiterhin betreffen sie verschiedene Personalangelegenheiten (46 Bde) mit Einzelvorgängen über höhere $\mathrm{Be}$ amten, Wahlkonsuln, Sachverständige sowie technische Angestellte (32 Bde), Verwaltungsangelegenheiten (30 Bde), das Chiffrier- und Nachrichtenwesen (24 Bde) sowie Bibliothek und Politisches Archiv (75 Bde).

\section{Abteilung Protokoll}

Zu den Bonner Aktenresten gehören Vorgänge über Nationalfeiertage (2 Bde, bis 1935), Teilnahme von Diplomaten an Veranstaltungen (11 Bde, 1933-1938), Ehrungen für Staatsoberhäupter (12 Bde, 1933-1938), Diplomatenverzeichnisse (bis 1938), Verkehrsund andere Zwischenfälle, Beschwerden und Forderungen (19 Bde, bis 1939), Angelegenheiten Hindenburgs und Hitlers als Staatsoberhaupt (21 Bde, 1932-1945), Angelegenheiten der ausländischen Konsulate (ca. 100 Bde, 1933-1944), ausländische Vertretungen in besetzten Gebieten (7 Bde, 1940-1944), Schutzmachtangelegenheiten (3 Bde, 1939-1944), Verleihung deutscher und ausländischer Orden und Ehrenzeichen (5 Bde, 1933-1934, 1938-1945) und Dienststellenverwaltung (ca. 60 Bde, 1934-1944, u. a. betr. Kosten für Staatsbesuche 1944 und für Jagden 1939-1944).

$\mathrm{Zu}$ den wenigen in Potsdam überlieferten Aktenresten gehören im wesentlichen Regelungen für die Übermittlung von Glückwünschen (7 Bde), bei Besuchen von Persönlichkeiten in Deutschland (4 Bde), Auszeichnungen (6 Bde) und Aufstellungen über das Personal einzelner Gesandtschaften (11 Bde).

\section{Politische Abteilung}

1936 wurden die bis dahin auf drei Abteilungen verteilten Referate für die Beziehungen zu einzelnen Ländern und Gebieten zur Politischen Abteilung vereinigt und verloren ihre Zuständigkeit für wirtschaftliche Angelegenheiten z. T. an die Handelspolitische Abteilung.

Den Hauptteil der Überlieferung bilden die Serien über einzelne Länder und die Beziehungen zu ihnen, die auch Unterlagen über deren Verhältmis zu anderen Staaten (Po 3), ihre Innenpolitik (Po 5, dabei auch faschistische und nationalsozialistische 
Bewegungen, über diese auch Po 29), Minderheitenfragen (Po 6, deutsche Minderheiten z. T. Po 25)), Personalien (Po 11), Militärangelegenheiten (Po 13), Rechtswesen und innere Verwaltung enthalten; Geheimakten, zu denen auch Vorgänge über deutsche und ausländische Nachrichtendienste und einzelne Agenten gehören, wurden gesonder geführt. Aus den Jahren 1933 bis 1936 sind in Bonn und Potsdam vornehmlich Akten über folgende Länder und deren Kolonien vorhanden:

- Ägypten (ca. 60 Bde AA, 108 Bde ZStA);

- Äthiopien (ca. 80 Bde AA, 48 Bde ZStA);

- Afghanistan (15 Bde AA, 70 Bde ZStA);

- Arabien mit Irak, Syrien, Palästina (ca. 120 Bde AA, 81 Bde ZStA);

- Argentinien (ca. 50 Bde AA, 136 Bde ZStA);

- Albanien (30 Bde AA);

- Baltikum (ca. 300 Bde +82 Bde Geheimakten AA, insbes. betr. Litauen und Memelgebiet, 306 Bde ZStA)

- Belgien (ca. 80 Bde + 10 Geheimakten AA);

- Brasilien (ca. 50 Bde AA, 132 Bde ZStA);

- Bulgarien (67 Bde + 4 Geheimakten AA);

- Chile (ca. 40 Bde AA, 97 Bde ZStA);

- Dänemark mit Nordschleswig, Island und Grönland (ca. 80 Bde + 4 Bde Geheimakten AA, 70 Bde ZStA);

- Frankreich mit Elsaß-Lothringen und Fremdenlegion im allgemeinen und Einzelfällen (ca. 400 Bde + 30 Geheimakten AA, 43 Bde ZStA);

- Finnland (ca. 50 Bde AA, 146 Bde ZStA);

- Griechenland (58 Bde + 4 Geheimakten AA, 59 Bde ZStA);

- GroBbritannien mit Dominien und Kolonien (ca. 300 Bde AA, 225 Bde ZStA);

- Iran (ca. 60 Bde +2 geheime Vorgänge);

- Italien (117 Bde + 29 Geheimakten AA, 259 Bde ZStA);

- Jugoslawien (65 Bde + 14 Geheimakten AA, 169 Bde ZStA);

- Kuba (24 Bde ZStA)

- Lateinamerika auBer ABC-Staaten und Mexiko (ca. 400 Bde AA, 236 Bde ZStA);

- Liechtenstein (8 Bde AA);

- Liberia (20 Bde AA);

- Luxemburg (35 Bde + 3 Geheimakten AA, 58 Bde ZStA);

- Mexiko (ca. 40 Bde AA);

- Niederlande mit Kolonien (74 Bde + 4 Geheimakten AA, 233 Bde ZStA);

- Nordafrika mit Marokko und Tunesien (19 Bde ZStA);

- Norwegen (ca. 40 Bde AA, 84 Bde ZSLA);

- Ostasien (ca. 300 Bde, davon ca. 110 betr. China, 60 betr. Japan, + 17 Bde Geheimakten AA, ca. 500 Bde ZSLA, davon 130 betr. China, 102 betr. Japan, 50 betr. Mandschurei, 39 betr. Siam);

- Österreich (180 Bde + 47 Geheimakten AA, 204 Bde ZStA);

- Polen mit Danzig und Ostoberschlesien (ca. 700 Bde + 158 Bde Geheimakten, außerdem geheime Vorgänge über einzelne Deutsche AA, 281 Bde ZStA);

- Portugal (44 Bde AA, 48 Bde ZStA);

- Rumänien (60 Bde + 10 Geheimakten AA, 11 Bde ZStA);

- Schweden (ca. 50 Bde AA, 59 Bde ZStA);

- Schweiz (61 Bde + 10 Geheimakten AA); 
- Sowjetunion (ca. 400 Bde + 133 Bde Geheimakten, auch über internationalen Kommunismus AA, 13 Bde ZStA);

- Spanien mit Kolonien (108 Bde + 6 Geheimakten AA, 93 Bde ZStA);

- Südafrikanische Union (85 Bde ZStA);

- Tschechoslowakei (122 Bde + 18 Geheimakten AA);

- Türkei (ca. 70 Bde AA, 167 Bde ZStA);

- Ungarn (55 Bde + 9 Geheimakten AA, 50 Bde ZSLA);

- USA (ca. 130 Bde + 3 Geheimvorgänge, auBerdem 60 Bde betr. deutschamerikanische Entschädigungsansprüche 1933-1941 AA, 206 Bde ZStA):

- Vatikan (250 Bde + 10 Geheimakten).

Von den nach 1936 angelegten Akten der Länderserien sind in beiden Archiven nur Reste vorhanden, die überwiegend bis 1940, vereinzelt bis 1943 reichen: dabei stammt der Potsdamer Teil (80 Bde) in der Hauptsache aus der besonderen Registratur für .geh. RS.“ (= geheime Reichssachen). Sie betreffen folgende Staaten und Gebiete:

- Baltikum (34 Bde, vor allem betr. Litauen) und Memelgebiet (80 Bde AA);

- Belgien (18 Bde + 5 Bde Geheimakten AA);

- Danzig (105 Bde AA);

- Frankreich (53 Bde bis 1940, 22 Bde Richtlinien und Arbeitsmaterial 1941-1943, +

9 Bde Geheimakten AA, 6 weitere Bde ZStA);

- Griechenland (4 Bde AA);

- Großbritannien (64 Bde + 8 Bde Geheimakten AA, 1 Bd ZStA);

- Indien (3 Bde AA);

- Irland (2 Bde AA, 1 Bd ZStA);

- Italien mit Südtirol (29 Bde AA, 5 Bde ZStA);

- Jugoslawien (90 Bde AA, 1 Bd ZStA);

- Karpatho-Ukraine (29 Bde, 1939-1940, AA);

- Lateinamerika (45 Bde AA, davon Argentinien 11 Bde, Brasilien 6 Bde, Chile 3 Bde, 7 Bde ZStA);

- Niederlande (16 Bde AA);

- Ostasien (101 Bde, davon speziell über Japan 31 Bde, + 4 Bde Geheimakten AA, ein weiterer ZStA);

- Österteich (129 Bde, 1936-1938, einzelne bis 1943, + 4 Bde Geheimakten AA, 2 Bde ZStA);

- Ostoberschlesien (102 Bde AA);

- Polen (240 Bde + 7 Bde Geheimakten AA, 2 Bde ZStA);

- Portugal (3 Bde AA, 1 Bd ZStA);

- Protektorat Böhmen und Mähren (40 Bde, 1939-1944, AA);

- Rumänien (15 Bde AA, 2 Bde ZStA);

- Schweiz (18 Bde AA, 3 Bde ZStA);

- Skandinavien im allgemeinen (14 Bde AA), Norwegen (2 Bde AA), Schweden (5 Bde AA, 2 Bde ZStA), Dänemark (6 Bde, auBerdem 14 Bde betr. Nordschleswig, je 1 Bd über Island und Grönland AA, weitere 5 Bde ZStA), Finnland (15 Bde, auBerdem 4 Bde betr. Aland-Inseln AA, 1 Bd ZStA);

- Slowakei (6 Bde + 5 Bde Geheimakten AA, 2 Bde ZStA);

- Sowjetunion (ca. 100 Bde + 19 Bde Geheimakten AA, auBerdem über die Besetzten Ostgebiete ca. 50 Vorgänge ab 1941, 2 Bde ZStA);

- Spanien (238 Bde, vor allem betr. Waffenembargo im Bürgerkrieg, + 10 Bde Geheimakten AA, 12 Bde ZStA); 
- Südafrikanische Union (63 Bde AA, 1 Bd ZStA).

- Tschechoslowakei (156 Bde, 1936-1939, weitere 39 Bde betr. Durchführung des Münchener Abkommens + 20 Bde Geheimakten AA, 2 Bde ZSLA):

- Türkei (5 Bde AA, 3 Bde ZStA):

- Ukraine (7 Bde, 1936-1940, AA):

- Ungarn (10 Bde AA, 4 Bde ZStA);

- USA (49 Bde + 1 Bd Geheimakten AA. 2 Bde ZStA);

- Vatikan (23 Bde + 1 Bd Geheimakten AA, 2 Bde ZStA):

- Vorderer Orient (20 Bde, dabei 3 Bde betr. Palästina 1937-1938. weitere 8 Bde betr. Ägypten und arabische Länder, Palästina ZStA).

Nur je ein Band ist in Potsdam über Afghanistan, den Balkan, Iran, Kroatien, Serbien und die Slowakei, je zwei Bände über Luxemburg und Kanada sind in Bonn überliefert. Über Einzelfälle - meist sehr geringer Bedeutung (Ausweisungen, Strafverfahren, Aufenthaltsermittlungen u. dgl.) - liegen wie auch vor 1936 für viele Länder Spezialakten vor (insgesamt ca. 250 Bde AA, 50 Bde ZStA).

Aus den Jahren 1933 bis 1936 sind (AA) ferner Akten über Dienststellenverwaltung (36 Bde), außenpolitische Beziehungen im allgemeinen (ca. 50 Bde), über zwischenstaatliche Probleme Südosteuropas (17 Bde), über deutsche und ausländische Politiker (4 Bde), Rechtsangelegenheiten (8 Bde), Nachwirkungen des Weltkriegs (24 Bde), über das Saargebiet (ca. 300 Bde, häufig bis 1938, z. T. bis 1940), Eupen-Malmedy (22 Bde) vorhanden. Weitere Teilbestände (II F) bilden Akten über Luftverkehr und entsprechende Abkommen (220 Bde, 1933-1936, dabei auch Vorgänge über einzelne Flugzeugfirmen, Flieger, Luftattachés, Luftschutz), über Abrüstung, insbes. Genfer Abrüstungskonferenz (ca. 200 Bde. 1933-1936, dabei auch Kommissions- und Delegationsakten, auch Rheinlandbesetzung 1936) und militärische und Rüstungsangelegenheiten (95 Bde + 88 Geheimakten, 1933-1936, vor allem Auslandsbesuche deutscher Kriegsschiffe, Export von Kriegsmaterial, Angelegenheiten der Militärattachés). Auch Akten des Referats Völkerbund reichen bis 1936 (ca. 300 Bde).

Für die Zeit von 1936 bis 1940 liegen in Bonn außer den Länderakten ebenfalls Unterlagen über militärische und Rüstungsangelegenheiten (ca. 1000 Bde und Einzelvorgänge, hauptsächlich mit nachrichtendienstlichen Erkenntnissen der Abwehr und des $\mathrm{OKH}$ über einzelne Länder, auch über Flottenrüstung und über Einbau von ca. 60 Agenten in deutsche Auslandsvertretungen) und über Luftverkehr ( 3 Bde) vor. Ein weiterer Teilkomplex (ca. 250 Bde, 1936-1942) betrifft den Völkerbund. Schließlich gibt es noch einzelne Akten und Materialsammlungen über allgemeine außenpolitische und multilaterale Fragen (ca. 75 Bde).

Die im Auswärtigen Amt - z. T. bis 1943 - geführten Akten über die ehemaligen deutschen Kolonien setzten Vorakten des Reichskolonialamtes fort und wurden deshalb im ZStA mit dessen Überlieferung vereinigt (Best. 10.01). Sie betreffen die Abwicklung von Aufgaben nach den Bestimmungen des Versailler Vertrages, die kolonialpolitischen Aktivitäten der NS-Regierung und die laufende Unterrichtung deutscher Dienststellen über die Entwicklung in diesen Gebieten. Sie sind wie folgt gegliedert:

- Kolonien und Kolonialpolitik: Allgemeines (101 Bde, 1909/1917-1943), Militär und Marine (2 Bde, 1930-1939), Kolonialrecht und Polizeiangelegenheiten (11 Bde. 1928-1941), Sklaven und Sklavenhandel (5 Bde, 1931-1940), Erforschung, Vermessung. Grenzziehung (18 Bde, 1918-1941), Einwanderung, Ansiedlung, Unterstützung (38 Bde. 1905-1941), Wirtschaft, Handel, Zölle, Steuern (24 Bde, 1907/1921-1941), Land- und 
Forstwirtschaft (44 Bde, 1908/1921-1941), Post und Verkehr (15 Bde, 1919-1941), Missionen und Schulen (2 Bde, 1913-1941), Gesundheitswesen (24 Bde, 1904/1921-1942); - Deutsch-Ostafrika: u. a. Kolonisation, politische Entwicklung (93 Bde, 1908/19211941), Kolonialrecht, Strafsachen, Nachlaß- und Liegenschaftswesen (12 Bde, 1912 bzw. 1924-1943). Einwanderung, Ansiedlung, Personenstandswesen (31 Bde, 1908/ 1924-1941), Wirtschaft, Handel, Zölle, Steuern (27 Bde, 1901/1925-1943), Land- und Forstwirtschaft, Fischerei (105 Bde, 1913/1920-1942), Missionen und Schulen (3 Bde, 1927-1939), Gesundheitswesen (15 Bde, 1918-1939);

- Deutsch-Südwestafrika: u. a. Kolonisation, allgemeine Leitung und Verwaltung, politische Entwicklung (31 Bde, 1907/1921-1941), Kolonialrecht, Strafsachen, NachlaBund Liegenschaftswesen (10 Bde, 1908/1924-1942), Einwanderung, Aussiedlung, Unterstützung, Personenstandswesen (51 Bde, 1904/1924-1942). Wirtschaft, Handel, Zölle, Steuern (25 Bde, 1907/1024-1942), Land- und Forstwirtschaft, Fischerei (16 Bde, 1927 1941), Missionen und Schulen (5 Bde, 1928-1941), Gesundheitswesen;

- Westafrika: Allgemeines (10 Bde, 1911/1921-1943), Deutsch-Westafrikanische Handelsgesellschaft, Gesellschaft Süd- und Nordwestkamerun (3 Bde, 1929-1942):

- Kamerun: u. a. Kolonisation, zentrale und regionale Verwaltung, politische Entwicklung (27 Bde, 1915/1926-1943), Einwanderung, Aussiedlung, Unterstützung, Personenstandswesen (5 Bde, 1909/1920-1940), Wirtschaft, Handel, Zölle, Steuern, Banken (13 Bde, 1925-1943), Land- und Forstwirtschaft, Fischerei (25 Bde, 1922-1942);

- Togo: u. a. Kolonisation, zentrale und regionale Verwaltung, politische Entwicklung (6 Bde, 1924-1942), Wirtschaft, Handel, Zölle, Steuern, Banken, Land- und Forstwirtschaft, Fischerei (7 Bde, 1910-1941), Missionen und Schulen, Gesundheitswesen (1 Bd, 1930-1937);

- Neuguinea (18 Bde, 1902-1941, dabei Neuguinea-Kompagnie, 2 Bde, 1902/19121938). - Karolinen-, Marianen- und Palau-Inseln (6 Bde, 1924-1941); - Samoa (13 Bde, 1902-1941); - Marshall- und Salomon-Inseln (4 Bde, 1918-1939).

\section{Handelspolitische Abteilung}

Das Schriftgut der 1936 errichteten Abteilung setzt die Aktenserien der politischen Abteilungen über die wirtschaftlichen Beziehungen zu einzelnen Ländern (mit Teilserien u. a. betr. Handel, Industrie, Rohstoffe, Post, Verkehrswesen, Zölle) fort, die mit deren Registraturen überliefert sind (im AA insges. ca. 3500 Bde, 1933-1936). Außerdem bestand bis 1936 ein Sonderreferat Wirtschaft, das sich mit allen Grundsatzfragen des Außenhandels, u. a. Anleihen, Devisen- und anderen Finanzfragen befaßte (ca. 500 Bde). Umfangreich sind Akten über den Handel mit Kriegsgerät (44 Bde, 1936-1942) und Länderakten u. a. über Belgien, Frankreich, die Niederlande, die Schweiz, Spanien, Portugal, GroBbritannien, Italien, Türkei, Nord- und Südamerika, Restakten betreffen Schiffahrtsangelegenheiten und enthalten Material zu Handelsverträgen. Die gesamte Tätigkeit der Abteilung ist durch zahlreiche Handakten ihres Leiters (1937-1944) Ministerialdirektor Emil Wiehl (ca. 200 Bde, 1927-1942), seines Vertreters und Nachfolgers Karl Clodius (ca. 200 Bde, 1931-1941) und von etwa 20 weiteren Beamten dokumentiert, die z. T. auch Ersatzüberlieferung für verlorene Akten der Politischen und anderer Abteilungen enthalten.

Ähnlich ist die Überlieferung im ZStA (ca. 3400 Bde vor 1936) mit den Schwerpunkten ab 1936 bei den Sachgruppen Finanzwesen (174 Bde), Handel (481 Bde), Industrie, Technik, Gewerbe (70 Bde), Rohstoffe und Waren (87 Bde), Wirtschaft (108 Bde). Bei den Länderakten sind Polen mit Danzig (344 Bde), Dänemark (202 Bde), 
Italien (195 Bde) und Finnland (171 Bde) stark vertreten. Für die übrigen Länder und Gebiete liegen nur jeweils ein bis ca. 20 Bände vor.

\section{Abteilung Deutschland}

Die Abteilung unter der Leitung des Unierstaatssekretärs Martin Luther. von dem KorTespondenz (38 Bde, überwiegend 1941-1943) und Material über Organisationsangelegenheiten und NSDAP vorhanden sind, entstand 1940 aus dem 1919 eingerichteten Referat Deutschland, von dessen Akten ein Teil gesondert überliefert ist (ca. 120 Bde, meist 1933-1934, z. T. - u. a. 18 Bde betr. Reichsparteitage, 30 Bde betr. Olympiade und andere Sportveranstaltungen - bis 1938). Sie sollte als Mittelstelle zwischen Auswärtigem Amt und anderen obersten Reichsbehörden und Dienststellen der NSDAP, nicht zuletzt der SS und Polizei, dienen. Nach Luthers Sturz infolge interner Machtkämpfe wurde sie mitsamt den seit Beginn der dreißiger Jahre geführten Akten 1943 in die Arbeitsgruppen Inland I und Inland II aufgeteilt. Die Überlieferung ist im AA relativ gut erhalten und bietet vielfältige Informationen über die Struktur des NS-Regimes. Vorhanden sind Akten aus folgenden Zuständigkeiten:

- Kirchenpolitik (Inland I D, ca. 350 Bde, 1941-1945): Angelegenheiten einzelner Geistlicher, Beziehungen zu den Kirchen im Reich (35 Bde. z. T. ab 1938) und zum Vatikan (65 Bde, 1940-1944), Angelegenheiten einzelner Länder und besetzter Gebiete. - Angelegenheiten der NSDAP (Inland I Partei, ca. 300 Bde), u. a. HJ und Jugendorganisationen anderer Länder (69 Bde. 1929-1941); Organe und Gliederungen der NSDAP (16 Bde, 1938-1944); Presse und Propaganda (26 Bde. 1939-1942); DAF und Sozialpolitik (12 Bde, 1938-1941); Sport (25 Bde, 1938-1942); Wissenschaftsbeziehungen, Studentenangelegenheiten (16 Bde, 1937-194 I): Flaggen, Hoheitszeichen und Nationalfeiertage (64 Bde, 1934-1941, dabei auch Reichsparteitage 1937-1939); Rassenpoiitik (20 Bde, 1934-1944, dabei Eheschließung mit Ausländern).

- Volkstumspolitik (Inland II C und D. ca. 400 Bde + ca. 60 Geheimakten. 1934-1944). u. a. deutsche Volksgruppen und Auslandsdeutsche in einzelnen Ländern. vor allem Südosteuropas (ca. 90 Bde, meist 1942-1944 + 21 Bde Geheimakten. 1935-1941), deren Kirchen- (6 Bde, 1939-1944) und Schulwesen (12 Bde, 1942-1944), Genossenschaften, Kreditinstitute und sonstige wirtschaftliche Einrichtungen. Grundbesitz (ca. 80 Bde, 1936-1944), Umsiedlung (ca. 30 Bde, 1940-1944): Volkstumsforschung und einzelne Institute. Organisationen und Projekte (45 Bde. 1943-1945); Zusammenarbeit mit der Volksdeutschen Mittelstelle (4 Bde, 1941-1944); Minderheiten in Deutschland (3 Bde, 1938-1944).

- Innenpolitik, Zusammenarbeit mit SS und Polizei (Inland II A B, ca. 600 Bde + ca. 1000 Geheimakten mit vielfach heterogenen Vorgängen), $u$. a. Reichs- und preuBische Behörden (5 Bde, 1933-1941); Verhältnis von Partei-, insbesondere Auslandsorganisation, und Staatsorganen (6 Bde, 1933-1941); Ortsgruppen der NSDAP im Ausland (7 Bde, 1933-1938); Aufnahme von Ausländern und Volksdeutschen in die Waffen-SS (3 Bde + 17 Geheimakten, 1940-1944); Internierung deutscher Emigranten im unbesetzten Frankreich (4 Bde, 1940-1944); Maßnahmen gegen Juden: Gesetzgebung (8 Bde, 1933-1944), ausländische Einsprüche gegen Beschlagnahme von Vermögen (17 Bde, 1938-1944), Lage der Juden in Deutschland (18 Bde, 1933-1944). Auswanderung (22 Bde + 2 Geheimakten, 1939-1944), Antisemitismus und Judentum in anderen Ländern (ca. 75 Bde +6 Geheimakten, meist ab 1940): Endlösung der Judenfrage im Reich und einzelnen besetzten Ländern (23 Geheimakten, 1939-1945); politische Emigration und antideutsche Propaganda im Ausland (ca. 100 Bde + 18 Geheimakten, 1933-1944); 
internationale Zusammenarbeit der Polizei, SS- und Polizeiattachés (5 Bde, $+31 \mathrm{Ge}-$ heimakten, mit Berichten, 1937-1944); Attentate und Attentatsversuche (9 Bde + 9 Geheimakten, 1934-1944), Maßnahmen gegen politische Gegner (5 Bde, 1933-1944), Kirchen (3 Bde +2 Geheimakten, 1934-1944) und Glaubensgemeinschaften (3 Bde. 1935-1942); Aberkennung der Staatsangehörigkeit (ca. 75 Bde allgemeines und Listen, 32 Einzelfälle prominenter Emigranten, 1933-1944); Spionageabwehr (12 Bde, 19331944); Grenzzwischenfälle (2 Bde, 1934-1936): Interventionen fremder Regierungen zugunsten ihrer Staatsangehörigen (ca. 130 Bde, 1933-1944); Organisation und personelle Angelegenheiten des Auslandsnachrichtendienstes (18 Geheimakten, 1940-1944) und Berichte, vor allem des SD, aus Feind- und neutralen Staaten sowie besetzten Gebieten (ca. 100 Geheimakten); Mitwirkung bei Reisen von Angehörigen anderer, auch NSDAP-Dienststellen ins Ausland und besetzte Gebiete (42 Geheimakten, 1939-1944).

In den Bestand des ZStA gelangten nur Splitter und Einzelvorgänge (54 Bde, 19391945) über Kirchenpolitik (23 Bde, 1941-1945), Angelegenheiten einzelner Länder und besetzter Gebiete (27 Bde, 1941-1943) und über die Balfour-Deklaration (5 Bde, 19391942, mit Bericht des Amtes VII des RSHA, Dez. 1942).

\section{Rechtsabteilung}

Die Akten sind mit Ausnahme der Grundsatzakten des Abteilungsleiters (1936-1943) Unterstaatssekretär Friedrich Gaus weitgehend erhalten. Sie stammen im AA aus folgenden Sachgebieten :

- Kriegsrecht (ca. 1000 Bde ab 1937): u. a. betr. Seekriegsrecht (ca. 200 Bde mit Urteilen des Oberprisenhofes und von Prisengerichten), Neutralitätsfragen (ca. 70 Bde), Angelegenheiten der Schutzmacht (24 Bd), Behandlung feindlichen Vermögens in Deutschland und deutschen Vermögens im Ausland (ca. 200 Bde), Völkerrechtsverletzungen (14 Bde), Kriegsgefangene (insbes. aus Frankreich und Strafverfahren gegen sie, Arbeitsbedingungen, einzelne Lager, Flucht, Mißhandlungen, ca. $200 \mathrm{Bde}$ ), Hilfe für deutsche Kriegsgefangene (u. a. Gefangenenaustausch, ca. $150 \mathrm{Bde}$ ), deutsche und ausländische Zivilinternierte (je ca. $200 \mathrm{Bde}$ ), Kriegsschäden (ca. 50 Bde), Internierungen in neutralen Staaten (ca. 80 Bde, insbes. Argentinien, Irland, Rumänien, Sowjetunion 1939-1941, Schweiz, Ungarn, auch Vatikan).

- Völkerrecht (ca. 2500 Bde, z. T. geteilt in Serien vor und nach 1937): u. a. betr. Kriegsschäden und Feindvermögen Erster Weltkrieg (ca. 50 Bde), Folgen des Versailler Vertrags (ca. 70 Bde, ferner 28 Bde betr. Reparationen), Konsularwesen, -gerichtsbarkeit und -verträge (ca. 150 Bde), Pazifismus (12 Bde bis 1937), Rotes Kreuz u. a. Hilfsorganisationen (ca. 80 Bde), Schiedsgerichte und -verträge (ca. $150 \mathrm{Bde}$ ), Völkerbund (ca. 160 Bde), wissenschaftliche Gesellschaften und Institute (ca. 100 Bde), Währungsfragen (ca. 40 Bde), Handelsrecht (ca. 100 Bde), Patent- und Umeberrecht (ca. 200 Bde), Beamtenrecht, insbes. Ansprüche von Ausländern und Deutschen im Ausland (ca. 300 Bde), Steuer-, Zoll- und sonstiges Abgabenrecht, dabei Doppelbesteuerung. Steuerflucht (ca. 400 Bde), außerdem Länderakten (ca. 240 Bde vor 1937).

- Staatsangehörigkeits- (ca. 750 Bde, 1932-1945) und Verwaltungsrecht (ca. 50 Bde).

- Strafrecht (ca. 300 Bde, außerdem ca. 150 Bde Geheimakten betr. Strafverfolgung wegen Landesverrats 1933-1944): Allgemeines, ausländisches und internationales (ca. 50 Bde), Auslieferung von Ausländern und Deutschen im Ausland (ca. 120 Bde), Strafverfolgung und -vollzug (ca. 60 Bde), Rechtshilfe in Strafsachen (ca. 60 Bde).

- Wehrrecht (ca. 1800 Bde, 1935-1944), u. a. betr. Wehrpflicht von Auslandsdeutschen, Dienst von Ausländern in der Wehrmacht, Familienunterhalt und Versorgung, Ar- 
beitsdienstpflicht (ca. 100 Bde), Kriegsgräberfürsorge (allgemeines und einzelne Länder. ca. 180 Bde, 1933-1945).

- Arbeitsrecht (ca. 400 Bde), u. a. betr. Rechts- und Versicherungsverhältnisse deutscher Arbeimehmer im Ausland und von Ausländern im Reich, Sozialpolitik (dabei KdF-Reisen), Internationales Arbeitsamt, Heimschaffung mittelloser Deutscher und Ausländer.

- Polizei: Allgemeines (15 Bde), Fremdenpolizei (50 Bde), PaBrecht, Erteilung von Pässen und Visa, auch an Juden, speziell Ostjuden (ca. 300 Bde, 11 Bde speziell betr. Juden- und Flüchtlingsfragen 1933-1939), Gesundheits- und Sittenpolizei, 33 Bde).

- Bürgerliches Recht (ca. 150 Bde, vor allem betr. NachlaBsachen und Beglaubigungen) mit Familienrecht (ca. 300 Bde, dabei Anwendung des Blutschutzgesetzes, Anerkennung von Ehescheidungen und Vaterschaften. Personenstandsrecht), ProzeBrecht (Konkurse, Armenrechtsgewährung, Rechtshilfesachen, Vollstreckung und Zustellung von Erkenntnissen, ca. 300 Bde, außerdem betr. ca. 80 Zivilprozesse des Auswärtigen Amtes) und internationales Privatrecht.

Außerdem sind noch $-z$. T. bei der Dienststelle Wien der Rechtsabteilung gefuhrte - Akten in österreichischen Rechtssachen (72 Bde, 1938-1944) und eine Vielzahl von Einzelfallakten betr. Interzessionen (ca. 50000, 1937-1945), Nachlaßangelegenheiten (ca. 1000 Bde, vorwiegend nach 1942), Beschaffung von Personenstands- und anderen Urkunden vorhanden.

Im Potsdamer Bestand liegen neben Akten aus den Serien innere Verwaltung (bis 1937), Staatsangehörigkeit und Liquidationen (bis 1935) überwiegend aus folgenden Sachgruppen Unterlagen:

- Auswanderung: Allgemeines (24 Bde), Länderakten (ca. $300 \mathrm{Bde}$, vor allem betr. Staatsangehörigkeit, ca. 130 Bde Einzelfälle $A-Z$ ), Beglaubigung von Urkunden in Staatsangehörigkeitssachen (ca. 150 Bde);

- Militaria (7 Bde betr. Wehrpflicht von Deutschen in Dänemark, Griechenland, Italien. Rumänien, Schweiz, Spanien und von Angehörigen dieser Staaten 1941-1942);

- Nachrichten (75 Bde) über Gesetzgebung und Rechtspflege bis 1936 (31 Bde), Gefängniswesen, Strafanstalten, Internationaler Strafrechts- und Gefängniskongreß Berlin 1935 (40 Bde);

- Neutralität (17 Bde);

- Paßangelegenheiten (ca. 100 Bde, überwiegend Erteilung von Sichtvermerken);

- Polizei (ca. 20 Bde), u. a. betr. Staatspolizei, Strafverfolgung wegen Landesverrats (8 Bde);

- Rechtssachen (ca. 300 Bde), vor allem betr. Kriegsgefangenenwesen (63 Bde), Verträge (55 Bde), Strafrecht einzelner Länder (ca. 100 Bde), Völkerrecht (5 Bde);

- Abwicklung der ehemaligen diplomatischen und konsularischen Vertretungen Jugoslawiens (8 Bde), Norwegens (1 Bd), Österreichs (35 Bde), Polens (45 Bde) und der Tschechoslowakei (105 Bde).

\section{Kulturpolitische Abteilung}

Die Überlieferung ist in beiden Archiven sehr trümmerhaft, vor allem fehlen wesentliche Unterlagen über die Schul- und Wissenschaftspolitik. Zu den Resten im AA gehören einige Geheimakten über Wissenschaftsbeziehungen, u. a. der Hochschulen, und Dienststellenverwaltung (30 Bde, 1935-1945), ferner Akten über Förderung des Auslandsdeutschtums (85 Bde, 1933-1938), Vereine und Forschungseinrichtungen für 
Volkstumsfragen (42 Bde, 1933-1942), allgemeine Minderheitenfragen (17 Bde, 19331937), Gesellschaften zur Pflege zwischenstaatlicher Beziehungen (1938-1942, u. a. Deutsch-niederländische Gesellschaft). Dieser Teilbestand enthält auch die Geheimakten der Informationsabteilung über Dienststellenverwaltung, WeiBbücher und andere Publikationen (19 Bde, 1939-1943), Flugblattpropaganda (4 Bde, 1939-1943) und Propaganda in einzelnen Ländern, vor allem Asiens (39 Bde, 1937-1942, dabei 11 Bde betr. Indien) sowie Berichte und Akten von 23 Vertretern dieser Abteilung bei den Oberkommandos der Armeen an der Front (70 Bde, 1939-1943).

- $\mathrm{Zu}$ den in Potsdam überlieferten Resten gehören vor allem Akten über allgemeine Kirchenfragen (ca. 50 Bde, u. a. Kirchenverfassung, Kongresse, Ordensgemeinschaften, Missionen), Kirchensachen der Länder (126 Bde), Wanderung, Siedlung, Nachforschungen (11 Bde), Kunst und Kunsthandel (3 Bde), Literaturpropaganda ( 8 Bde), Schulwesen im Ausland (4 Bde), Wissenschaftsbeziehungen zum Ausland, Hochschulund Studentenwesen (17 Bde), Archäologisches Institut des Deutschen Reiches (12 Bde) und zwischenstaatliche Verbände (3 Bde).

\section{Nachrichten- und Presseabteilung}

Aus den Jahren 1933 bis 1936, in denen die Abteilung einen erheblichen Teil ihrer früheren Zuständigkeiten für die Informationspolitik an das Reichsministerium für Volksaufklärung und Propaganda verloren hatte, sind im AA Verwaltungs- und Grundsatzakten, Vorgänge über die Unterrichtung des In- und Auslandes und die Beobachtung der Auslandspresse in unterschiedlicher Vollständigkeit vorhanden (u. a. über Gegenmaßnahmen gegen ausländische Propaganda allgemein und in einzelnen Ländern bis 1938, Bekämpfung der jüdischen Presse, Zeitungsverbote). Unter Ribbentrop und besonders nach Kriegsbeginn wurde die Tätigkeit erheblich ausgeweitet, jedoch ist die Überlieferung (bis 1943) lückenhaft. $\mathrm{Zu}$ ihr gehören einige Handakten des Leiters, Gesandter Paul Schmidt, mit Aufzeichnungen für Ribbentrop (4 Bde, 1941-1942) und Material über Auslandsreisen (ca. 12 Bde und Fotos, 1940-1943).

Zu den Publikationen des Amtes (BA, Best. RD 16) zählen neben den Weißbüchern und Verzeichnissen der deutschen Auslandsvertretungen und der ausländischen Diplomaten im Reich die Reihen "Außenpolitische Dokumente“ (ab 1935), „Dokumente des Auswärtigen Amtes“ (u. a. zur Vorgeschichte des Zweiten Weltkriegs, ab 1939) und - herausgegeben von der Archivkommission - „Die Entstehung des Krieges von 1939. Geheimdokumente aus europäischen Archiven“" (1943), ferner (Best. RD 113) die „Schriften“ (ca. 100 Hefte, 1937-1943) und „Veröffentlichungen des Deutschen Instituts für außenpolitische Forschung" (16 Bde, 1937-1943).

Der Potsdamer Teilbestand enthält neben einer umfangreichen Zeitungsausschnittsammlung (ca. 1450 Bde, davon 266 Bde betr. Deutschland, 380 Bde betr. GroBbritannien, 340 Bde betr. USA) einige Geschäftsakten ( 83 Bde), umfangreiches Material des Deutschen Nachrichtenbüros (ca. 200 Bde, davon 77 Bde DNB-Material grün, 13 Bde DNB-Material Abhördienst, 31 Bde DNB-Material Auslandsagenturen, 71 Bde DNBMaterial Eigendienst) sowie Material anderer Presseinformationsdienste, u. a. Sonderdienst Politische Nachrichten (ca. 100 Bde).

\section{Rundfunkpolitische Abteilung}

Während in Bonn die Funktionen der 1941 aus dem Rundfunkreferat der Informationsabteilung hervorgegangenen Abteilung nur durch einen spärlichen Rest von Arbeitsunterlagen dokumentien sind (172 Bde, 1939-1943, überwiegend über einzelne Länder 
und Sendegesellschaften), umfaBt der Potsdamer Teilbestand, der zu publizistischen Angriffen gegen Bundeskanzler Kiesinger wegen seiner Tätigkeit in der Abteilung benutzt wurde, Akten folgender Aufgabengebiete:

- Personal-, Verwaltungs- und Haushaltsangelegenheiten (21 Bde, 1940-1945).

- Rundfunkpropaganda (12 Bde, 1940-1945) im und gegen das Ausland (USA, GroBbritannien, Frankreich, Skandinavien, Rumänien, UdSSR, u. a. durch Sender Belgrad, Deutscher Kolonialfunk 1940-1941).

- Sammlung von Informationen über die internationale politische und wirtschaftliche Lage (64 Bde, 1938-1945, mit z.T. fragmentarischer Überlieferung von Einzelvorgängen), u. a. über Innenpolitik und Beziehungen der Feindstaaten, Aspekte des Kriegsverlaufs, Kirchenpolitik mit Berichten einzelner Diplomaten (z. B. Krug v. Nidda, v. Oetting, v. Stahmer an Kiesinger vor allem über Afrika und Japan), außerdem DNBBerichte.

- Rundfunkprogramme, Nachrichten- und Sendeübersichten, -manuskripte, Sprachregelungen (39 Bde, 1939-1945), dabei Programm der deutschen Überseesender (21.-28. Jan. 1945), Akten über Technik und Inhalt von Sendungen für das Ausland (6 Bde, 1939-1944), arabische, iranische, griechische, spanische und italienische Sendungen, Sprachregelungen für Meldungen über den Vormarsch sowjetischer Truppen (2 Bde, 1945), nichtamtliche Fassung der Hitler-Rede vom 4. Oktober 1939.

- Abrechnungen und Belege der Rundfunkreferate bei den deutschen Auslandsvertretungen A - Z (61 Bde, 1938-1944).

- Handakten C.R. v. Haeftens (u. a. zu Personalangelegenheiten vor allem bei Liquidation der Berliner Radio-Mundial-Niederlassung und Tochtergesellschaften, 3 Bde, 1940-1942), des Gesandten Rühle (Beschlüsse des Aufsichtsrates der Interradic AG 1942) und Dr. Timmlers über die besetzten Westgebiete (Reisen ausländischer Rundfunkjournalisten, Programme für Frankreich, Zusammenarbeit mit dem italienischen Rundfunk, Interview mit Seyss-Inquart, 1940).

\section{Informationsabteilung}

Sie bestand von 1939 bis 1943 zur Koordinierung der Auslandspropaganda. Über ihre Tätigkeit, die ab 1943 von der Kulturpolitischen (vgl. oben) und der Presseabteilung fortgesetzt wurde, sind im AA wenige Sachakten und Handakten des Beauftragten für das Informationswesen Karl Megerle (ca. 50 Bde, 1940-1943, u. a. mit Richtlinien und Vorgängen über einzelne unterstellte Leit- und Informationsstellen) vorhanden.

Eine wesentliche Ergänzung für die amtlichen Akten enthalten zahlreiche Nachlässe und Aufzeichnungen von Diplomaten; soweit sie überwiegend aus der Funktion als Leiter einer Botschaft oder Gesandtschaft stammen, wird bei diesen darauf hingewiesen. Während der NachlaB Ribbentrops (BA, NL 163, 17 Bde) fast ausschlieBlich aus privaten Papieren besteht und der NachlaB Neuraths (BA, NL 310) aus der Amtszeit als Reichsaußenminister nur wenige Akten- und Korrespondenzsplitter (15 Vorgänge, vor allem über Reisen und Repräsentationsaufgaben, 1933-1937) enthält, gehören zum NachlaB v. Weizsäckers (in Familienbesitz, Mikrofilm BA, NL 273) aus der Zeit als Staatssekretär Tagebücher (1 Bd, 1933, 1938-1941), Aufzeichnungen und Notizen (4 Bde, 1933-1946) und Vorträge (1939-1943). Wenige Akten und Aufzeichnungen aus der Nachkriegszeit stammen vom zeitweiligen Leiter des Ministerbüros Erich Kordt (teils IfZ, teils AA), und der Leiter des Orientreferats ab 1939, Werner Otto v. Hentig, 
sowie der Referent für Westeuropa und zuletzt Botschafter z. b. V. Emil v. Rintelen haben Manuskripte über ihre Tätigkeit im Auswärtigen Amt hinterlassen (IfZ bzw. AA).

Die Tätigkeit der Kulturpolitischen Abteilung wird außer durch die Akten der Deutschen Akademie (vgl. unten Abschnitt 4.6.3) durch Schriftgut der Deutsch-japanischen Gesellschaft (BA, Best. R 64 IV: 294 Bde, 1933-1945, z. T. ab 1930, dabei Handakten des Präsidenten Admiral Foerster) und der Deutsch-spanischen Gesellschaft (BA, Best. R 64 I: 37 Bde, 1933-1945, zum Ibero-amerikanischen Institut vgl. unten 4.3.8) dokumentiert, über bilaterale Wirtschaftsbeziehungen geben die Akten der SüdosteuropaGesellschaft (BA, Best. R 63: 364 Bde, 1938-1945) AufschluB.

Die Beteiligung des Amtes an NS-Verbrechen wurde zuerst im ProzeB gegen Neurath und Ribbentrop vor dem DMT in Nürnberg, dann im sog. WilhelmstraBenprozeB erörtert, in dem Weizsäcker, sein Nachfolger Steengracht von Moyland, Keppler, Woermann, Ritter und der Ministerialdirigent der Politischen Abteilung Otto v. Erdmannsdorff vor dem amerikanischen Militärgericht angeklagt waren. Wegen der Mitwirkung an der Ermordung der Juden wurden aus der Deutschlandabteilung der Legationsrat Rademacher 1952 und 1968 von den Landgerichten Nürnberg und Bamberg, der Legationssekretär v. Hahn 1968 vom Landgericht Frankfurt verurteilt. Langwierige Ermittlungsverfahren in Essen und Köln gegen den Vortragenden Legationsrat Horst Wagner, Leiter von Inland II, und den Referatsleiter Legationsrat Eberhard v. Thadden muBten nach dem Tod der Beschuldigten eingestellt werden. Unterlagen über diese Verfahren und einzelne Diplomaten enthält der Nachlaß des Historikers Kurt Rheindorf (BA, NL 263).

Die Überlieferung zur Geschichte vor allem der auBereuropäischen Staaten wird vom Internationalen Archivrat durch mehrere Serien von "Quellenführern zur Geschichte der Nationen/Guides to the Sources for the History of the Nations" nachgewiesen: für die Bundesrepublik liegt darin vor: Quellen zur Geschichte Nordafrikas, Asiens und Ozeaniens in der Bundesrepublik Deutschland bis 1945. Hrsg. von Ernst Ritter. München 1984 (Serie 3, Bd. 6), und unabhängig davon erschien von Leon E. Bieber: Katalog der Quellen zur Geschichte Mexikos in der Bundesrepublik Deutschland 1521-1945. Berlin 1990 (Bibliotheca Ibero-Americana 35). Die in Akten des Auswärtigen Amtes und der Auslandsvertretungen im Politischen Archiv enthaltenen Vorgänge über die politische Emigration aus Deutschland 1933-1945 sind in einer Kartei im IfZ erschlossen.

Unveröffentlicht, aber im ZStA benutzbar sind die dort erstellten Spezialinventare, die außer den diplomatischen Akten noch andere staatliche und nichtstaatliche Bestände (Parteien, Verbände, Versicherungsunternehmen, Nachlässe) berücksichtigen und zwischenstaatliche und multilaterale Beziehungen auch im Zeitraum 1933-1945 nachweisen. Sie bieten Übersichten über Quellen zur Geschichte Polens und der deutschpolnischen Beziehungen 1918-1939 (1964), zur Geschichte der UdSSR und der deutschsowjetischen Beziehungen 1917-1945 (1984) und betreffen die Geschichte Afrikas südlich der Sahara (1974), Burundis (1980), Asiens und Ozeaniens, Deutsch-Südwestafrikas (Namibias), der Türkei und der deutsch-türkischen Beziehungen, Irans und der deutsch-persischen Beziehungen, Afghanistans und der deutsch-afghanischen Beziehungen.

Lit: A CATALOG of Files and Microfilms of the German Foreign Ministry Archives 1920-1945. vol. I-III. 1962-1966. - H. FHILIPPI: Das Politische Archiv des Auswärtigen Amtes. 1960. - I. SCHMID: Der Bestand des Auswärtigen Amts im Deutschen Zentralarchiv Potsdam. 1962. - K. METSCHIES: Quellen zur kolonialen Politik des deutschen Imperialismus in Afrika und Nahost im Zentralen Staatsarchiv Potsdam. 1989, desgl. des Deutschen Reiches in Afrika und Nahost. 1990. - QUELLEN zur tschechoslowakischen Geschichte 1867-1945 im ZStA Potsdam. 1958. - DOKUMENTE und Materialien aus der Vorgeschichte des Zweiten 
Weltkriegs. Bd. 1. Nov. 1937-1938. 1948. - AKTEN zur Deutschen Auswärtigen Politik 1918-1945. Aus dem Archiv des Auswärtigen Amtes. Serie C, D und E. 1933-1945. - TRIALS of WAR CRIMINALS. vol. 12-14. - H. KÖNIG: Das deutsch-sowjetische Vertragswerk von 1939 und seine Geheimen Zusalzprotokolle. 1989. - A. HILLGRUBER: Staatsmänner und Diplomaten bei Hitler. 1967. - M. W. KEMPNER: Das Drize Reich im Kreuzvertör. 1969. - J. v. RIBBENTROP: Zwischen London und Moskau. (1953) - R. SCHNABEL.: MiBbrauchte Mikrofone. 1967. - EINHUNDERT JAHRE Auswärtiges Amt. 1970. - H.-A. JACOBSEN: Nationalsozialistische AuBenpolitik 1933-1938. 1968, und: Zur Struktur der NS-AuBenpolicik 1933-1945. 1976. - K. SCHWABE: Das Diplomatische Korps 1871-1945. 1985. - C. R. BROWNING: The Final Solution and the German Foreign Office. 1978. - H.-J. DÖSCHER: Das Auswärige Amt im Dritten Reich. 1987. - W. A. BOELCKE: Presseabteilungen und Pressearchive des Auswärtigen Amtes 1871-1945. 1961. - P. LON. GERICH: Propagandisten im Krieg. 1987. - J. L. HEINEMANN: Hitler's First Foreign Minister Constantin Freiherr von Neurath. 1979.

1.4.2 Diplomatische und konsularische Vertretungen des Reichs AA ZStA, Best. 09.02

Im Politischen Archiv des Auswärtigen Amtes befindet sich der Hauptteil der zwischen 1933 und dem Abbruch der Beziehungen bzw. bis Kriegsende bei deutschen Botschaften und Gesandtschaften im Ausland wie auch bei einigen Generalkonsulaten und Konsulaten entstandenen und nicht bei Einstellung ihrer Tätigkeit vernichteten Akten. Die Überlieferung im ZStA Potsdam ist dagegen mit Ausnahme von Akten der Vertretungen in Afghanistan, China und der Sowjetunion von geringem Umfang; von den Gesandtschaften bzw. Botschaften Helsinki, Athen, Rom, Zagreb, Kowno, Belgrad, Warschau, Buenos Aires und Washington sind dort nur jeweils ein bzw. zwei Bände uberliefert.

Folgende Bestände sind wegen Umfang und Bedeutung hervorzuheben, wobei für den Inhalt der Bonner Überlieferung auf die Angaben in Band IV des CATALOG verwiesen werden kann:

Gesandtschaft Agram (ca. 900 Bde, 1940-1944, mit Vorakten, außerdem Handakten des Gesandten Kasche).

Botschaft Ankara (ca. 200 Bde, 1933-1943).

Gesandtschaft Athen (ca. 150 Bde, 1933-1940).

Gesandtschaft Belgrad (ca. 80 Bde, 1933-1940).

Gesandtschaft Bern (ca. 700 Bde, 1920-1938, ca. 200 Bde + 17 Bde Geheimakten, 1939-1943).

Botschaft Brüssel (33 Bde, überwiegend 1939-1940).

Gesandtschaft Budapest (ca. 300 Bde, 1933-1941).

Gesandtschaft Bukarest (AA ca. 150 Bde, 1933-1943, ZStA 6 Bde, 1935, 1941-1942).

Gesandtschaft Helsinki (vor allem 47 Bde Erlasse und Berichte, 1940-1943).

Gesandtschaft Kabul (nur ZStA 146 Bde, 1924-1944);

Gesandtschaft Kopenhagen (ca. 200 Bde, 1933-1939, außerdem Handakten des Gesandten v. Renthe-Fink).

Gesandtschaft Kowno (ca. 800 Bde, 1933-1941).

Gesandtschaft Lissabon (ca. 700 Bde, 1933-1943).

Botschaft London (nur 18 Bde Geheimakten, 1933-1937, und Reste von Unterlagen des Botschafters v. Dirksen, dessen Nachlaß sich im ZStA Potsdam befindet).

Gesandtschaft Luxemburg (ca. 180 Bde, 1933-1940).

Botschaft Madrid (ca. 700 Bde, 1933-1942).

Botschaft Moskau: kleinerer Bestand in Bonn (ca. 250 Bde, 1933-1941, dabei jedoch ca. 80 Bde Geheimakten ab 1937), größerer in Potsdam mit Akten (ca. 350 Bde, 19231941 ) betr. Auswärtiges Amt und Auslandsvertretungen, Geschäftsgang, Haushalts- 
und Rechnungswesen, zwischenstaatliche Probleme, Wirtschaft, Handel, Verkehr, Finanzen, Rechtswesen, Kulturpolitik und Pressearchiv der Botschaft (ca. 400 Bde), dabei AuBenpolitik, deutsch-sowjetische Beziehungen (17 Bde), Beziehungen zu anderen Staaten und dem Völkerbund (ca. 40 Bde), Wirtschaftsfragen (ca. 230 Bde), im ZStA ferner Nachlaß des Botschafters Graf v. d. Schulenburg und Handakten des Botschaftsrats Gustav Hilger.

Gesandtschaft Oslo (ca. 400 Bde, 1933-1940).

Botschaft Paris (ca. 700 Bde, 1933-1944, + 200 Bde Geheimakten, 1940-1944 im AA, im ZStA 10 Bde, 1937-1944).

Botschaft Peking bzw. Nanking: Hauptbestand im ZStA (ca. 2400 Bde, die z.T. bereits weit vor 1933 einsetzen und bis in die 40er Jahre fortgeführ wurden), dabei Akten vor allem betr. Geschäftsbetrieb, Grundbesitz und Ausstattung, Haushalt, Protokoll und diplomatisches und konsularisches Korps in China und Ostasien (ca. 400 Bde, 1920-1945, dazu ca. 200 Personalakten), politische Lage in den Provinzen, politische Beziehungen Chinas zu fremden Staaten (ca. 200 Bde, 1920-1945), Wirtschaft, Handel, Verkehr, Finanzen (ca. 520 Bde, 1920-1944), Rechtswesen (ca. 175 Bde, 1920-1945), Kulturpolitik, dabei auch Hochschul- und Schulwesen (ca. 400 Bde, 1919-1945), deutsche Politik, Wirtschaft, Kultur (ca. 400 Bde, 1920-1945); im AA Akten (ca. 500 Bde, 1933-1945) und Tagebücher und Aufzeichnungen des Botschafters Trautmann.

Gesandtschaft Prag (ca. 400 Bde, 1933-1939).

Gesandtschaft PreBburg (ca. 400 Bde, 1939-1944 mit Vorakten).

Gesandtschaft Reval (ca. 200 Bde, 1933-1940).

Gesandtschaft Riga (AA ca. 500 Bde, 1933-1941, 34 Bde, 1930-1941, ZStA).

Botschaft Rom, Quirinal (ca. 1400 Bde, überwiegend 1933-1939, + ca. 1500 Geheimvorgänge, überwiegend 1935-1943, außerdem Handakten des Botschafters v. Mackensen, 1938-1944, und Nachlaß seines Nachfolgers Rahn, auch aus dessen Tätigkeit als Gesandter in Tunis).

Botschaft Rom, Vatikan (ca. 200 Bde, 1933-1943, auBerdem NachlaB des Botschafters v. Bergen).

Gesandtschaft Sofia (ca. 150 Bde, 1933-1941, AA, 134 Bde, ausschlieBlich Personalangelegenheiten, 1923-1944, ZStA).

Gesandtschaft Stockholm (ca. 200 Bde, 1933-1943).

Gesandtschaft Teheran (Handakten des Gesandten Ettel ab 1939).

Gesandtschaft Tirana (vor 1934 und nach 1939 Generalkonsulat, ca. 40 Bde, 1924 1943).

Botschaft Tokio (15 Bde, 1938-1939, im ZStA, Papiere des Botschafters Eugen Ot im IfZ).

Botschaft Warschau (ca. 700 Bde, 1933-1939).

Botschaft Wien (AA ca. 100 Bde, + 30 Bde Geheimakten, 1933-1938, ZStA 8 Bde, 1933-1938).

In Dänemark, der Slowakei und Ungarn wurden nach der Besetzung durch deutsche Truppen die Gesandten zu Reichsbevollmächtigten bestellt, die den Regierungen Weisungen erteilten. Die Tätigkeit der Reichsbevollmächtigten in Dänemark, v. RentheFink (1940-1942) und Best (1942-1945) ist in deren Nachlässen (AA und BA, NL 192, NL 23) dokumentiert. Der Reichsbevollmächtigte in Ungarn, Edmund Veesenmayer, war im Nürnberger Wilhelmstraßen-ProzeB angeklagt, der Reichsbevollmächtigte in der Slowakei, Hans Ludin, wurde in PreBburg verurteilt. 
Zur Überlieferung der Militärattachés, die teilweise auch in Botschafts- und Gesandtschaftsakten enthalten ist, und der Deutschen bevollmächtigten Generale vgl. Abschnitt 8.2.1 und .2.

Die Überlieferung der deutschen konsularischen Vertretungen ist inhaltlich überwiegend von geringerer Bedeutung, jedoch teilweise von Interesse für die Politik gegenüber deutschen Minderheiten in den nach dem Ersten Weltkrieg abgetretenen Gebieten. Schriftgut aus der NS-Zeit enthalten folgende Bestände im Politischen Archiv, von denen im CATALOG nur einzelne Bände beschrieben sind:

Generalkonsulat Innsbruck (130 Bde, 1933-1938) und Konsulate Graz (100 Bde, 1920-1938) und Klagenfurt (50 Bde, 1925-1938).

Generalkonsulat Antwerpen (38 Bde, 1936-1940).

Generalkonsulat Zürich (790 Bde, 1922-1945) und Konsulate Basel (250 Bde, 1929 . 1945) und Genf (480 Bde, 1925-1944).

Generalkonsulat Danzig (430 Bde, 1920-1939).

Konsulat Apenrade (120 Bde, 1920-1944).

Generalkonsulat Barcelona (100 Bde, 1926-1945).

Konsulat Liverpool (200 Bde, 1920-1939).

Generalkonsulat Triest (6 Bde, 1930-1940).

Konsulat Reykjavik (70 Bde, 1921-1940).

Konsulat Memel (860 Bde, 1925-1939).

Generalkonsulat Amsterdam (350 Bde, 1930-1940) und Konsulate MaastrichtHeerlen (114 Bde, 1921-1940) und Rotterdam (300 Bde, 1920-1940).

Generalkonsulate Kattowitz (300 Bde, 1922-1939), Posen (120 Bde, 1925-1939) und Thorn (440 Bde, 1924-1939), Konsulate Krakau (130 Bde, 1922-1940) und Lodz (50 Bde, 1919-1938).

Konsulat Czernowitz (45 Bde, 1926-1943) und Galatz (60 Bde, 1925-1944).

Konsulate Göteborg (100 Bde, 1920-1945) und Malmö (200 Bde, 1922-1945).

Generalkonsulate Istanbul (70 Bde, 1924-1945) und Izmir (300 Bde, 1921-1944).

Konsulat Bagdad (35 Bde, 1926-1939).

Konsulat Windhuk (170 Bde, 1923-1939).

Generalkonsulat San Francisco (15 Bde, 1924-1941).

Konsulat Winnipeg (56 Bde, 1914-1939).

Von den unvollständigen und bruchstückhaften Beständen (Best. 09.3) in Potsdam sind zu erwähnen vor allem Akten der

Konsulate Kronstadt (267 Bde, 1926-1944, hauptsächlich betr. Unterhaliszahlungen, Hinterbliebenenversorgung, Wohlfahrtsunterstützung, Wehr- und Arbeitsdienst im allgemeinen und in Einzelfällen) und Temesvar (ca. 700 Bde, 1921-1944, davon betr. Auswärtiges Amt und deutsche Auslandsvertretungen $8 \mathrm{Bde}$, Personalangelegenheiten 22 Bde, Wirtschaft, Handel und Verkehr ca. 40 Bde, Kulturpolitik 20 Bde, deutsche Politik ca. 400 Bde), der

Generalkonsulate Tiflis (32 Bde, 1929-1939) und Charkow (10 Bde, 1923-1938) und der Konsulate Odessa, Kiew und Leningrad (35 bzw. 14 bzw. 8 Bde, 1925-1941), ferner der

Konsulate Chunking (73 Bde, 1937-1941, vor allem zu Personalangelegenheiten, Finanzwesen, Polizei und Kulturpolitik), Täbris (17 Bde, 1930-1941) und Lemberg (36 Bde, 1934-1939). 
Lit: Vgl. zum vorangehenden Abschnith, auBerdem A CATALOG of Files and Microfilms of the German Foreign Ministry Archives. vol. IV. 1972. - DOKUMENTE und Materialien aus der Vorgeschichue des Zweiten Welckriegs. Bd. 2. Das Archiv Dirksens. 1948. - J. WEISER: Die deutsche Botschaft in China 1962. - G. HLLER: Wir und der Kreml. 1956. - W. JOOST: Botschafter bei den Roren Zaren. 1967. K. PFULLMANN: Geschichie der Deutschen Botschafi Moskau 1922-1941. 1989. - D. WEIDEMANN: Das Schicksal der Akten der Deutschen Gesandtschaft Kabul. 1990.

\subsubsection{Vertretungen der Länder beim Reich und anderen Staaten}

Das Recht der Länder, Einrichtungen zur Pflege zwischenstaatlicher Beziehungen zu unterhalten, hatte sich schon in der Weimarer Republik auf die Vertretungen PreuBens (vereinigt mit der Botschaft des Reiches) und Bayerns beim Vatikan und auf Gesandtschaften in Berlin unter der Leitung der Bevollmächtigten zum Reichsrat beschränkt. Alle diese Behörden verschwanden ab 1933 almählich, ihr Schriftgut gibt jedoch, soweit es erhalten blieb, AufschluB über die Gleichschaltung der Länder zu Beginn der NS-Herrschaft. Folgende Bestände sind überliefert:

\subsubsection{Bayerische Gesandtschaft beim Heiligen Stuhl M, Best. G 12}

Die Akten aus den Jahren 1933 und 1934 betreffen Dienststellenverwaltung (12 Bde), protokollarische und zeremonielle Angelegenheiten (6 Bde), politische Beziehungen (6 Bde), Angelegenheiten der katholischen Kirche in Bayern (6 Bde, dabei auch Heilig- und Seligsprechungen), Wissenschaft und Kunst und Einrichtungen für diese (13 Bde, dabei Gesuche um Zugang zu Archiven, Bibliotheken und Sammlungen), Pressewesen und Ausstellungen ( 2 Bde); sie belegen auch Bemühungen um Freilassung eines politischen Gefangenen.

Lit: WIDERSTAND UND VERFOLGUNG in Bayern. Bd. 5. S. 125. - E. KRAUSEN: Die Akten der bayerischen Gesandtschaft beim Päpstlichen Stuhl. 1960.

\subsubsection{Vertretungen der Länder in Berlin}

Bayerische Gesandtschaft Berlin

M, Best. G 2

Der Bestand enthält Aufzeichnungen und Berichte des Gesandten Franz Sperr über außenpolitische Angelegenheiten, Verhandlungen zwischen bayerischen und Reichsministerien (1934) und Akten über den Umbau der Staatsverwaitung in Bayern (19331934), Reichsreform und -verfassung, Finanz- und Wirtschaftsfragen (1933).

\section{Amt des Braunschweigischen Bevollmächtigten zum Reichsrat}

WF, Best. 19 B Neu Nach der nationalsozialistischen Machtergreifung wurden bis 1934 vornehmlich noch Akten (ca. 20 Bde) über Reichsreform, die allgemeine innenpolitische Lage, Justiz, Wirtschaft und Soziales, Kreditwesen, Straßen- und Luftverkehr fortgeführt; außerdem liegen Akten aus der Tätigkeit des Gesandten Boden als Mitglied des Verwaltungsrates der Deutschen Reichspost (3 Bde, 1927-1933) und des Reichsdisziplinarhofes (19221934) vor.

Bremische Gesandtschaft in Berlin

HB, Best. 4,49 Bis 1936, z. T. bis 1937, wurden Akten aus folgenden Sachgebieten geführt:

- Auswärtige Politik (dabei Berichte von Auslandsvertretungen, Angelegenheiten ausländischer Vertretungen, Auslandsdeutschtum bis 1934, Folgen des Ersten Weltkriegs, Verträge mit anderen Staaten). 
- Innenpolitik (mit Vorgängen über Reichsverfassung und Neugliederung, Behörden, politische Parteien, Zeitungsverbote, alle Sparten der Polizei, Staatsangehörigkeitsfragen, Ein- und Auswanderung. Wissenschaft, Erziehung und Kunst, Kirchensachen, Gesundheitswesen, Sport, Beamtenrecht, Saarfrage bis 1935, Pressewesen, Orden und Ehrenzeichen).

- Wirtschaftspolitik (u. a. Schutz des Einzelhandels, Kreditwirtschaft und Devisen, Preisüberwachung, ständischer Aufbau der Wirschaft und Landwirsschaft, Deutsche Arbeitsfront, Land- und Forstwirtschaft, AuBenhandel, Produktionslenkung in der Industrie, Vierjahresplan).

- Sozialpolitik (Sozialversicherung, private Versicherungen, Tarifrecht und Reichstreuhänder der Arbeit, Arbeitsschutz und Gewerbeaufsicht, Bekämpfung der Arbeitslosigkeit, Freiwilliger und Reichsarbeitsdienst, Wohnungs- und Siedlungswesen, Versorgung von Parteigenossen bis 1934, Wohlfahrspflege, Jugendpflege).

- Finanzpolitik (Reichs- und andere staatliche Banken, Finanzausgleich, Haushalt, Steuern und Zölle, Anleihen und Schulden, Fürstenentschädigung).

- Verkehrspolitik (Autobahnbau, Eisenbahnwesen, Schiffahrt und Schiffbau, Wasserstraßen und Häfen, Post und Fernmeldewesen, Luft- und Kraftverkehr).

- Rechtswesen (einzelne Rechtsgebiete, auch Militärstrafrecht, Seerecht).

- Landesverteidigung (Gesetzgebung, Garnison Bremen, Kriegsmarine- und Luftwaffenangelegenheiten, Kriegsopferversorgung).

Weitere Akten über spezielle Angelegenneiten Bremens betreffen Verfassung und Verwaltung, Besuche von Politikern, Wirtschaft und Industrie.

\section{Lübeckische Gesandtschaft zu Berlin}

HL, Gesandischaftsarchive Die Akten des Gesandten Werner Daitz enden meist 1934/35, einige auch 1937 und 1938. Sie betreffen u. a. Dienststellenverwaltung, Verhältmis Reich-Länder und Lübecks zu Preußen, Außenhandel und Schiffahrt, auswärtige Beziehungen (u. a. Propaganda in Schweden 1933), Arbeitsbeschaffung, kulturelle Angelegenheiten, Industrie und Gewerbe; sie enthalten auch Schriftwechsel mit Vertretungen anderer deutscher Länder (bis 1935).

Lit.: H.J. SCHRECKENBACH: Innerdeutsche Gesandtschaften 1867-1945. 1956

\subsubsection{Bayerische Gesandtschaften Karlsruhe und Darmstadt}

M, Bestände $G 10$ und $G 5$

Die Bestände enthalten bis zur Auflösung der Gesandtschaften Ende Mai 1933 geführte Akten (61 bzw. 13 Bde) u. a. über Verfassungsfragen, Verwaltungsorganisation, politjsche Parteien, kirchliche und Wissenschaftsangelegenheiten, Wirschaft und Landwirschaft.

\subsubsection{Württembergische Konsulate in Hamburg und Bremen}

$\mathrm{S}$, Bestände $\mathrm{E} 70 \mathrm{j}$ und $\mathrm{g}$

Aus Hamburg sind Akten und einzelne Schreiben über Staatsbesuche, andere Konsulate, Förderung der Wirtschaftsbeziehungen und des Fremdenverkehrs, Gewährung von Unterstützungen und kulturelle Veranstaltungen (1933 bis zur Aufhebung 1938), aus Bremen nur Akten über Konsul Ernst Heinemann und Baumwollkontingente vorhanden (1933-1938). 


\section{$1.5 \quad$ Besatzungsverwaltung}

Mit Ausnahme des Reichsministeriums für die besetzten Ostgebiete in Berlin hatten die zur Verwaltung der ab 1939 dem Reich angegliederten und besetzten Gebiete über den Landesbehörden oder statt dieser geschaffenen Reichsbehörden ihren Sitz in diesen Gebieten, und ihr Schriftgut wird, soweit es erhalten blieb, überwiegend in den dortigen Staatsarchiven aufbewahrt. Die in das Gebiet der Bundesrepublik Deutschland gelangten Teilbestände befinden sich ausschlieBlich im Bundesarchiv und sind in der Übersicht über seine Bestände hinreichend beschrieben. Es handelt sich um folgende:

Reichsprotektor in Böhmen und Mähren/ Deutsches Staatsministerium für Böhmen und Mähren, Prag

BA, Best. R 30

Regierung des Generalgouvernements, Krakau, mit Kanzlei des Generalgouverneurs, Hauptabteilungen Innere Verwaltung, Wirtschaft, Ernährung und Landwirtschaft, Forsten (BA, Best. R 52) und (ZStA, Best. 12.01) Sonderbevollmächtigter für die Erdölwirtschaft (189 Bde, mit Inventaren der einzelnen Betriebe) und Hauptverwaltung der Bibliotheken (26 Bde).

Reichsministerium für die besetzten Ostgebiete

BA, Best. R 6 Restbestand (633 Bde, 1941-1945) aus dem Ministerbüro, dem Führungsstab Politik und vor allem der Hauptabteilung Verwaltung, in Potsdam (Best. 11.01) wenige Splitter aus der Hauptabteilung Politik (6 Bde, Gebietsbeschreibungen), der Hauptabteilung Allgemeine Verwaltung (4 Bde) mit Abteilungen 8, Presse und Aufklärung (19 Bde), der Zentralverwaltung (12 Bde, vor allem Beschaffungsamt) und Hauptabteilung Technik (15 Bde, meist Personalien von Bewerbern für den Osteinsatz); Ergänzung bieten Akten der Zentralhandelsgesellschaft Ost für landwirtschaftlichen Absatz und Bedarf mbH (ZHO) (ZStA, Best. 34.02, 123 Bde, dabei 46 Bde mit Tätigkeits- u. a. Berichten, auch über Betriebe unter Treuhandverwaltung).

Reichskommissar für das Ostland (Estland, Lettland, Litauen, Weißrußland), Riga BA, Best. R 90

Reichskommissar für die Ukraine, Kiew bzw. Rowno BA, Best. R 94

Reichskommissar für die besetzten norwegischen Gebiete, Oslo BA, Best. R 83

Reichskommissar für die besetzten niederländischen Gebiete, den Haag

BA, Best. R 83

Chef der Zivilverwaltung im Elsaß, Straßburg

BA, Best. R 83

Chef der Zivilverwaltung in Lothringen, Metz

BA, Best. R 83

Chef der Zivilverwaltung in Luxemburg

BA, Best. R 83

Oberste Kommissare für die Operationszonen Alpenvorland und Adriatisches

Küstenland, Bozen bzw. Triest

BA, Best. R 83 
Militärbefehlshaber in Belgien und Nordfrankreich, Brüsse]

BA-MA, Best. RW 36

Militärbefehlshaber in Serbien, Belgrad

BA-MA, Best. RW 40

Militärbefehlshaber in Griechenland und Saloniki-Ägäis $\quad$ BA-MA. Best. RW 40

Befehlshaber und Kommandeure der Sicherheitspolizei und des SD und der Ordnungspolizei

BA, Best. R 70

Mit Ausnahme des Verfahrens vor dem IMT, in dem sich wegen ihrer Verbrechen in der Tschechoslowakei Neurath und Frick, in Polen Frank, in den Niederlanden SeyBInquart, in der Sowjetunion Rosenberg verantworten muBten, und des Nürnberger Verfahrens gegen Kommandeure deutscher Truppen in Jugoslawien wurden Prozesse gegen die fuhrenden Beamten und Offiziere der Besatzungsverwaltungen in den jeweiligen Ländern geführt, so daß die dafür herangezogenen Beweisdokumente ebenfalls dort verblieben; sie wurden jedoch in großem Umfang für die Zentrale Stelle der Landesjustizverwaltungen in Ludwigsburg kopiert und für Verfahren vor deutschen Gerichten ab 1965 herangezogen, in denen fast ausschließlich Angehörige der Sicherheitspolizei und des SD sowie Wachmannschaften von Lagern, nur vereinzelt Beamte und Mitarbeiter der allgemeinen Verwaltung, z. B. Gebietskommissare und Kreishauptleute, angeklagt waren.

Lit.: GUIDES to German Records. vol. 28, 31, 38, 39, 57. - FINDBÜCHER zu Beständen des Bundesarchivs. Bd. 26: Bestand R 6. - TRIALS of WAR CRIMINALS. vol. 11. - EUROPA unterm Hakenkreuz 8 Bde. 1990 ff. - K. OLDENHAGE: Die Verwaltung der besetzren Gebiete. 1987. 